\title{
TOURISM MANAGEMENT IN PROTECTED AREAS: GUIDING CONCESSIONS AND ENVIRONMENTAL INTERPRETATION IN NEW ZEALAND'S CONSERVATION ESTATE
}

By

Rogério Ferreira de Souza Dias

A thesis submitted to the Victoria University of Wellington in partial fulfilment of the requirements for the degree of Master of Tourism Management

Victoria University of Wellington

New Zealand

2010 


\begin{abstract}
New Zealand stands out in the global conservation scene and in the nature-based tourism industry with one third of its land area comprising the Conservation Estate (the conjunct of all public protected areas). New Zealand's Department of Conservation $(D o C)$ is responsible for the conservation and management of the Estate, including the concession system that regulates all commercial activities on the Conservation Estate. Typically, DoC does not provide guiding services, with guided activities in the Conservation Estate almost entirely provided by tour operators that hold guiding concessions. Environmental interpretation is one of the main roles of tour guides, and DoC expects guiding concessionaires to deliver quality interpretation in order to provide quality visitor experiences; to educate tourists about natural and cultural values; to minimize the impacts of tourists; and to promote conservation advocacy. However, knowledge relating to tour operators' interpretation management and to guiding concession management is limited.
\end{abstract}

This thesis seeks to understand how the concession system deals with aspects of interpretation, by investigating DoC managers' and tour operators' perceptions about the benefits and importance of interpretation; their actions and challenges to develop and monitor the interpretation capabilities of tour operators; and their perceptions on the concession system and their relationship. A mixed method approach was employed in order to gain an understanding of the situation at the national level (through an email survey), as well as at a regional level in the Nelson-Marlborough Conservancy (mostly through interviews and some observations). The national survey and the case study provided breadth and depth to the investigation. 
This research found that DoC managers and tour operators regarded interpretation as important or very important, but both perceived it as less important to the other party. For most tour operators interpretation was a major part of their guiding services, whereas for most DoC managers it was a minor part of their concessions related work. Some DoC managers argued that the Department should put more emphasis and resources into interpretation support to tour operators, since they are providing an important service that has been transferred from the government to the private sector. Most tour operators and DoC managers demonstrated good understanding about interpretation, particularly about its purposes and benefits. However, few participants demonstrated understanding about the principles of, and techniques for effective interpretation. This research also found that tour operators and DoC managers were undertaking a wide range of actions, and facing many challenges and constraints to develop, support, and monitor the interpretation capabilities of the operators.

Some of the key implications for interpretation management of guiding concessionaires arising from this thesis are: the need for DoC to hold annual meetings with tour operators in order to support their interpretation practices, and to review regulations and minimum impact behaviour in protected areas; the need for DOC and the tourism industry to discuss the insertion of conditions and standards related to tour guide's qualification in concessions contracts; and the need to promote DoC's Interpretation Handbook and Standards. 


\section{Acknowledgments}

I am deeply thankful for the following organizations and people for this wonderful opportunity, and for helping me to achieve this humble scientific contribution, but great personal challenge:

NZAID - New Zealand Agency for International Development - for the scholarship that made this postgraduate study possible.

VUW - Victoria University of Wellington: Faculty of Commerce and Administration MTM - Master of Tourism Management Programme: Professor Douglas Pearce;

Dr. Karen Smith my patient, optimistic and wise supervisor; and all tutors and staff.

DoC - Department of Conservation: Graeme Ayres, Gavin Walker, William Bevil, Paul Thornton, DoC managers from Nelson/Marlborough Conservancy that took part in the case study, and all the other managers that took part in the national survey.

Tour operators (guiding concessionaires) from Nelson/Marlborough region that took part in the case study, and all the others that participated in the national survey.

Charles, Fabiola, Melissa, Stephens, and Tiago for graciously helping with the transcriptions.

My parents Domiciano and Regina, my wife Isabella, and my sons Gabriel and André the roots, flower, and branches of my life. 
"Through interpretation, understanding;

through understanding, appreciation;

through appreciation, protection."

(Tilden, 1977 p.38)

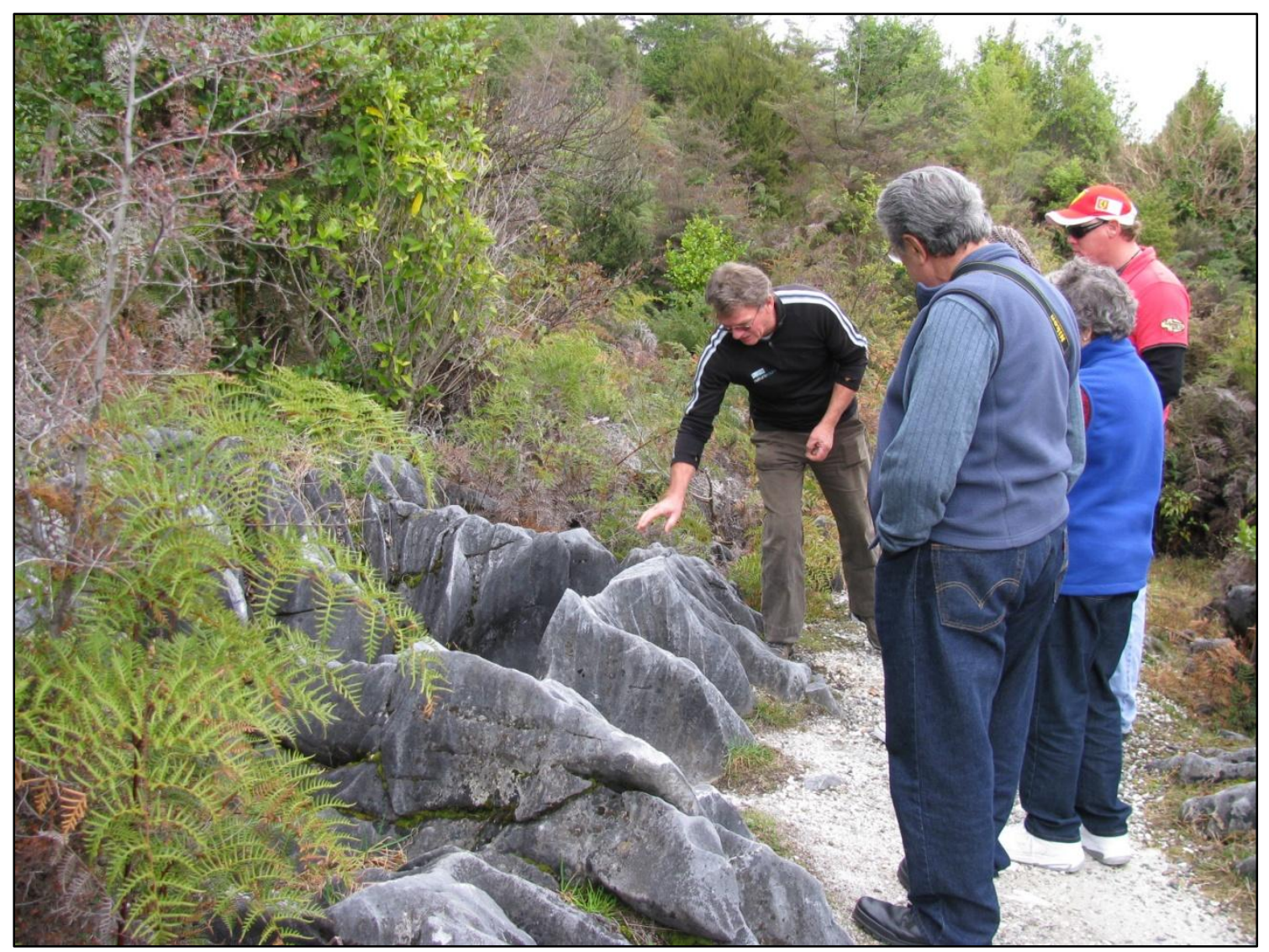

Tour guide interpreting the geology along a track, and pointing out the impact of an unconscious visitor that had taken part of the rock as a souvenir.

"Interpretation has the potential to make significant and substantial contributions to the development of a more sustainable tourism industry."

(Moscardo, 1998 p.11) 


\section{Table of Contents}

1. Introduction ........................................................................................... 1

1.1. Tourism in Natural Protected Areas................................................. 2

1.2. Environmental Interpretation, Conservation and Tourism ............... 10

1.3. The Research Project........................................................................ 12

1.4. Thesis Structure …............................................................................ 14

2. Literature Review .......................................................................................... 15

2.1 Tourism in Natural Protected Areas ...................................................... 15

2.2. Environmental Interpretation .......................................................... 26

2.3. Tour Guiding ........................................................................... 31

2.4. Literature Summary and Gaps ...................................................... 33

2.5. Conceptual Framework .......................................... 34

3. Methodology ….............................................................................................. 36

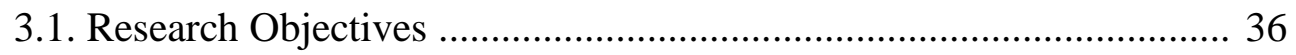

3.2. Methodological Framework ........................................................... 37

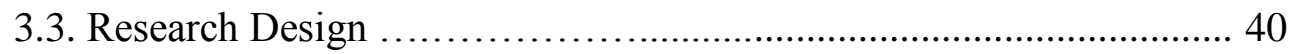

3.4. Analytical Framework ............................................................... 52

4. Findings of National Survey ............................................................... 55

4.1. Perceptions on the importance and benefits of environmental

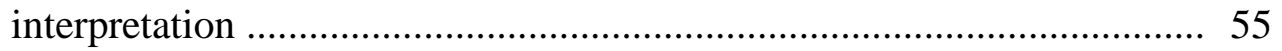

4.2. Actions employed by both stakeholders to develop the interpretation capabilities of tour operators ........................................................... 62

4.3. Challenges and constraints faced by both stakeholders in developing and assuring quality interpretation practices by tour operators ............ 70

4.4. Perceptions towards the concession system .................................. 73

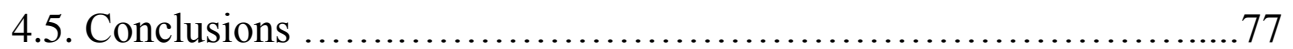

5. Findings of the Case Study ............................................................. 79

5.1. Attitudes towards interpretation .................................................... 79

5.1.1. Tour operators' attitudes toward interpretation ...................... 80

5.1.2. DoC Managers' attitudes toward interpretation ............................. 84

5.2. Actions to develop the interpretation capabilities of tour operators ... 87

5.2.1. Tour operators' actions to develop their interpretation capabilities .. 88

5.2.2. DoC managers' actions to develop the interpretation capabilities of tour operators, and to assure quality interpretation practices 
5.3. Challenges and constraints to develop and support the interpretation capabilities of tour operators, and assure quality interpretation

5.3.1. Challenges and Constraints faced by tour operators in developing and to maintaining their interpretation capabilities

5.3.2. Challenges and constraints faced by DoC managers in supporting the interpretation practices of tour operators, and assuring quality

5.4. Views on their relationship and on the concession system

5.4.1. Tour operators' views on their relationship with $\mathrm{DoC}$ and on the concession system.

5.4.2. DoC managers' views on their relationship with tour operators and on the concession system

5.5. Participant observations

5.6. Conclusions

6. Discussion and Conclusion

6.1. Perceptions on the importance and benefits of environmental interpretation.

6.2 Actions employed by both stakeholders to develop the interpretation capabilities of tour operators

6.3 Challenges and constraints faced by both stakeholders in developing and assuring quality interpretation practices by tour operators

6.4 Perceptions towards their relationship and the concession system .......146

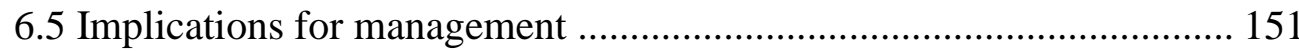

6.6 Implications for Future Studies ..................................................... 152

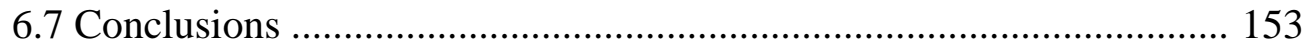

Appendix I: Information sheet and questionnaire sent to guiding concessionaires (tour operators) during national survey

Appendix II: Information sheet and questionnaire sent to DoC concessions managers during national survey

Appendix III: Interview schedule and semi-structured questionnaire used to guide interviews with guiding concessionaires during the case study

Appendix IV: Interview schedule and semi-structured questionnaire used to guide interviews with DoC's concessions managers during the case study.... 165

Appendix V: DoC's messages accompanying the national surveys 


\section{List of Figures}

Figure 2.1: Research topics and focus .................................. 15

Figure 2.2: Concessions by activity for $2008 / 2009$...................... 23

Figure 2.3: Sowman and Pearce's conceptual framework for an integrated approach to visitor management in national parks

Figure 2.4: Taylor and Gough's integrating framework for planning and management of tourism in natural areas

Figure 2.5: Conceptual framework for studying guiding concessions and environmental interpretation in New Zealand's Conservation Estate 35

Figure 3.1: Methodological framework for studying guiding concessions and environmental interpretation in New Zealand's Conservation Estate ..............38

Figure 3.2: National survey: business sizes of tour operators ............................ 43

Figure 3.3: National survey: guided activities offered by tour operators ............ 44

Figure 3.4: Nelson-Marlborough Conservancy - protected areas ................ 46

Figure 3.5: Nelson-Marlborough Conservancy - DoC areas ................. 48

Figure 3.6: Case study: activities offered by the 13 tour operators interviewed.... 50

Figure 3.7: Analytical Framework ........................................ 52

Figure 4.1: Significance of interpretation to tour operators' and

Figure 4.2 Importance of interpretation to each stakeholder ........................... 59

Figure 4.3 Importance of interpretation to visitors according to each group ....... 59

Figure 4.4: DoC's Interpretation Handbook and Standards (cover) ............ 63

Figure 4.5: DoC's interpretation toolkit Conservation Revealed (CD cover) ...... 64

Figure 4.6: Interpretation resources possessed and used by tour operators ...... 65

Figure 4.7: Tour operators' and DoC managers' satisfaction with DoC's support to interpretation

Figure 4.8: Proportion of guiding concessions that deliver quality interpretation that meet DoC's standards according to DoC managers .......................... 70

Figure 5.1: DoC's interpretation panels at Ship Cove - Queen Charlotte Track ... 101 


\section{List of Tables}

Table 2.1: Summary of existing published research into visitor uses

of protected areas

Table 2.2: DoC visitor facility network. Adapted from Walker (2007)

Table 3.1: Number of guiding concessions per conservancy held by 33 tour operators in the national survey

Table 3.2: National survey: DoC concessions managers 45

Table 3.3: Case study: scope of operation of tour operators interviewed 49

Table 3.4: DoC managers interviewed - scope of operation and function 50

Table 4.1: Significance of interpretation to tour operators per activity type 57

Table 4.2: Significance of interpretation to tour operators (per business size) ..... 57

Table 4.3: Significance of interpretation to DoC managers (per role) 58 


\section{DEFINITIONS:}

Conservation Estate: public conservation lands and waters, including different categories of protected areas, such as: national parks, marine parks, many different categories of reserves, and wildlife areas.

Environmental Interpretation: a communication process that helps people understand about, engage with, enjoy, and care for the environment.

Guiding Concession: an official authorisation to operate a guiding business, such as: nature walking, wildlife watching, fishing, hunting, climbing, skiing, and kayaking in an area managed by the Department of Conservation (adapted from DoC, 2009g).

Protected Area: “a clearly defined geographical space, recognised, dedicated and managed, through legal or other effective means, to achieve the long-term conservation of nature with associated ecosystem services and cultural values" (Dudley, 2008 p.8). In New Zealand the term "conservation land" is a synonym, and it is used more often.

\section{ABBREVIATIONS \& ACRONYMS:}

AHI - Association for Heritage Interpretation

ATTTO - Aviation, Tourism, and Travel Training Organisation

CBD - Convention on Biological Diversity

DoC - Department of Conservation of New Zealand

INNZ - Interpretation Network New Zealand

IUCN - International Union for Conservation of Nature

NAI - National Association for Interpretation

NZCA - New Zealand Conservation Authority

NZQA - New Zealand Qualification Authority

TIANZ - Tourism Industry Association New Zealand

TMT - The Ministry of Tourism of New Zealand

TNZ - Tourism New Zealand

TO - Tour Operator

SCBD - Secretariat of the Convention on Biological Diversity 


\section{Introduction}

This research project investigated the management of environmental interpretation in New Zealand's Conservation Estate, by focusing on the relationship between resource managers from the Department of Conservation (DoC) and the tour operators that held guiding concessions. The key aims were: to understand how the concession system, that regulates tourism activity in the Conservation Estate, deals with interpretation aspects; to assess resource managers' and tour operators' perceptions about the benefits and importance of interpretation; to identify the actions undertaken by them to develop the interpretation capabilities of tour operators; and to understand the challenges they face in supporting and monitoring the interpretation practices of tour operators.

This chapter begins by describing the roots and importance of protected areas to the tourism industry worldwide, and specifically to New Zealand. Next, the benefits and impacts of tourism in protected areas are outlined, followed by a discussion of the potentially conflicting goals of protected areas: resources preservation and public use.

The next section introduces tourism and visitor management in protected areas, and tourism management in New Zealand's Conservation Estate. Subsequently, New Zealand's concession system that regulates commercial activities in the Conservation Estate is presented, including existing issues regarding tourism concessions. The following section presents environmental interpretation and discusses its benefits to natural resources conservation and to the tourism industry. Afterwards the motivations, overall aim, specific objectives, and methodology of this research project are presented. At the end of this chapter the structure of this thesis is described, followed by a summary of the conclusions. 


\subsection{Tourism in Natural Protected Areas}

At present, tourism in natural protected areas is widespread throughout the world, but this is not a new phenomena. According to Eagles et al (2002, p.5) "in Europe, some areas were protected as hunting grounds for the rich and powerful nearly 1,000 years ago". It can be argued that those medieval hunting expeditions were an early type of nature-based tourism, and thus the relationship between natural protected areas and tourism is a long one. However, modern tourism in protected areas has its roots in the establishment of the first national parks in the second half of the $19^{\text {th }}$ Century in the USA, Canada, Australia, and New Zealand (Eagles et al, 2002). Back then, protection of outstanding natural scenery for the enjoyment of the public was the main criteria for establishing protected areas, while nowadays the major concern and criteria for new protected areas is the conservation of biodiversity (IUCN, 2004a). Nonetheless, both natural scenery and biodiversity are important tourism attractions, and protected areas play a critical role in the tourism industry worldwide. In 1872 the first national park in the world, Yellowstone, was established in the USA "as a public park or pleasuring ground for the benefit and enjoyment of the people" (Eagles et al, 2002, p.6). Shortly after, in 1879 Australia created the second national park - the Royal National Park, and in 1887 the Canada created the third - Banff National Park. New Zealand was also one of the pioneering countries, establishing in 1887 the world's fourth national park Tongariro National Park, in a volcanic area sacred to the indigenous Maori people (DoC, 2009h). The success of those first parks have stimulated the establishment of parks all over the world, and have helped to stimulate an outdoor culture. Nowadays, those pioneering countries have extensive and well equipped protected area systems that underpin their nature-based tourism industry (DoC, 2006a; TTF, 2007). Nature-based tourism comprises many different outdoor activities ranging from low impact activities, such as: nature walking, hiking, wildlife watching, kayaking, and scenic tours; to higher 
impact adventure activities, such as: skiing, jet boating, and climbing. The Ministry of Tourism of New Zealand identifies 75 different types of nature-based tourism activities currently practiced in this country (TMT, 2009).

National parks and other public protected areas represent major assets of the tourism industry in many countries, and this is particularly true in New Zealand where approximately one third of the land area comprises the Conservation Estate (DoC, 2006a). As pointed out by the national tourism organization - Tourism New Zealand (2001, p.12): "New Zealand as a tourist destination came to fame through its natural unspoiled beauty and the activities that beauty offered. The early icons still exist today as pivotal tourist attractions." The protected area status of those early icons, such as: Tongariro National Park, and Mount Cook National Park, has been critical to their conservation, as well as to their attractiveness.

New Zealand's Conservation Estate also supports the famous clean and green image of the country, as well as the successful $100 \%$ Pure tourism marketing campaign that draws international tourists to the country. The New Zealand Tourism Strategy 2015, aimed at the development of a sustainable tourism industry, recognizes that the natural environment is one of the key elements of this industry, and sets one of its two central values as kaitiakitanga (guardianship), for the care and protection of the environment. The Strategy also emphasizes the responsibility of the tourism industry towards the environment in one of its strategic outcomes: "The tourism sector takes a leading role in protecting and enhancing the environment.” (The Ministry of Tourism - TMT, 2007 p.5)

\section{Benefits and Impacts of Tourism in Natural Protected Areas:}

At the same time that natural protected areas benefit tourism by attracting tourists, this 
industry can also benefit those areas. Buckley (2004, p.75) argues that "conservation interests hope to use tourism as a tool in conservation, whereas tourism interests want to use conservation as a tool in tourism development." While protected areas provide the tourism industry with outstanding landscapes, pristine vegetation, native wildlife, and culturally significant sites; tourism can provide considerable benefits to nature conservation programs (Eagles et al, 2002; Buckley, 2004; Lacy and Whitmore, 2006; Bushell, 2005; Bushell and McCool, 2007). Tourism in protected areas can generate significant economic gains boosting national, regional and national economies, and improving the livelihood of local communities. Tourism can increase the knowledge of visitors and host communities, fostering appreciation and respect for natural and cultural heritage. Both the economic and educational gains brought by nature-based tourism increase the public support and advocacy for protected areas and conservation programs. Finally, tourism revenues are increasingly sought as a complementary source of funding for the management of protected areas.

The United Nations Environment Program - UNEP (2005) indicates that tourism in national parks and World Heritage sites can benefit biodiversity conservation and local communities, however, it acknowledges the need for increased cooperation between managers of protected areas and the tourism industry in order to achieve those benefits. Partnerships between these two stakeholders can generate a series of tourism and conservation outcomes, including: parks visitor infrastructure, accommodation experiences, visitor experiences, visitor management and services, and conservation services (TTF, 2007).

However, tourism can also cause many negative impacts on protected areas and adjacent communities, and it has been called a double-edged sword (Mowforth and Munt, 1998 
in Duim and Caalders, 2002; Figgis, 2000; McCool, 2006). If it is not properly planned and managed, tourism can cause environmental impacts on ecosystems, soils, vegetation, water, air, and wildlife (Eagles et al, 2002). It can also cause socio-economic impacts, such as: local community displacement and exploitation, cultural deterioration, increased local living costs, and pressure on existing facilities shared with local communities such as transport, sanitation, energy and water supply. Poorly managed tourism can also negatively impact upon itself deteriorating the visitor experience by crowding, inappropriate behaviour, or by the destruction of natural and cultural attractions. It is the responsibility of tourism and resource managers to maximize the benefits and minimize the negative impacts of tourism in natural protected areas and adjacent communities. This can be achieved through sound planning and effective management.

$\underline{\text { Resources Preservation and Public Use - Conflicting or Complementary Goals?: }}$ Protected areas managers are faced with a dual mandate - to preserve the natural resources and to foster public use. While these could be seem as conflicting goals, they are also complementary, since public use, for recreation and tourism, allows understanding (education) and enjoyment (visitor experience), which lead to appreciation, respect, and care. However, balancing those goals has been a big challenge for resource managers. There is a general agreement among policy makers, resources managers and scholars that preservation is a primary and more important goal of protected areas, and that public use should comply with that premise (Cessford and Thompson, 2002; Tonge et al, 2005; Jager et al, 2006; Rodger et al, 2007). In the past, protected area agencies emphasized the preservation aspect, but there has been a shift in managers' views and approaches. The practice of preservation has been largely replaced by conservation, which includes the concept of sustainable use; and government 
agencies have adopted integrated management approaches to cater for protection and use of the resources. Jager et al (2006, p.19) point out that "instead of viewing the issue as a dichotomy of people versus parks, a cohesive management approach integrates the three elements." These elements are: preservation, education, and visitor experience.

\section{Tourism and Visitor Management in Protected Areas:}

Effective financial, staff, legal, and political management underpin the whole process of protected area management (Eagles, 2002). The International Union for Conservation of Nature (IUCN) points out that the lack of financial resources, particularly in developing countries, is a major obstruction for adequate protected area management (IUCN, 2004a), and tourism is sought as a complementary source of funding (IUCN, 2004b; Bushell, 2005; Emerton et al 2006).

Management of tourism in protected areas is a complex task that must address different objectives and involve many stakeholders and interests. Protected areas managers are primarily interested in the conservation of the resources, tourism businesses have a focus on economic sustainability, local communities are concerned with social and cultural impacts, and tourists are looking for good experiences. There are different types of management mechanisms or tools to manage visitors and tourism activities in protected areas. Regulations, codes of conduct, zoning, structures provision, site hardening, pricing, and environmental interpretation provide managers with a variety of tools that have been classified into hard and soft approaches (Kuo, 2002; Mason, 2005).

Eagles (2002) points out that the success of tourism and visitor management in protected areas depends on the integration of this component with natural and cultural resources management. McArthur and Hall (1996, p.37) define visitor management as 
"the management of visitors in a manner which maximises the quality of the visitor experience while assisting the achievement of the area's overall management objectives." Thus, visitor management should address both protected area management goals - public use and conservation of the resources, in a complimentary way. Quality experiences, that favor both the visitor and the area, are a key objective for protected area agencies and the tourism industry alike. $\mathrm{Mc} \operatorname{Cool}(2006$, p.7) affirms that "the ability to provide high quality opportunities over extended time frames is fundamental to being competitive in the global arena that characterises $21^{\text {st }}$ century tourism." The current thesis investigates an important component of visitor experience which is also a tool for visitor management in protected areas - environmental interpretation. Interpretation, when properly prepared and delivered, can enhance the visitor experience and assist with the conservation of the resources simultaneously.

\section{Tourism Management in New Zealand's Conservation Estate:}

The great majority of protected areas that comprise New Zealand's Conservation Estate are open to free public access, and the Department of Conservation (DoC) maintains an extensive network of trails and facilities that support high levels of visitation. However, the provision of guided activities and face-to-face environmental interpretation in that land is largely done by private tourism operators that hold guiding concessions.

The Conservation Act (1987) is the main national-level legislation in New Zealand directing the conservation of natural and cultural resources, establishing the Department of Conservation and its mandate, and regulating recreation and tourism concessions in the country's Conservation Estate. DoC is responsible for the conservation of New Zealand's natural and historic heritage and the stewardship of the Conservation Estate. According to the Conservation Act, the Department's key functions are: 
to manage land and other natural and historic resources;

$>$ to preserve as far as practicable all indigenous freshwater fisheries, protect recreational fisheries and freshwater habitats;

$>$ to advocate conservation of natural and historic resources;

$>$ to promote the benefits of conservation;

$>$ to provide conservation information; and

$>$ to foster recreation and allow tourism, to the extent that use is not inconsistent with the conservation of any natural or historic resource. (DoC, 2009b)

Recreation and tourism are clearly part of DoC's key functions, but these activities must be consistent with the primary objective of the Conservation Estate - the conservation of the natural and historic resources. Nonetheless, recreation and tourism management is one of the main activities carried out by DoC, accounting for $39 \%$ of its budget in the year ended in June 2009 (DoC, 2009f).

The most significant and comprehensive policy regarding visitor management in New Zealand's Conservation Estate is the Visitor Strategy (1996), which is intended to guide DoC's planning and management of visitor services. The Strategy has five inter-related goals (DoC, 2009c):

$>$ protection of the natural and historic values;

$>$ fostering visits;

> managing tourism concessions on protected lands;

$>$ informing and educating visitors; and

$>$ visitor safety.

The current thesis addresses two of these goals - managing tourism concessions, and informing and educating visitors. It focuses on the interaction between two management tools - tourism concessions, and environmental interpretation. The former, classified as a hard management approach, is a licensing mechanism used to regulate commercial activity in the Conservation Estate, and the latter, a soft approach, focuses on communication and education. 


\section{New Zealand's Concession System:}

Licensing mechanisms, such as tourism concessions, allow the private sector to explore commercial activities in public conservation estates, and help protected area agencies to increase the offer and the diversity of recreation and tourism opportunities in those areas. They also provide resources managers with a regulatory framework to control and to set standards to commercial activities:

"The concession system helps DOC ensure that the various concession activities are compatible with the primary aim of protecting the land and other resources. It also helps ensure that services and facilities provided for visitors are appropriate, of a suitable standard, and that other activities do not conflict with visitor enjoyment" (DoC, 2009g).

DoC is currently dealing with a number of issues regarding tourism concessions, and those have been in the media, and debated by the Tourism Industry Association New Zealand (TIANZ, 2006). The main issues to the tourism industry have been: the allocation of concessions where supply is limited, short tenure, and slow application process. New Zealand's concession system is currently undergoing a review process that addresses those issues. However, little attention has been paid to specific concession's conditions and mechanisms dealing with visitor management and visitors experience. Parr (2000, p.5) argues that "visitor management could be improved by integrating concession management with recreation planning."

The presence of illegal tour operators working in the Conservation Estate without concessions is another issue that has been tackled by DoC, but still exists to some extent. Another issue pointed out by Maher (2004) is the conflicts between domestic recreationists and commercial operators and their clients, a situation that has been 
aggravated by rising international visitor arrivals. He argues that such conflicts enhance the importance of the concession system as a visitor experience management tool.

\subsection{Environmental Interpretation, Conservation, and Tourism}

According to the Association for Heritage Interpretation (AHI, 2009) "interpretation is primarily a communication process that helps people make sense of, and understand more about, your site, collection or event." Environmental interpretation is an important tool to promote natural and cultural heritage conservation, as stated by Tilden (1977, p.38): "Through interpretation, understanding; through understanding, appreciation; through appreciation, protection."

According to Ham and Weiler (2005 p.iv): "Over the past five decades, tourism providers across the world have recognised the importance of high quality interpretation as central to their mission." Interpretation provides many benefits to the tourism industry. Effective interpretation can enhance the visitor experience, add value to the tourism product, strengthen public relations, protect visitors from on-site hazards, and promote the conservation of the resource base (Moscardo, 1998; Kuo, 2002; Ham and Weiler, 2005; Lacy and Whitmore, 2006). Vargas (2007) pointed out that successful tourism destinations depend on conservation and restoration strategies to maintain and enhance their natural and cultural resources, as well as on effective interpretive resources and activities so that tourists can understand, appreciate, and connect with those elements. According to Moscardo (1998, p.11) "interpretation has the potential to make significant and substantial contributions to the development of a more sustainable tourism industry."

Directives that environmental interpretation should be applied in the management of 
protected areas are found in all levels of the policy and planning hierarchies, from international agreements and strategies (IUCN, 2004b; SCBD, 2004), through to national legislation and policies (NZCA, 2005; DoC, 2009c), and all the way down to regional and local conservation management plans. Likewise, interpretation is mentioned as an important tool in tourism management strategies, policies, and plans. For instance, the Ministry of Tourism of New Zealand - TMT (2007, p. 19) states in the New Zealand Tourism Strategy 2015 that: "the world-class visitor experiences anticipated by this Strategy will [...] provide visitors with a rich experience of our cultural, environmental, and social values through quality interpretation and opportunities to learn and engage."

However, gaps between planning and implementation are a common phenomenon, and quality interpretation might not be occurring in many cases due to a number of constraints, such as: lack of skillful tour guides, lack of resources, and low priority of interpretation for protected area managers and tour operators. Black and Weiler (2005) found that tour guides in Australia are underperforming in interpretation. Weiler and Ham (2001) point out that many tour operators have little understanding of interpretation, and that land management agencies do not have a clear understanding if tourism concessionaires can and do meet conservation objectives. This research projects seeks to investigate that by assessing the importance of environmental interpretation to protected area managers and nature-based tourism operators, as well as their actions and constraints to develop the interpretation capabilities of tour operators that hold guiding concessions to operate in New Zealand's Conservation Estate. 


\subsection{The Research Project}

As a Brazilian conservation biologist, my motivations to come to New Zealand to study tourism management are related to New Zealand's large experience in nature-based tourism and conservation management, and to my belief in the potential of tourism to contribute to natural resources conservation and sustainable development. Brazil has an immense potential for nature-based tourism, and recently many new natural protected areas have been created throughout the country. However, the lack of recreation facilities, as well as of financial and human resources have recently led the Brazilian government to initiate partnerships with tourism businesses, through commercial concessions, in order to overcome those shortages. Learning from the experiences of other countries is an important strategy in that context, and although there are significant differences in the environmental, economic, and social settings between Brazil and New Zealand, there are many lessons to learn. In 2008 the Brazilian and New Zealand governments signed a cooperation agreement to exchange experience on the management, research and protection of natural protected areas, where tourism management is one of the key topics. The present study has allowed me to analyze and understand New Zealand's concession system with an emphasis on the conditions and approaches that support environmental interpretation delivered by tourism operators in the Conservation Estate.

\section{Research Aim, Objectives, and Methods:}

The overall aim of this research was to investigate how the concession system regulates, supports, and assures quality interpretation by guiding concessionaires (tourism operators) in New Zealand's Conservation Estate. The research focused on the relationship between DoC managers and tourism operators, and it was carried out in two phases: a national survey and a case study in Nelson-Marlborough Conservancy. 
The specific objectives of this research were to identify, analyze, and compare the perspectives of resource managers (DoC concessions managers) and guiding concessionaires (tour operators) in relation to:

$>$ the importance and benefits of environmental interpretation;

> the actions employed by both stakeholders to develop the interpretation capabilities of tour operators;

$>$ the challenges and constraints faced by both stakeholders in developing and assuring quality interpretation practices by tour operators; and

$>$ their relationship and the concession system.

Originally, the objectives of this research also included the assessment of tour guides' and tourists' perspectives. However, timing and logistical issues during field work meant these were not possible, and the objectives were revised. Those limitations are discussed in Chapter 3.

The national survey was sent out via e-mail to all guiding concessionaires and all DoC concessions managers. The case study was based mostly on face-to-face interviews with a sample of tour operators, and most DoC concessions managers in NelsonMarlborough Conservancy. A couple of participant observations during guided tours were also conducted during field work. 


\subsection{Thesis Structure}

This thesis begins with a literature review on tourism in natural protected areas, environmental interpretation, and tour guiding. Chapter 3 presents the methodology used in both phases of the research, and presents the profile of the participants and an overview of the case study region. On Chapter 4, the findings of the national survey with tour operators and DoC managers are presented. Chapter 5 presents the findings of the case study undertook in Nelson-Marlborough Conservancy. Chapter 6, the last one, compares the findings from the two phases, and discusses the implications for guiding concessions management, as well as for future research. 


\section{Literature Review}

This research focuses on the intersection of three distinct but complementary topics: tourism in natural protected areas, environmental interpretation, and tour guiding (Figure 2.1). While there is a large literature on the first two topics, there is a smaller body of research on the latter. This chapter will present an overview of the existing literature on each of these topics focusing on their intersection.

Figure 2.1: Research topics and focus

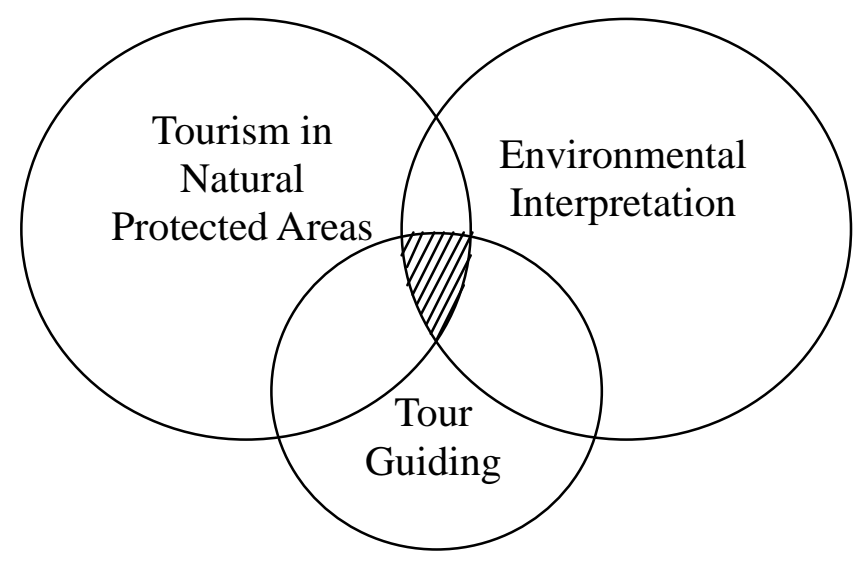

\subsection{Tourism in Natural Protected Areas}

The establishment of protected areas worldwide has gained momentum in the past few decades, following a greater awareness of the environmental crisis and the spread of the conservation movement. The IUCN reports a ten fold increase in the number of protected areas in the last four decades (Emerton et al, 2006). Developing countries like Brazil, which still have large unspoiled natural areas, have substantially expanded their protected area systems in recent years. However, most of those areas still lack adequate resources and infrastructures for effective conservation management, as well as for quality recreation and tourism activities. 
Throughout the world more than 104,000 protected areas have been established so far, covering approximately $12 \%$ of the global land surface (Emerton et al, 2006). These areas safeguard the most outstanding natural landscapes and ecosystems of the world, including precious biological, geological, archaeological, and historical features that are prominent tourism attractions. New Zealand stands out in the global conservation scene and in the nature-based tourism industry with one third of its land area comprising the Conservation Estate (the conjunct of all public protected areas), including 14 national parks, more than 3,000 reserves, and many other types of protected areas (DoC, 2009e).

\section{Types of protected areas:}

National park is probably the most popular and iconic type of protected area, but there are many other types, such as: nature reserve, wilderness area, natural monument, forest park, and marine park. Different countries have different nomenclature for their protected areas, and there are hundreds of different types of protected areas worldwide. The new IUCN definition for protected area is: "a clearly defined geographical space, recognised, dedicated and managed, through legal or other effective means, to achieve the long-term conservation of nature with associated ecosystem services and cultural values" (Dudley, 2008 p.8).

While nature conservation is the primary purpose of most protected areas, human presence and use vary widely across the different types. Most types of protected areas are open to public recreation and tourism, some allow human settlement and extraction of natural resources, but a few are very restrictive and are set aside exclusively for nature preservation. The IUCN $(1994$, p.7) recognizes a variety of purposes or management objectives for protected areas: 
$>$ Scientific research

$>$ Wilderness protection

> Preservation of species and genetic diversity

> Maintenance of environmental services

> Protection of specific natural and cultural features

$>$ Tourism and recreation

$>$ Education

$>$ Sustainable uses of resources from natural ecosystems

> Maintenance of cultural and traditional attributes

The IUCN used these management objectives as the basis for an international classification system of protected areas which sets a global standard that help the planning, establishment, and management of those areas (Dudley, 2008). According to the IUCN system, tourism and recreation not only are among the main purposes of most categories of protected areas, but they are listed as primary objectives for half of the six categories, including national parks, natural monuments and protected landscape/seascape.

\section{$\underline{\text { Research on Tourism in Protected Areas: }}$}

This section will primarily draw on two published literature reviews: Ormsby et al's (2004) review of the international literature on tourist and recreational uses of protected areas, and Booth and Mackay's (2007) review of the published researches on tourism and recreation in New Zealand's Natural Environment. Ormsby et al. (2004) contend that tourism and recreation are the dominant uses of many protected areas, and they find that the literature on human uses of these areas is concentrated on those two activities. They also point out that much of the published research on tourist and recreational uses of protected areas was conducted in terrestrial national parks in North America, and that the literature is "heavily focused on understanding visitor motivation, specialisation and perceptions of crowding" (p.44). Table 2.1 provides a summary of literature reviewed 
by those authors.

Table 2.1: Summary of existing published research into visitor uses of protected areas.

\begin{tabular}{|c|c|c|c|}
\hline Category of Variables & Extensive Research & Some Research & Little or No Research \\
\hline Visitor characteristics & $\begin{array}{l}\text { Motives or expected } \\
\text { benefits } \\
\text { Specialisation or } \\
\text { experience with } \\
\text { activities }\end{array}$ & $\begin{array}{l}\text { Social groups } \\
\text { Experience with } \\
\text { sites/places }\end{array}$ & Cultural backgrounds \\
\hline $\begin{array}{l}\text { Perceptions of the } \\
\text { physical environment }\end{array}$ & & $\begin{array}{l}\text { Features associated } \\
\text { with scenic beauty } \\
\text { judgements in forests } \\
\text { and some other } \\
\text { northern hemisphere } \\
\text { settings }\end{array}$ & $\begin{array}{l}\text { Marine and southern } \\
\text { hemisphere settings }\end{array}$ \\
\hline $\begin{array}{l}\text { Use density and } \\
\text { crowding }\end{array}$ & $\begin{array}{l}\text { Number of encounters } \\
\text { Use conflict }\end{array}$ & $\begin{array}{l}\text { Noise } \\
\text { Evidence of } \\
\text { inappropriate } \\
\text { behaviour and } \\
\text { impacts of others }\end{array}$ & Social group identity \\
\hline Perceptions of service & & $\begin{array}{l}\text { Quality of facilities } \\
\text { and infrastructure } \\
\text { Quality of staff } \\
\text { interactions }\end{array}$ & $\begin{array}{l}\text { Features of tour } \\
\text { operations }\end{array}$ \\
\hline
\end{tabular}

Source: Ormsby et al (2004 p.44).

Particularly relevant to this thesis is the finding of Ormsby et al (2004) that there are little or no research on perceptions of services regarding features of tour operators. Although the current thesis does not attempt to investigate visitors' perceptions, it does assess DoC managers' and tours operators' perceptions about the interpretation practices of tour operators in New Zealand's Conservation Estate.

One of the key points identified by Ormsby et al (2004) in the existing literature, and that is particularly relevant to this thesis, is that visitor behaviour in, and satisfaction with, protected areas is influenced by the perceived quality of the services provided by tour operators, and the effectiveness of interpretation programs. They also list other influencing factors, such as: visitor characteristics; quality of the physical environment, facilities and infrastructure; and interactions with other people. The quality of the 
services provided by tour operators and the effectiveness of their interpretation programs are two aspects potentially influenced by concession systems, and these aspects are discusses in the present thesis.

Booth and Mackay (2007) recorded 602 publications from 1990 to mid-2006 on tourism and recreation in New Zealand's natural environment. They noted that one third of those publications were focused on protected areas:

"A considerable proportion of the tourism/environment literature is focused upon protected areas (36 percent of all publications), especially national parks. Owing to New Zealand's extensive system of protected areas and their importance for tourism and recreation, this is not surprising." (Booth and Mackay, 2007, p. 21).

Despite the large number of research carried out in New Zealand's protected areas, Booth and Mackay (2007) listed only five publications about DoC's concession system: Parr (2000), two similar publications by Cessford and Thompson (2002), Maher (2004), and Thompson (2005). It is important to note that all those publications provided the resource managers' perspective since they were written by DoC staff. Nonetheless, Thompson (2005) also provided the tour operators' perspective, since he interviewed some of them when investigating their contribution to nature conservation.

$\underline{\text { Trends in protected areas visitation and drivers for nature-based tourism: }}$

Nature-based tourism and visitation in protected areas is increasing in most countries (Parr, 2000; Sowman and Pearce, 2000; Eagles, 2002; Balmford et al, 2009). In New Zealand tourism in protected areas is growing and this trend is mainly driven by international visitors (Walker, 2007). This driver is confirmed by Balmford et al, (2009) for many other countries. According to The Ministry of Tourism of New Zealand (TMT, 2009), in $200870 \%$ of all trips undertaken by international tourists in New Zealand, and $22 \%$ of all domestic trips were nature-based. Walker (2007) estimates that there are 
more than 30 million visits per year to New Zealand's Conservation Estate, and he indicates that this is still growing. In 2008, international tourists made more than 1.3 million visits to the six most popular national parks of this country (Fiordland, Westland, Mount Cook, Abel Tasman, Paparoa, and Tongariro) (DoC, 2009a). That figure is the double of ten years ago and it shows how international tourism in New Zealand's national parks is increasing. This growth trend is celebrated by the tourism industry, but it also causes concern for natural resource managers since tourism can cause negative impacts on the environment and on the visitor experience. Maher (2004) points out that the growth trend in the visitation of protected areas in New Zealand will probably cause the increase in concession activity, creating management issues such as: user conflicts, crowding, and displacement.

Some of key drivers for the growth of nature-based tourism are: the growth of international travel, longer life span, rising popularity of outdoor activities, rising educational levels, advances in communications and information technology, and increasing environmental concern (Eagles et al, 2002; Emerton et al, 2006).

\section{Tourism and protected areas partnerships:}

The tourism industry relies on the public sector to establish and maintain protected areas, as well as to provide access and infrastructure that allow the development of nature-based tourism in these special places. (Fennell, 1999; Weaver, 2001; Eagles and McCool, 2002; Eagles, 2002; Newsome et al., 2002; McCool, 2009). On the other hand, natural resources management agencies rely on collaboration or partnerships with the private sector in order to increase the opportunities for public use of protected areas; to build support for conservation; and to develop sustainable tourism practices. According to Bushell (2005) the IUCN recommends that tourism policies and practices result in: 
a) the protection of nature conservation areas from being loved to death by visitors or exploited by industry, as feared by many conservationists;

b) the potential of tourism being harnessed to help finance conservation;

c) support for local communities through nature based tourism; and

d) visitor services and interpretation strategies that foster a greater level of understanding of the many values of protected areas and wider support for conservation.

“These objectives are best achieved through high level negotiation between key conservation and tourism bodies, together with on-the-ground partnerships between natural resource managers, local communities and tourism operators." (Bushell, 2005 p.143)

Wegner (2007) argues that communication and collaboration between resource managers and tour operators is essential to improve their relationship.

In New Zealand the Department of Conservation has worked closely with the private sector to increase recreation and tourism opportunities in the Conservation Estate. According to Walker (2007) DoC's main activities supporting nature based tourism are:

$>$ Land management (strategies and plans);

$>$ Facility provision; and

$>$ Concession and other partnership arrangements.

Recreation and tourism management is one the main activities carried out by DoC, it is second only to natural heritage management - DoC's core role. In the year ended in June 2009, DoC's total revenue was NZ\$312.5 million, 39\% of which was used for recreation opportunities management, and 51\% for natural heritage management (DoC, 2009f). DoC manages NZ\$ 400 million worth of visitor infrastructure (DoC, 2006a). Walker (2007) lists the visitor facility network provided by DoC that allows high levels of recreation and tourism in New Zealand's Conservation Estate (Table 2.2). 
Table 2.2: DoC visitor facility network. Adapted from Walker (2007)

\begin{tabular}{|l|l|}
\hline Visitor Facility & Quantity \\
\hline walking track & $12,800 \mathrm{~km}$ \\
\hline structures (bridges, boardwalks, jetties...) & 13,300 \\
\hline back-country huts & 986 \\
\hline front-country campsites & 230 \\
\hline visitor centres & 26 \\
\hline toilets & 1570 \\
\hline visitor sites & 3800 \\
\hline
\end{tabular}

Although DoC has substantial financial resources and maintains a robust visitor facility network, it also relies on partnerships to supplement visitors services and facilities. According to DoC's Visitor Strategy:

"DoC does not see itself as having sole responsibility for providing appropriate visitor facilities and services, but instead has the role of leader, guide, and facilitator in a range of partnerships with other groups" (DoC 2003, p.38). Cessford and Thompson (2002) identify two main types of such partnerships voluntary community groups that assist $\mathrm{DoC}$ with visitor facility maintenance and visitor information, and commercial enterprises. They note that "commercial enterprise in tourism concessions is the other main means of supplementing visitor services, facilities and opportunities" (p.33).

\section{$\underline{\text { Commercial Concessions in New Zealand's Conservation Estate: }}$}

Tour operators are important partners for the provision of recreation and tourism opportunities in New Zealand's Conservation Estate, and the concession system is the regulatory framework that guides this partnership. DoC defines a concession as: "an official authorisation to operate in an area managed by the Department of Conservation (DOC). It may be in the form of a lease, licence, permit or easement" (DoC, 2009g p.1). 
Concessions are required for any commercial activity such as: accommodation,

restaurants, transports, guiding, retail, telecommunications, filming, grazing, and some extraction purposes. Concessionaires are required to follow the conditions set out in contracts, and to pay fees for the privilege of obtaining commercial benefits from public land. Most concession processes in New Zealand are initiated by individuals or firms seeking permission to run businesses in the Conservation Estate, but occasionally DoC offers concession opportunities through tender processes (DoC, 2009g).

In the year 2007-2008 DoC managed 3,612 concessions throughout New Zealand, almost half of those were recreational, and the most common type under that group were guiding concessions $(n=473)$. Guiding concessions allow tourism operators to provide a variety of guided activities on the Conservation Estate, such as: wildlife watching, nature walks, kayaking, boating, hunting, fishing, climbing, and heli-skiing. In 2008-2009 those numbers increased sharply, reaching 4,675 concession (29.4\% increase), 634 of which are guiding concessions (34\% increase) (DoC, 2009d). Figue 2.2 shows the number of all different types of concessions in New Zealand in 2009/09.

Figure 2.2: Concessions by activity for 2008/2009.

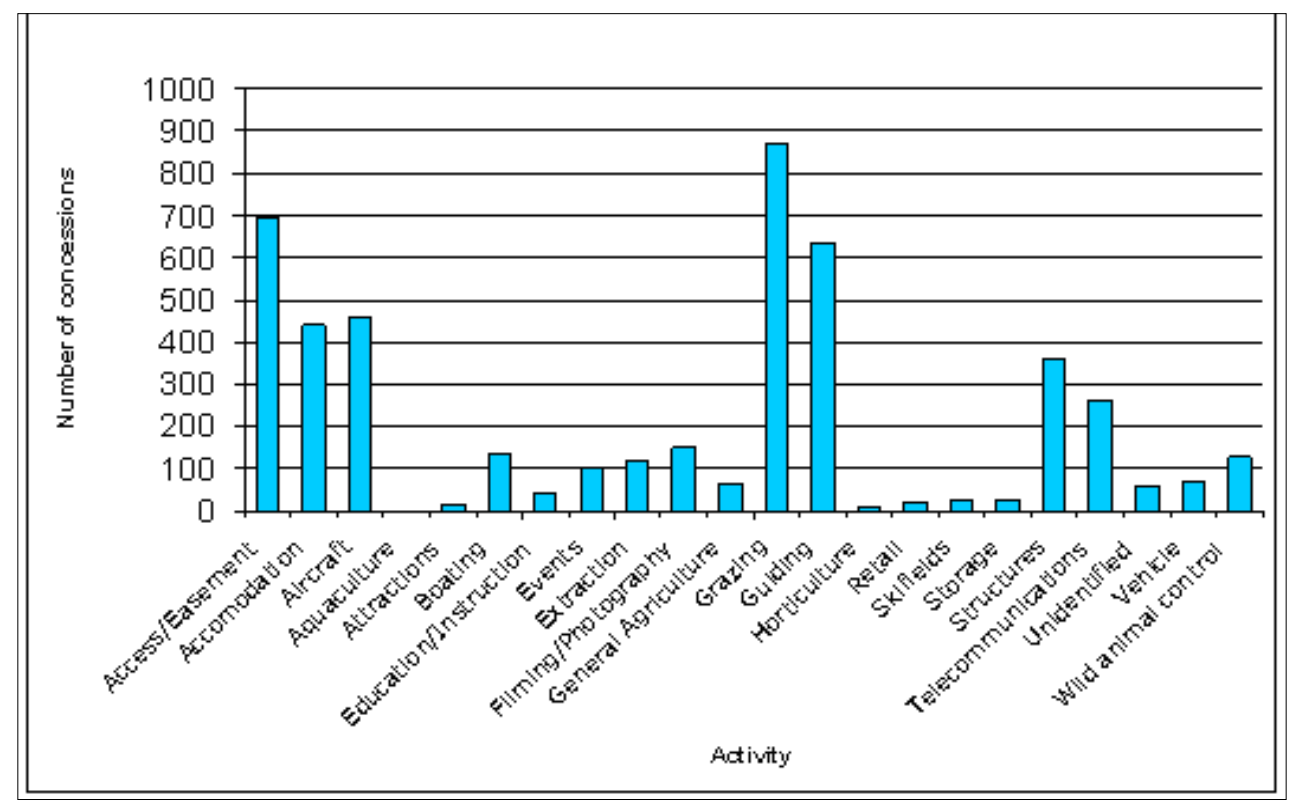

Source: DoC, 2009d. 
Integrated planning and management of tourism in protected areas:

Some authors have proposed integrated approaches to tourism planning and management in protected areas, taking into consideration the different settings and stakeholders, and using a mix of management tools (Sowman and Pearce, 2000; Eagles et al, 2002; Taylor and Gough, 2006; Warren et al, 2007). Sowman and Pearce (2000) provide a framework for an integrated approach to visitor management in national parks (Figure 2.3). Although that study is focused on national parks, their visitor management framework could be applied in other categories of protected areas. In that framework, the interactions between the public and private sectors, at the center of the model, are governed by policies, concessions, regulations, and attitudes.

Figure 2.3: Sowman and Pearce's conceptual framework for an integrated approach to visitor management in national parks.

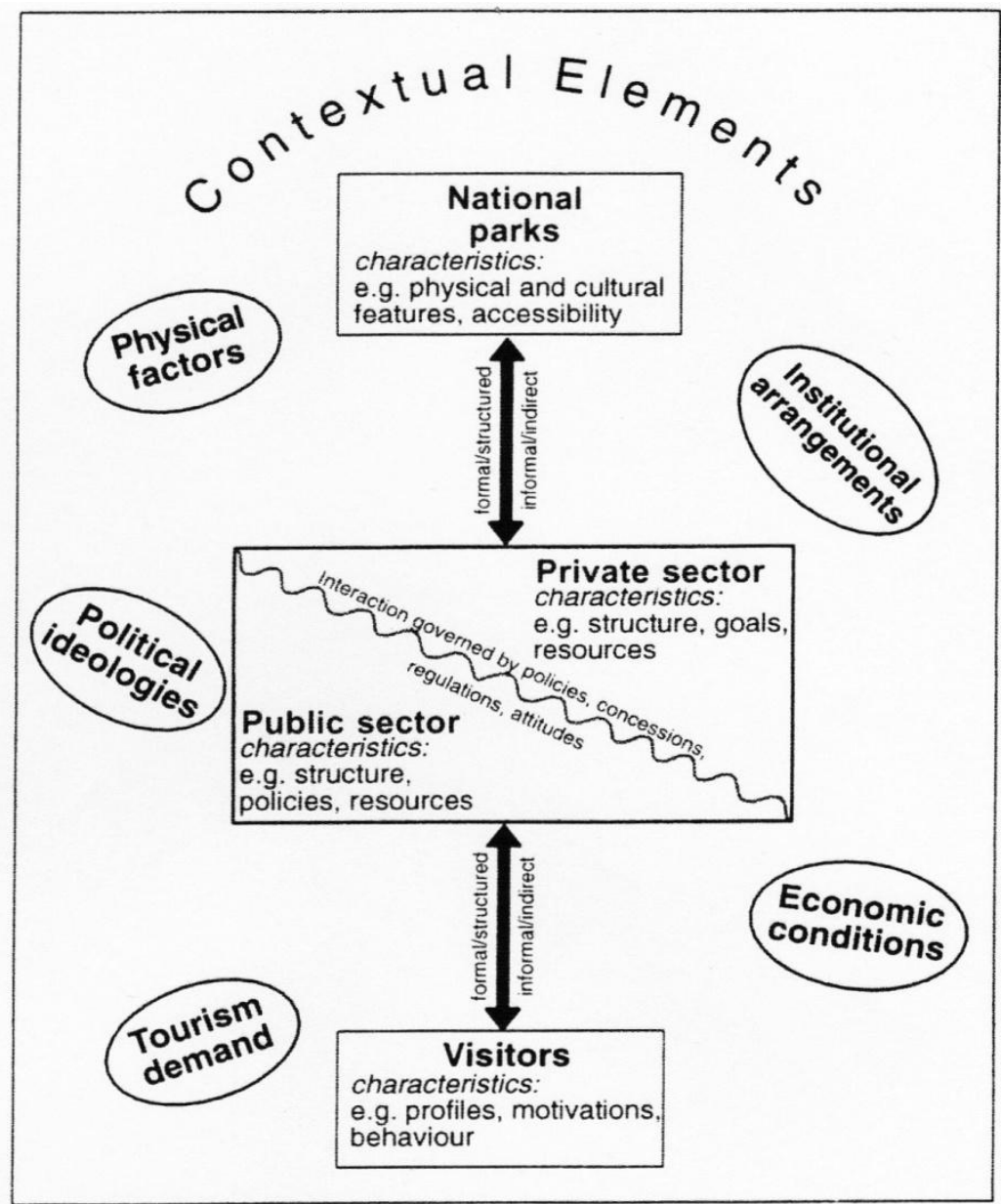

Source: Sowman and Pearce (2000, p. 224).

The diversity of contextual elements and stakeholders that influence visitor 
management in protected areas indicates that each protected has a unique setting and should therefore have a customized planning and management. Sowman and Pearce (2000, p.240) point out that:

"visitor management in national parks is a complex and challenging activity due to the exceptional physical and/or cultural settings, the varied demands which arise in providing for a satisfying visitor experience while protecting the resource base, and the range of parties involved."

Sowman and Pearce (2000) conclude that meetings those challenges requires greater knowledge of specific aspects of visitor management, as well as using a more comprehensive and integrated approach.

Taylor and Gough (2006) propose another integrating framework for planning and management of tourism in natural areas, highlighting six key management tools: plans, communication, limits, collaboration, impact assessment, valuation/allocation. (Fig.2.4).

Figure 2.4: Taylor and Gough's integrating framework for planning and management of tourism in natural areas.

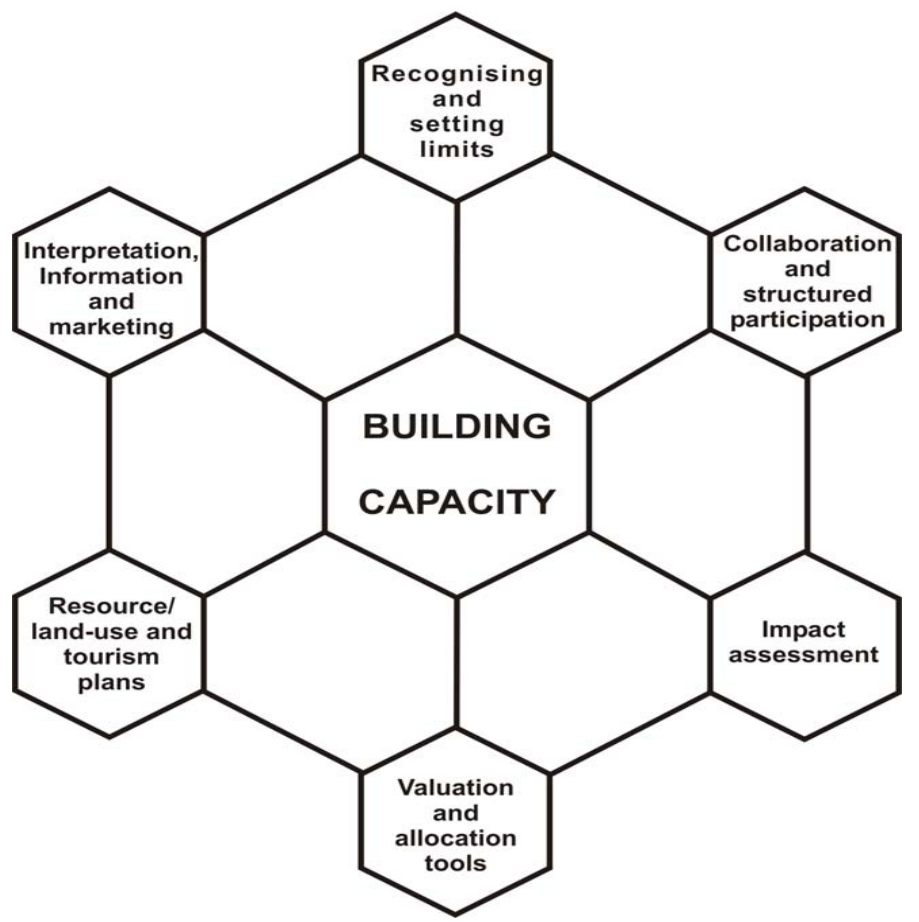

Source: Taylor and Gough (2006, p. 3)

Taylor and Gough (2006) argue that those tools applied together promote capacity 
building of the stakeholders and allow them to manage natural areas in a more integrated way. In this framework, interpretation is grouped with other communication tools, and the concession system is a type of allocation tool. It is interesting to note that DoC's concession system makes use of, and interact with all other tools presented in this framework. The concession system uses conservation management plans as guiding instruments, sets limits for commercial use, establishes conditions for interpretation, and it requires impact assessments from the businesses. Finally, the concession system can also be considered as a type of collaboration or structured participation, where the public and private sectors share the provision of recreation and tourism opportunities in the Conservation Estate.

\subsection{Environmental Interpretation}

The terms heritage interpretation and environmental interpretation are both widely used, and while the former seems to be more common and encompassing, the latter provides a clear focus on the natural environment and is more frequently used in the context of natural protected areas. There are many definitions for interpretation, the Association for Heritage Interpretation in the UK provides a very objective and concise one: "Interpretation is primarily a communication process that helps people make sense of, and understand more about, your site, collection or event." (AHI, 2009).

Communication and understanding are key elements present in most interpretation definitions (Tilden, 1977; DoC, 2005; AHI, 2009; NAI, 2009). Others, suggest that interpretation is a mission-based process (Weiler, 2005; Ham and Weiler, 2005; NAI, 2009). Weiler (2005 p.41) states that interpretation is "a vehicle for achieving organizational goals." Accordingly, DoC's definition of interpretation is directly related to its mission:

"Interpretation is an explanation of the natural, cultural or historic values attached to places. It enables visitors to gain insight and understanding about the 
reasons for conservation and ongoing protection of our heritages." (DoC, 2005 p.viii).

\section{Benefits and outcomes of interpretation:}

Quality interpretation is paramount to the long term sustainability of tourism.

Moscardo (1998, p.11) argues that "interpretation has the potential to make significant and substantial contributions to the development of a more sustainable tourism industry". According to her, the main roles for interpretation in

sustainable tourism are: to enhance visitors' experience and to manage visitors and their impacts. The visitors' experience can be enhanced by providing information on alternatives and options, providing information on safety and comfort, and creating the actual experience. Visitors and their impacts can be managed though interpretation by influencing where visitors go, providing a substitute experience, informing about appropriate behavior, and developing visitor' concern.

(Moscardo, 1998). There are many different benefits or intended outcomes from interpretation, and as stated by NAI (2009) these will vary according to the mission or goals of the organization that is delivering it. AHI (2009) lists the following potential outcomes of interpretation:

- Bring meaning to your cultural or environmental resource, enhancing visitor appreciation and promoting better understanding. As a result your visitors are more likely to care for what they identify as a precious resource.

- Enhance the visitor experience, resulting in longer stays and repeat visits. This will lead to increased income and create employment opportunities.

- Enable communities to better understand their heritage, and to express their own ideas and feelings about their home area. As a result individuals may identify with lost values inherent in their culture. 
Ham and Weiler (2005) note that the benefits of interpretation generally fall into four broad categories: enhancing visitor experiences; strengthening public relations; protecting the site from visitor impacts; and protecting visitors from on-site hazards.

Interpretation can also promote cultural understanding, and social inclusion. The use of indigenous and local knowledge in interpretation programs can include local people in tourism ventures, enhance visitors' experience, increase cultural awareness, and promote respect towards indigenous peoples. (Staiff et al, 2002; Zeppel and Muloin 2008b).

Grubb (2007) addressed the use of interpretation by tour operators in Nelson-Tasman region in his study about the environmental practices adopted by the operators, however the focus of his study was on the adoption of environmental practices, rather than an indepth investigation on the management of interpretation and its relationship with the concession system. Nonetheless, one of the key findings of Grubb (2007 p.ii) was "the opportunity to raise environmental awareness among tourists by extending environmental interpretation practices."

\section{Principles of effective interpretation:}

Although interpretation is an old practice, the modern basis for heritage interpretation was established by Freeman Tilden in 1957 in his seminal book Interpreting Our Heritage. According to Tilden, interpretation must go beyond the provision of factual information; its approaches should be adapted to different audiences; it should be related to the visitor's personality or experience to be meaningful; and it should provoke rather than instruct (Tilden, 1977). Similarly, Ham (1992 in DoC, 2005) provides four fundamental principles for effective interpretation (EROT), it must be: Enjoyable; Relevant; Organised; and Thematic. In order for interpretation to be enjoyable it is 
important to use interesting and stimulating narratives; to be relevant it must relate to the audience's interest and background; organization facilitates understanding; and the use of strong themes is a critical principle in order to deliver memorable messages. More recently, Professor Sam Ham inverted the order of those principles to "TORE", emphasizing the priority and importance of the use of themes. Other important aspects of effective interpretation are: the variety and interactivity of interpretation programs; the use of supporting materials; and the communication skills and passion of the interpreter (DoC, 2005). Weiler and Ham (2001, p.553) point out that:

“According to many writers (e.g. MacKinnon et al., 1986; Sweeting et al., 1999), it is the application of interpretive principles that will ensure visitors gain an understanding and appreciation of the parks they are visiting."

Interpretation quality, evaluation, and standards:

The quality of interpretation is crucial to its effectiveness. Sweeting et al. (1999 in Weiler and Ham, 2001) argued that high quality interpretation is good for business because it enhances clients' experiences; promotes repeated visits; provides unique marketing opportunities; and allows higher prices to be charged. Black and Crabtree (2007) present a series of articles on quality assurance and certification in Ecotourism.

Evaluation of interpretation programs is crucial in order to improve their effectiveness and quality. Many researchers have looked at the effectiveness of different types of interpretation media in diverse settings (Tubb, 2003; Madin and Fenton, 2004; Hugues and Morrison-Saunders, 2005; Zeppel and Muloin, 2008; Ballantyne et al, 2008). Most of those studies look at knowledge gain, attitude change and behavior modification of visitors as indicators of interpretation effectiveness. Munro et al (2008) review a sample of interpretation evaluation research and find an emphasis on quantifying knowledge gain and attitude change with few studies assessing behavioral change. 
Governmental agencies and academic institutions have developed methods and guidelines to help resource managers and tourism operators to plan and evaluate their interpretation programs. In 2005 two relevant tools of that kind were published and made freely available in the internet, they are: the Interpretation Evaluation Tool KitMethods and Tools for Assessing the Effectiveness of Face-to-Face Interpretive Programs (Ham and Weiler, 2005), and the Interpretation Handbook and StandardDistilling the Essence (DoC, 2005). The former was written by the renowned interpretation specialists - professors Sam Ham and Betty Weiler for the Sustainable Tourism Cooperative Research Centre in Australia. The latter was prepared by DoC and it was based mostly on Sam Ham's work and DoC's own experiences. It is important to note that DoC's handbook not only serves as a manual for planning and evaluating interpretation programs, but also it is an official document that sets the standards for DoC managers as well as for tourism operators that hold guiding concessions to operate in the Conservation Estate.

\section{Interpretation media:}

There are many different types of interpretation and these can be categorized in two groups based on the media used, these are: personal and non-personal interpretation. Personal interpretation is delivered face-to-face by an interpreter or guide, and nonpersonal interpretation uses a variety of media, such as: visitor centres and exhibitions, publications, websites, on-site panels, as well as video and audio devices. Different media have distinct strengths and weaknesses, non-personal interpretation media are particularly important in self-guided activities. Personal interpretation is an essential component of guided tours, and it can be powerful, but it requires well-trained interpreters to be effective (DoC, 2005; Lacy and Whitmore, 2006; Vargas, 2007). 


\subsection{Tour Guiding}

Tour guides perform a range of roles besides being interpreters. Black and Weiler (2005) reviewed the literature and identified ten key roles that guides must carry out in order to facilitate quality tourist experience, those are:

$>$ interpreter/educator;

$>$ information giver;

$>$ leader;

> motivator of conservation values/role model;

$>$ social role/catalyst;

$>$ navigator/protector;

$>$ cultural broker/mediator;

$>$ tour \& group manager/organizer;

$>$ public relations/company representative; and

$>$ facilitator of access to non-public areas.

The variety of roles that tour guides must perform is big a challenge of this profession, but interpretation is arguably their core role. Weiler and Ham (2001 p.554) point out that: "Clearly, interpretation is not just one of the many roles that an ecotour guide plays; when it is done well, it is the distinguishing feature of 'best practice' in guiding." The interpretation skills of tour guides is indeed critical for the quality of the visitor experiences, for the success of guiding businesses, and for the conservation of the resources. Therefore the performance of tour guides matters to all stakeholders: "it is apparent that tour guides play a pivotal role in ecotourism and are critical to meeting the needs and expectations of operators, clients, host communities, land managers, and the wider tourism industry in both developed and developing countries." (Weiler and Ham, 2001 p.554).

However, according to Black and Weiler (2005) despite its importance, tour guiding has received minimal attention in the tourism literature. Black and Weiler (2005) pointed out that guides are under-performing in some roles, particularly in relation to 
interpretation practices, minimal impact messages, and role-modeling conservation. Mc McGrath (2007) outlined the importance of interpretation training to tour guides as part of sustainable visitor management. Black and Weiler (2005) identified and examined six distinct mechanisms that can improve assure the quality of guiding services, which are:

$>$ codes of conduct;

$>$ professional associations;

$>$ awards of excellence;

$>$ training;

$>$ professional certification; and

$>$ licensing.

Although Black and Weiler (2005) dealt specifically with tour guides, the quality assurance mechanisms they analyzed are also applicable to tour operators, and by improving the businesses' performance those mechanisms should also promote better guiding practices. This can be particularly important where tour guiding is not regulated, but the businesses are. In New Zealand there is no mandatory professional certification or licensing for tour guides, despite the fact that New Zealand Qualification Authority (NZQA) sets qualification standards, and the Aviation, Tourism and Travel Training Organisation (ATTTO) provides training for a national certificate in tour guiding (ATTTO, 2009). In New Zealand's Conservation Estate, one could argue that guides are licensed by default, since tour operators must obtain licenses (guiding concessions) to operate in that land, and it is the businesses' responsibility to make sure their guides are skilled and comply with the concessions' conditions. However, guiding concessions in New Zealand as well as tour guide licensing elsewhere have focused on safety issues. Interpretation standards if often not included in those mechanisms.

"To date, these schemes [tour guide licensing] have revolved largely around legal, health and safety issues, and have tended to underestimate the importance of interpretation in law enforcement, in client safety and satisfaction, and in the overall viability of the guided tour sector of the tourism industry." (Weiler and Ham, 2001 p.554). 


\subsection{Literature Summary and Gaps}

There is a large body of literature about tourism in protected areas. However, much of the published research was conducted in North America, and the literature is "heavily focused on understanding visitor motivation, specialisation and perceptions of crowding" (Ormsby et al. 2004 p.44). In their review of research into tourist and recreational uses of protected areas Ormsby et al. (2004) also noted that there was little or no research on the perceptions of services regarding features of tour operators. The present thesis addresses that gap by providing the perceptions of tour operators and resource managers on the services provided by the operators. It also contributes to the knowledge about tourism management in protected areas of New Zealand, a highly regarded tourism destination.

In terms of the existing knowledge about tourism management in New Zealand's natural environment, Booth and Mackay (2007 p.9) commented that:

"Most research effort has been directed towards the biophysical and social setting for tourism/recreation. Very little research has focused upon the management setting, including the evaluation of visitor management processes/techniques, and the effects of managers' perceptions and actions on visitors. For example, despite its importance, no comprehensive evaluation of the DOC concession system has been published."

There are few published studies about New Zealand's concession system, and as pointed out by Parr (2000), little attention has been paid to specific concession's conditions and mechanisms dealing with visitor management and visitors experience. The current thesis not only contributes to the small body of research about New Zealand's concession system, but it also provides the first comparison about the views of resources managers and tour operators about the system.

In terms of environmental interpretation, there is an abundance of literature, much of it 
is about interpretation principles and benefits of interpretation, and a large part is about evaluation of interpretation programs. However, as pointed out by Black and Weiler (2008), most of that research is site-specific and content-focused. The present thesis provides insights on interpretation management at the national and regional scales, and it addresses the actions and challenges that tour operators and resource managers face in developing the interpretation capabilities of the operators.

Most of the literature on environmental interpretation comes from the United States and Australia. Booth and Mackay (2007) listed 14 studies about interpretation in their literature review about tourism and recreation in New Zealand's natural environment, 8 of those were related to protected areas. However, none of those studies looked at whether and how DoC concession system provides guidance, support, or assurance to quality interpretation practices of guiding concessionaires (tour operators). This is the main research gap addressed by the present thesis.

\subsection{Conceptual Framework}

A conceptual framework (Figure 2.5) guided the investigation of guiding concessions and environmental interpretation provided by tour operators in New Zealand's Conservation Estate. In the framework, the four main stakeholders (resource managers, tour operators, tour guides, and tourists) are placed around the main focus of the research - environmental interpretation. As indicated by the bold borders, the investigation concentrated in the two former stakeholders. The arrows represent the relationships among stakeholders, and the bottom one, in bold, indicates the relationship that was investigated. That relationship is mediated by the concession system - another focus of this investigation. 
Figure 2.5: Conceptual framework for studying guiding concessions and environmental interpretation in New Zealand's Conservation Estate

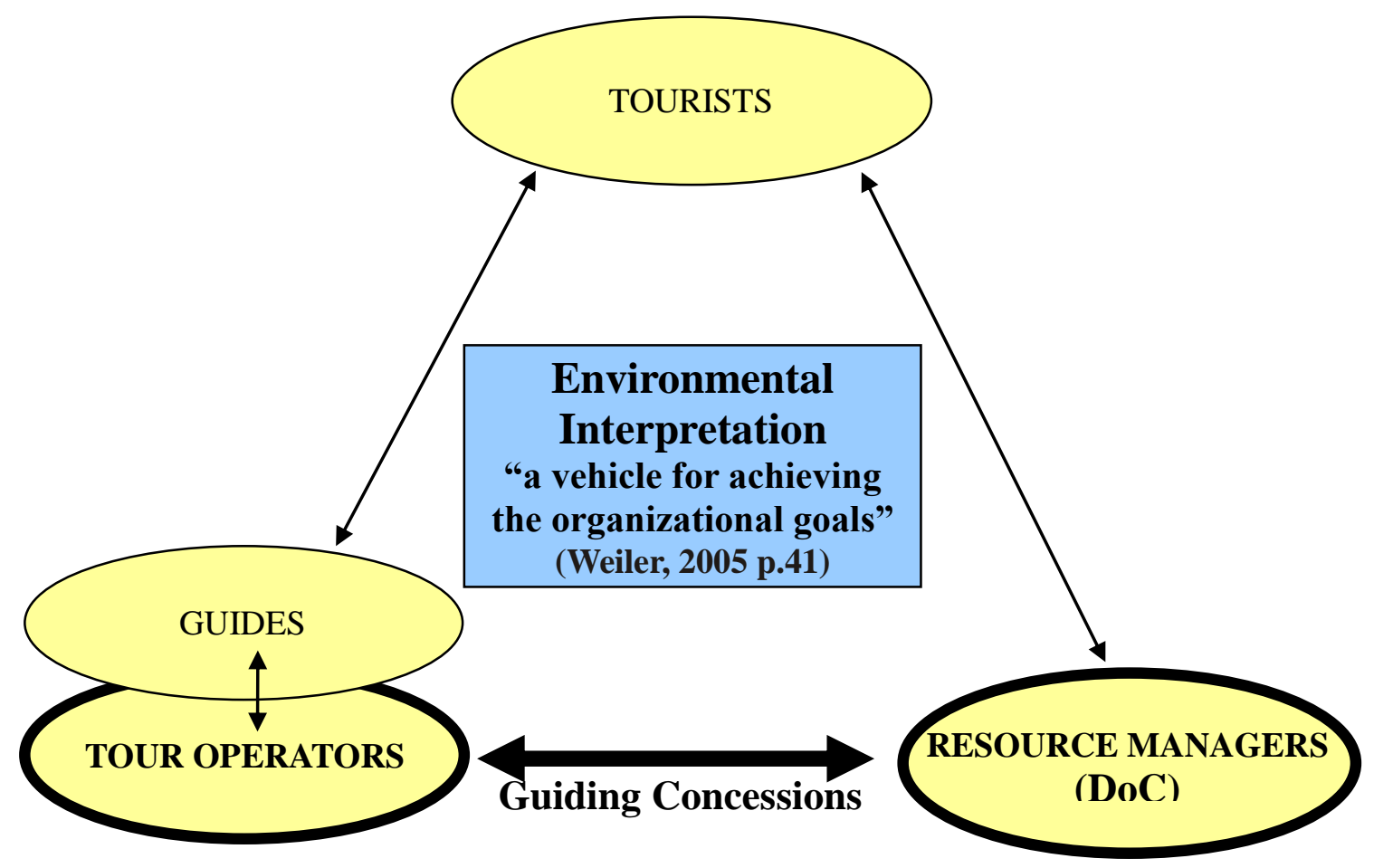

As already noted in this chapter (section 2.2) interpretation is viewed as "a vehicle for achieving organizational goals" (Weiler, 2005 p.41). This concept helps to explain the perspectives of the two stakeholders investigated. Like all businesses, tour operators' main goal is profit, but they also have secondary goals that ultimately help them to achieve the main one, and those are: client satisfaction (providing satisfying visitor experience), marketing or propagation, return business, conservation of resource base, and business sustainability (economic, environmental and social). Resource managers' main goal is the conservation of the resources, but they also are responsible for the public enjoyment of the resources, as stated in DoC's mission: "to conserve New Zealand's natural and historic heritage for all to enjoy now and in the future" (DoC 2009b). 


\section{Methodology}

This chapter delineates the methods used in this research project to assess how New Zealand's concession system regulates, supports and assures quality interpretation by tourism operators in New Zealand's Conservation Estate. It begins by outlining the specific objectives of the study, and explaining some of the limitations that led to a reduction in the original intents. Next it lays out the methodological framework that depicts the main stakeholders concerned with environmental interpretation in protected areas, and the two phases of data collection. The research strategy is then explained, including a discussion of the mixed method approach employed. In the following section the research design is detailed, including the sampling and data collection methods, the response rates, as well as the choice and context of the case study area. Next, an analytical framework is presented relating the research objectives to key characteristics of the two stakeholders investigated - tour operators that hold guiding concessions and DoC's concessions managers. At the end of this chapter a summary of the strengths and limitations of the methods is reviewed.

\subsection{Research Objectives}

As explained in the conceptual framework presented in section 2.5 , the main stakeholders involved in environmental interpretation in protected areas are the resource managers (DoC), the guiding concessionaires (tour operators), the tour guides, and the tourists. Although, the original intent was to investigate the perspectives of all four stakeholders, due to resources and time limitations this research focused on the relationship of DoC managers and tour operators (owners/managers). This choice is justified because the main purpose of this research was to investigate the influences of the concession system on tour operators' environmental interpretation, and this system mediates the relationship between these two stakeholders. It was decided in the outset 
that including a study on perspective of the tourists would not be feasible. Another major limitation encountered during field work was related to the timing of data collection, which took place from August to October - the low tourism season in the case study area. Although this season was ideal to find and interview tour operators' owners/managers, tour guides were not around since there was very little business happening. At this time of the year owners/managers prefer dismissing the guides, and do any guiding themselves. Many operators do not bother opening for business at all and either take a break or concentrate on other activities such as planning, marketing, and training. The low levels of guiding business also meant that it was not possible to undertake as many participant observations as originally planned.

The specific objectives of this research were to identify, analyze, and compare the perspectives of resource managers (DoC concessions managers) and guiding concessionaires (tour operators) in relation to:

> the importance and benefits of environmental interpretation;

$>$ the actions employed by both stakeholders to develop the interpretation capabilities of tour operators;

> the challenges and constraints faced by both stakeholders in developing and assuring quality interpretation practices by tour operators; and

$>$ their relationship and the concession system.

\subsection{Methodological Framework}

This section depicts the research methodological framework that provides a clear visual picture of the research subjects, scope, phases, and methods. Figure 3.1 shows the methodological framework with the four main stakeholders concerned with environmental interpretation in protected areas, as well as the two phases developed in the research. The stakeholders investigated in this research are inside the continuous line boxes on the left, and those that were not are inside the dashed line boxes on the 
right. The light shaded and dashed half of the second phase is the part of the study that had to be eliminated due to the limitations explained above.

Figure 3.1: Methodological framework for studying guiding concessions and environmental interpretation in New Zealand's Conservation Estate

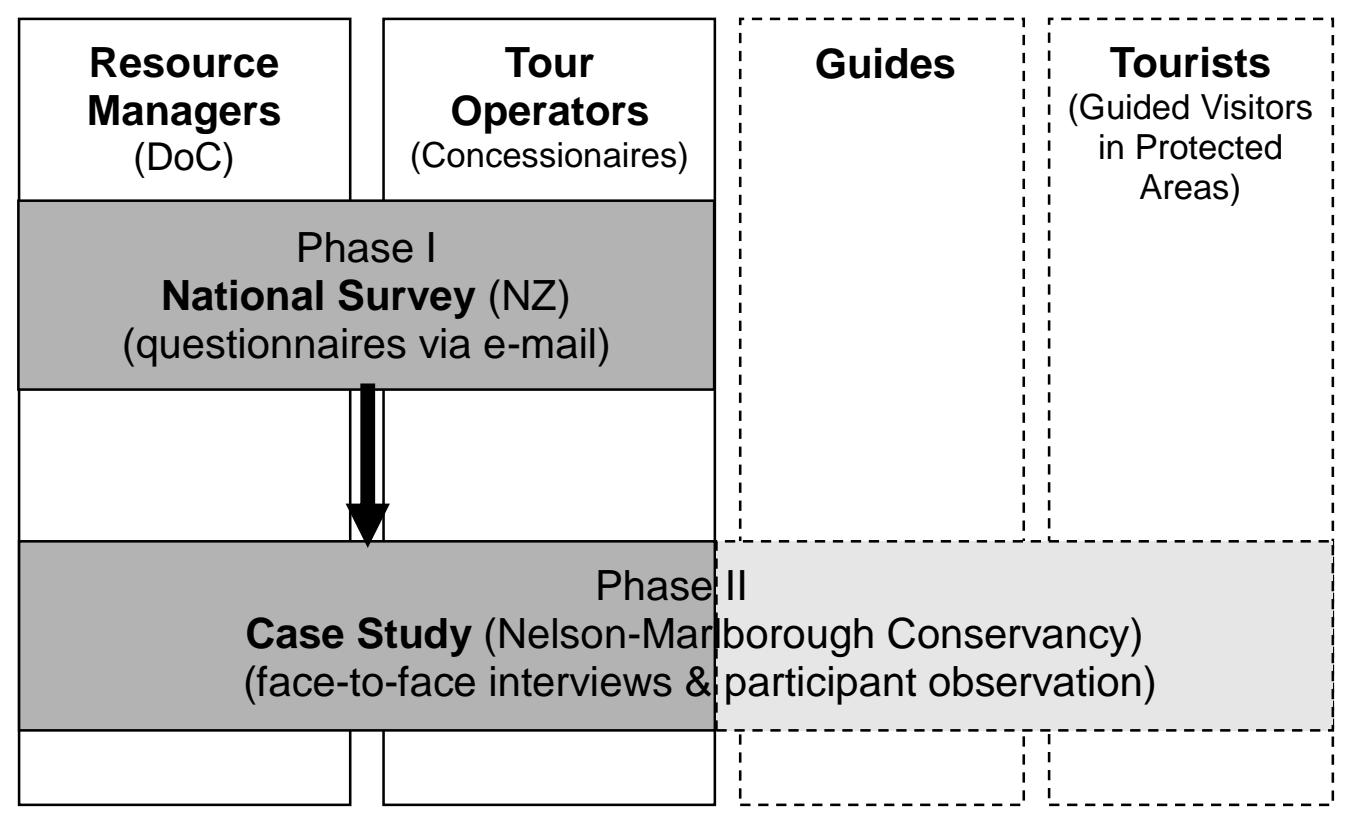

Primary data collection was divided in two phases: a national survey in New Zealand, and a regional case study in Nelson-Marlborough Conservancy using face-to-face interviews, and to a lesser extent participant observations. This mixed method approach provides "a comprehensive analysis of the research problem" (Creswell, 2003 p.16). Although this study relies mostly on qualitative research methods, quantitative data was also collected. Triangulation of quantitative and qualitative research methods were employed in order to gain an understanding of the complex issues and multiple perspectives regarding the interpretation practices. Quantitative data were sought in order to identify patterns and generalize findings, while the qualitative methods allowed explanation of patterns and provided insights into behaviour, motivation and satisfaction. Davies (2003, p. 104) states that "both the breadth and depth of an issue can be enhanced by triangulation as the strengths of both data are heightened." $\mathrm{He}$ concludes that triangulation "should lead to a 'truer analysis' of business behaviour and hence a more purposeful investigation of hotels, tour operators, travel agents and the 
business of tourism in general" (p. 110). The mixed method approach adopted in this research provided both breadth and depth to the investigation. The national survey gave a broader perspective allowing identification of conditions and issues in different parts of New Zealand, while the case study provided an in-depth investigation in one particular region of the country - Nelson-Marlborough. The case study also provided different perspectives and contexts since the businesses investigated offered distinct guided activities, and operated in contrasting environments and protected areas.

Phase one sought to develop an understanding of the concession system as it applies to tour operators' environmental interpretation throughout the country. This was done through a national e-mail survey from two perspectives: first, tour operators' views, actions, challenges, and constraints related to interpretation; second, the views, actions, challenges and constraints faced by DoC's concessions managers in supporting and assuring quality interpretation practices by tour operators. The main purposes of the first phase were to identify the existing conditions and issues, and to inform the development of data collection tools for the second phase.

The aim of the second phase was to understand the causes and consequences behind the existing conditions and issues faced by tour operators and DoC managers. Case studies are one of the strategies used in qualitative research approaches, they are usually developed in the natural settings (in the work place of the subjects), and allow researchers to obtain and develop a high level of detail about the place and subjects (Creswell, 2003). Accordingly, the present case study was developed in the natural setting and sought in-depth understanding of the situation, it also aimed at comparing the conditions and issues faced by DoC managers in different hierarchical levels and locations, and tour operators who have distinct characteristics, such as: type of guided 
activities offered, area of operation, and business size. According to Pearce et al (2007, p. 36) "comparative studies offer a very useful way forward by more readily enabling the general to be distinguished from the specific." This case study allowed in-depth analyses and comparisons of the attitudes, conditions, and issues around tour operators' interpretation in contrasting protected areas of Nelson-Marlborough Conservancy.

In-depth face-to-face interviews were undertaken with a selection of tour operators in the study region; with most DoC concessions managers in the region; and with two DoC managers at the national level. Participant observations in two guided tours were also carried out in order to analyze the interpretation practices as they occur during normal commercial operations. This approach allowed a more complete understanding of the existing conditions and issues from multiple perspectives.

\subsection{Research Design}

This section explains the process of research design beginning with preliminary conversations with DoC staff, and the preparation of the research proposal. Next, the specific methods applied in both phases of the research are described, including data collection tools, sampling, recruitment, and data collection processes. Following that, the response rates obtained, as well as the profile of the participants are presented. At the end of this section, the criteria for choosing the case study area are outlined, and the selected area is described.

Before the formal beginning of this research, in February 2009, the researcher and his advisor met with DoC's staff at the head office in Wellington in order to assess their views on the needs and importance of this study, to gather information about the concession system, and to ask for support for this research. Following positive feedback 
from DoC, analysis of DoC's documents about guiding concessions and environmental interpretation was undertaken in order to understand the details of the concession system regarding interpretation conditions and standards. Particularly relevant documents were the template for Guiding Permits (explanatory version), the document Possible Special Conditions for Guiding Permits, and the Interpretation Handbook and Standards (DoC, 2005).

After some preliminary readings on the main subjects of this study, namely concession systems and environmental interpretation, the initial step in this research process was the preparation of a formal proposal and its submission to the Tourism Management Department and the Human and Ethics Committee (HEC) of Victoria University of Wellington. Ethics approval is a standard requirement for any research conducted by students or staff of the university, to ensure that the research conform with statutory conditions, such as: human rights, and privacy issues. Businesses' and DoC managers' identities were kept confidential in this investigation to avoid any potential resentments or retaliations due to comments and criticisms provided.

\section{Phase I (National Survey)}

Preliminary informal interviews with two DoC managers at the head office and one guiding concessionaire in Wellington were undertaken beforehand to help identify the main issues, and to inform the elaboration of the questionnaires. The questionnaires were then sent to DoC's National Concessions Manager for final suggestions and approval. Both questionnaires contained a mix of closed and open-ended questions in order to gather quantitative and qualitative data. Similar questions were asked in both questionnaires to allow for comparisons between the two groups of respondents. The questionnaires (appendix 1\&2) contained 15 questions each, and were developed to 
address the four research objectives.

\section{$\underline{\text { Recruitment and Data Collection: }}$}

DoC's collaboration was particularly important in the access of all guiding concessionaires and all DoC's concessions managers, enabling a census survey to be conducted. The survey was sent to all tour operators that hold guiding concessions to work in New Zealand's protected areas, and/or that hold marine mammal permits (population $=482$ in June 2009); and to all DoC's concessions staff (11 concessions supervisors and 50 area managers) that work in the twelve conservancies throughout the country (population= 61 in June 2009). The survey was sent via e-mail from DoC's head office with a note of support from DoC's national concessions manager (appendix 3). Email is an appropriate method for census survey with the targeted groups, since they all use e-mail for communication on a daily basis, and because it is a fast and low cost vehicle. The recipients were asked to reply within a two weeks period, by e-mail, fax, or mail to an administrator at the Tourism Management Department of Victoria University, who then forwarded the responses to the researcher without the senders' addresses. These procedures allowed the recipients to remain anonymous to the researcher.

\section{Responses:}

The number of responses from tour operators was relatively small $(n=33)$, providing a low response rate $(6.9 \%)$. Although this means that generalizations cannot be made, participants provided many comments which allowed the identification of a wide range of situations and issues. Those comments will be presented in Chapter 4 and discussed in Chapter 6. The 33 participants of the survey held 66 guiding concessions throughout the country (Table 3.1). The number of concessions was higher than the number of participants because many hold multiple concessions. The number of concessions held by the participants were higher in Otago Conservancy $(n=14)$, followed by Nelson- 
Marlborough $(n=10)$, Southland $(n=9)$, West Coast $(n=7)$, and Canterbury $(n=6)$. Two participants hold nation-wide concessions.

Table 3.1: Number of guiding concessions per conservancy held by 33 tour operators in the national survey

\begin{tabular}{|l|c|}
\hline CONSERVANCY & Concessions \\
\hline Northland & 1 \\
\hline Auckland & 3 \\
\hline East Coast-Hawke's Bay & 3 \\
\hline Bay of Plenty & 2 \\
\hline Waikato & 4 \\
\hline Tongariro-Taupo & 1 \\
\hline Wanganui & 2 \\
\hline Wellington & 10 \\
\hline Nelson-Marlborough & 7 \\
\hline West Coast & 6 \\
\hline Canterbury & 14 \\
\hline Otago & 9 \\
\hline Southland & $\mathbf{6 6}$ \\
\hline Nation-wide & \\
\hline TOTAL & 2 \\
\hline
\end{tabular}

All respondents are commercial organizations, almost half $(n=16)$ are micro-enterprises with fewer than five employees in the peak season; many $(n=14)$ are small enterprises (6-49 employees); few ( $\mathrm{n}=2$ ) are medium enterprises (50-99 employees); and only one is a large enterprise (100+ employees) (Figure 3.2).

Figure 3.2: National survey: business sizes of tour operators $(n=33)$

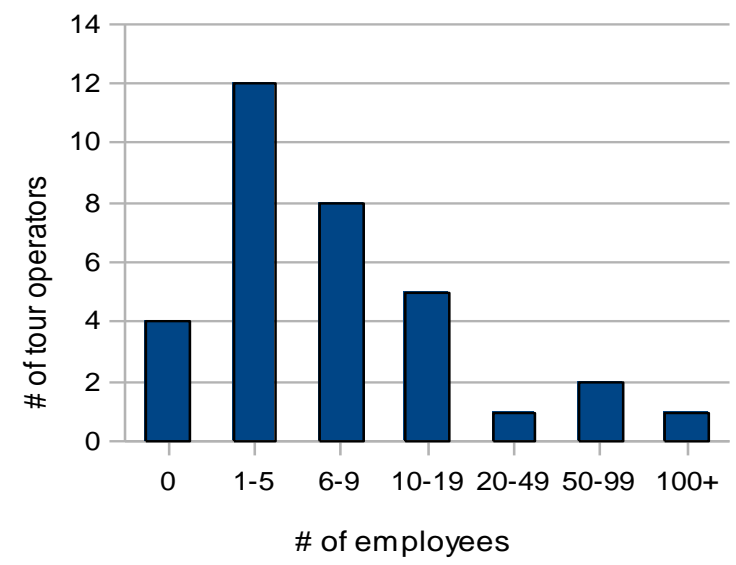


The most common activity offered by the tour operators that responded to the national survey was nature walk $(n=23)$; followed by water adventure activities $(n=8)$ which includes 4 rafting, 2 kayaking, and 2 river boarding; then wildlife watching $(n=7)$. There were a few respondents $(n=4)$ that operated boat or ship cruises, and the same number of coach or van tours. Other activities were less frequent (Figure 3.3). The sum of the activities in the graph below is larger than the number of tour operators because many operators offer more than one activity.

Figure 3.3: National survey: guided activities offered by tour operators

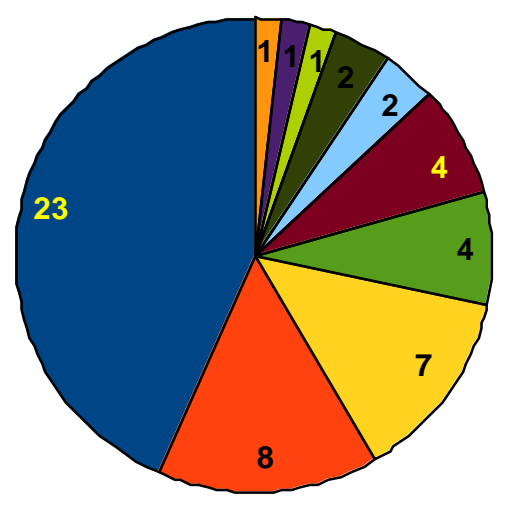

$$
\begin{aligned}
& \square \text { nature w alk } \\
& \square \text { w ater adventure } \\
& \square \text { wildlife w atching } \\
& \square \text { boat or ship cruise } \\
& \square \text { coach or van tour } \\
& \square \text { hunting or fishing } \\
& \square \text { mountain biking } \\
& \square \text { abseiling } \\
& \square \text { 4 w heel drive tour } \\
& \square \text { tractor-trailer tour }
\end{aligned}
$$

Compared to tour operators' responses, the number of responses from DoC concessions managers $(n=14)$ was better in relation to the population size, providing a higher response rate $(23.0 \%)$. However this is still a low number and response rate to allow proper generalizations and a comprehensive national picture to be obtained. Again, despite the low response rate, comments provided were rich and enabled many existing issues with the concession system and tour operators' environmental interpretation to be identified. Responses from four concessions supervisors and ten area managers came through from ten out of twelve existing conservancies (Table 3.2). There were no responses from Waikato, Wellington-Hawkes' Bay, and Canterbury conservancies. All other conservancies provided between one and two responses from DoC managers. 
Table 3.2: National survey: DoC concessions managers

\begin{tabular}{|l|c|c|}
\hline CONSERVANCY & RESPONSES & ROLE* \\
\hline Northland & 2 & CS, AM \\
\hline Auckland & 1 & CS \\
\hline East Coast - Bay of Plenty & 1 & AM \\
\hline Waikato & 0 & \\
\hline Tongariro - Taupo & 1 & AM \\
\hline Wanganui & 1 & AM \\
\hline Wellington - Hawkes' Bay & 0 & \\
\hline Nelson - Marlborough & 2 & CS, AM \\
\hline West Coast & 1 & AM \\
\hline Canterbury & 0 & \\
\hline Otago & 2 & AM, AM \\
\hline Southland & 2 & AM, AM \\
\hline Unknown & 1 & CS \\
\hline TOTAL & $\mathbf{1 4}$ & $\mathbf{4 C S ; ~ 1 0 A M ~}$ \\
\hline
\end{tabular}

\section{Phase II (Case Study)}

DoC has a decentralized structure and it divides the country into twelve regions (conservancies) which are further subdivided into different areas. Initially, it was considered that two or more case studies in different regions of the country would enable a strong comparative study. However, since the time and resources available for this research were limited, only one region could be chosen for the case study. Two approaches were used to make the choice of the case study region: first a number of criteria were established based on the responses to the national survey; and secondly, DoC managers at the national level, with wide knowledge of the situations across the country, were consulted to confirm if the choice was advisable. The criteria were:

> Guiding concessionaire's response rate;

$>$ DoC managers' response rate (with higher weight for concessions supervisors);

> Interpretation regarded as an important part of DoC managers' work;

> Interpretation regarded as important or very important among DoC managers; and

$>$ Presence of conditions related to interpretation in guiding concessions contracts. 
A preliminary analysis of the national survey results was necessary in order to assess those criteria. Applying those criteria, five conservancies stood out: Northland, Auckland, Nelson-Marlborough, Otago, and Southland, with the latter three having the highest ranking. Three other criteria were considered to choose between those:

$>$ Number of guiding concessions existent in the conservancy;

> Diversity of protected areas (categories, and geographical settings), as well as their significance in terms of tourism attraction; and

$>$ Concessions supervisor's interest in the research (assessed via telephone).

After all these considerations and consultation with DoC staff at the national level,

Nelson-Marlborough Conservancy was selected to be the case study region (Figure 3.4).

Figure 3.4: Nelson-Marlborough Conservancy - protected areas

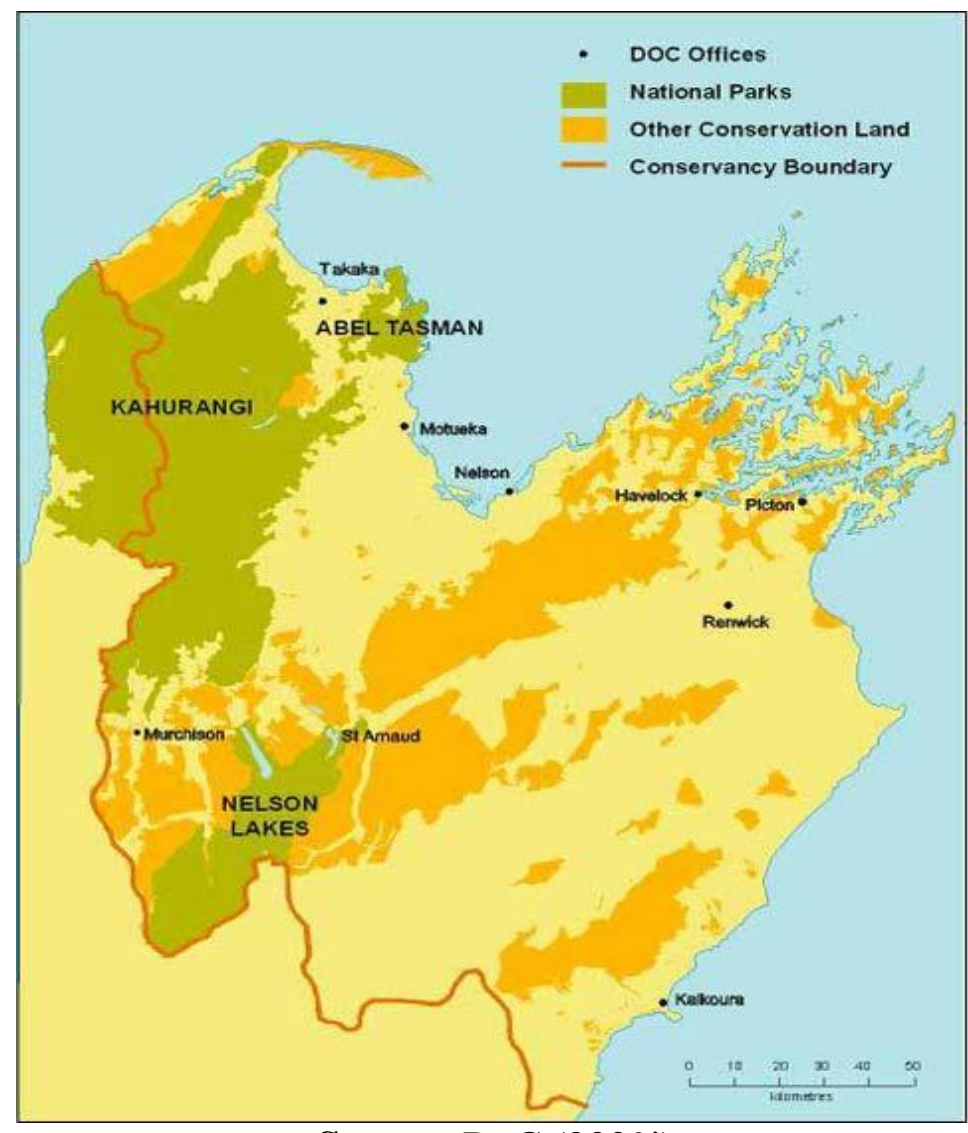

Source: DoC (2009j)

According to DoC managers at the national level, this conservancy was a good choice do to the recent advances in concessions management. Nelson-Marlborough

Conservancy is situated at the top of New Zealand's South Island and is an important 
tourism destination for both domestic and international tourists. This conservancy has three national parks: Abel Tasman, Kahurangi, and Nelson Lakes, as well as many other protected areas such as: Mt Richmond Forest Park, and a great number of different types of reserves (nature, scenic, historic, marine, and foreshore). The region has diverse landscapes from rugged snow capped mountains, to extensive plains covered with vineyards and orchards, and an extensive coast line with many sounds, peninsulas, islands, and sandy beaches.

The current study was concentrated in the northern half of Nelson-Marlborough Conservancy, including the Marlborough Sounds, Motueka, and Golden Bay areas (Fig. 3.5). This decision was based in three aspects: first because the northern half concentrates a larger diversity of protected areas, and some of those are important tourism attractions; second because there were few tourism studies undertaken in that area; and third to facilitate the study because the conservancy covers a large area. The Marlborough Sounds area in the Northeast includes many predator free island reserves and the internationally famous Queen Charlotte Track. The Motueka area included the most visited half of Abel Tasman National Park, one of the most popular Parks of the country with intense coastal trekking and sea kayaking activities. The Golden Bay area shares parts of Abel Tasman and Kahurangi National parks with Motueka area. Kahurangi is the newest and one of the largest park in the country, it contains the famous Heaphy Track - the longest of DoC Great Walks. In the far Northwest of Golden Bay area lies Farewell Spit Nature Reserve, a wetland and bird sanctuary of international importance. It is one of the few protected areas in New Zealand where visitors are allowed just in a small section, and vehicle access further in the Spit is granted only to guiding concessionaires. The study excluded Nelson Lakes and South Marlborough areas, including an area of high tourism profile - Kaikoura, with its world 
famous whale watching tours. This area was excluded from this study partially because it has been the focus of a number of tourism studies developed by Lincoln University, see for example Horn and Simmons (2002).

Figure 3.5: Nelson-Marlborough Conservancy - DoC areas

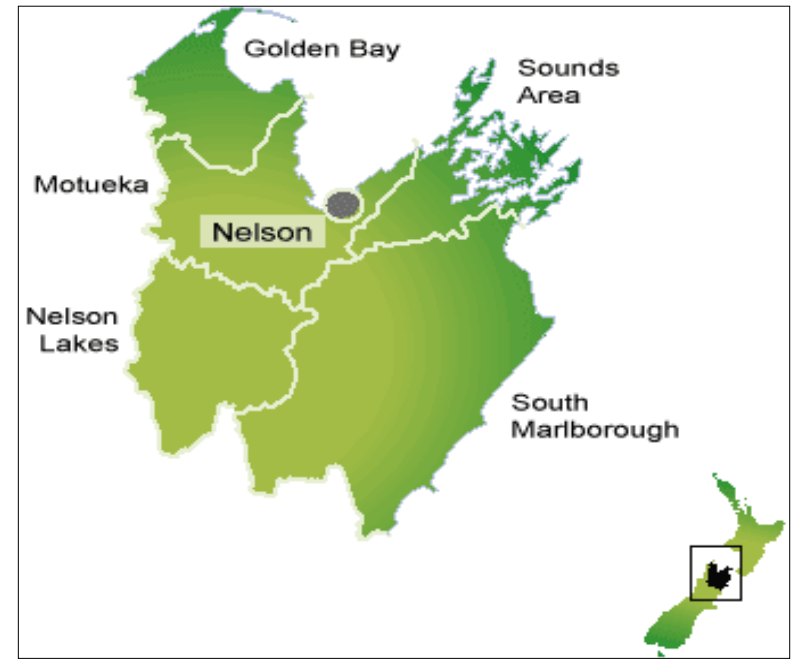

Source: DoC (2009k)

The results from phase one were used to inform the development of two semi-structured interview schedules (appendix 4\&5) used to guide the interviews tour operators and DoC's concessions managers. Before field work these questionnaires were also sent to DoC's National Concessions Manager for suggestions and approval. The interviews had four distinct sections: profile of respondent and business, environmental interpretation, concession system, and concluding comments. Similar questions were asked for both stakeholders to allow for comparisons between the two groups. Although the interview schedules contained a large number of questions they were not all verbalized because many were addressed by the respondents during the interviews.

\section{Sampling and Data Collection:}

Once the Nelson-Marlborough Conservancy was chosen, the concessions supervisor of that conservancy became the main contact and gate keeper. He provided a list of all tour operators $(n=67)$ that hold guiding concessions managed by that conservancy. There were actually a total of 90 guiding concessions as some operators held multiple 
concessions. While the choice of participants was guided by the gatekeeper, the final decision on who to approach was the researcher's. The following criteria were used to select a sample of tour operators:

$>$ Include large and small businesses;

> Include tour operators that are based locally and outside the area of operation;

$>$ Include tour operators that offer different guided activities; and

> Include tour operators working in different types of protected areas and settings; A total of 22 interviews were conducted, 13 with tour operators and 9 with DoC managers. Nine tour operators were based locally, having their offices next to the protected areas where they work, while the other four operators had their offices located in larger urban centers, Nelson $(n=2)$ and Christchurch $(n=2)$. Seven operators had a local scope of operation, four had a regional, and two had a national scope (Table 3.3).

Table 3.3: Case study: scope of operation of tour operators interviewed

\begin{tabular}{|l|c|}
\hline Scope of operation & n \\
\hline National & 2 \\
\hline Regional: Nelson-Marlborough Conservancy & 4 \\
\hline Local: Golden Bay (Puponga Farm Park; Farewell Spit NR) & 2 \\
\hline Local: Motueka (Abel Tasman National Park) & 2 \\
\hline Local: Marlborough Sounds & 3 \\
\hline TOTAL & $\mathbf{1 3}$ \\
\hline
\end{tabular}

Ten tour operators have had concessions or other arrangements to work in the Conservation Estate for more than 10 years, and three operators have had their concessions for a short time (3-4 Years). Eleven of the tour operators interviewed were owners/managers, and two were only managers. Twelve of them also guide, and although they were not interviewed as tour guides, they also had the guide's perspective.

The sample of DoC staff for the interviews included all concessions staff at the local level - one area manager in each of the three area offices studied. They were responsible for day to day engagement with concessionaires. The sample also included one extra 
manager in one of the area offices. At the regional level most concessions staff, who dealt with concessions processing, were interviewed. Two interviews were conducted at the national level, one with an interpretation specialist, and another with a former DoC social science researcher with a long experience in visitor research. (Table 3.4)

Table 3.4: DoC managers interviewed - scope of operation and function

\begin{tabular}{|l|c|l|}
\hline Scope of operation: Office & n & Function \\
\hline National: Wellington & 2 & $\begin{array}{l}\text { 1 Tech. Support Officer (Interpretation); } \\
\text { 1 former DoC staff (Social Science Researcher) }\end{array}$ \\
\hline Regional: Nelson-Marlborough & 3 & $\begin{array}{l}\text { 1 Concessions Supervisor; } \\
\text { 2 Concessions Officers }\end{array}$ \\
\hline Local: Golden Bay & 1 & 1 Program Manager (Community Relations) \\
\hline Local: Motueka & 1 & 1 Program Manager (Community Relations) \\
\hline Local: Marlborough Sounds & 2 & 1 Area Manager; 1 Program Manager \\
\hline TOTAL & $\mathbf{9}$ & \\
\hline
\end{tabular}

Tour operators interviewed offered a range of activities (Figure 3.6). The total number of activities was higher than the number of tour operators because many offered more than one activity. Hiking ( $n=6)$ and short walks $(n=4)$ were the most common activities offered, followed by kayaking and cycling ( $\mathrm{n}=3$ each), then and bird watching and water taxi $(n=2$ each). Another five activities were offered by one tour operator each.

Figure 3.6: Case study: activities offered by the 13 tour operators interviewed

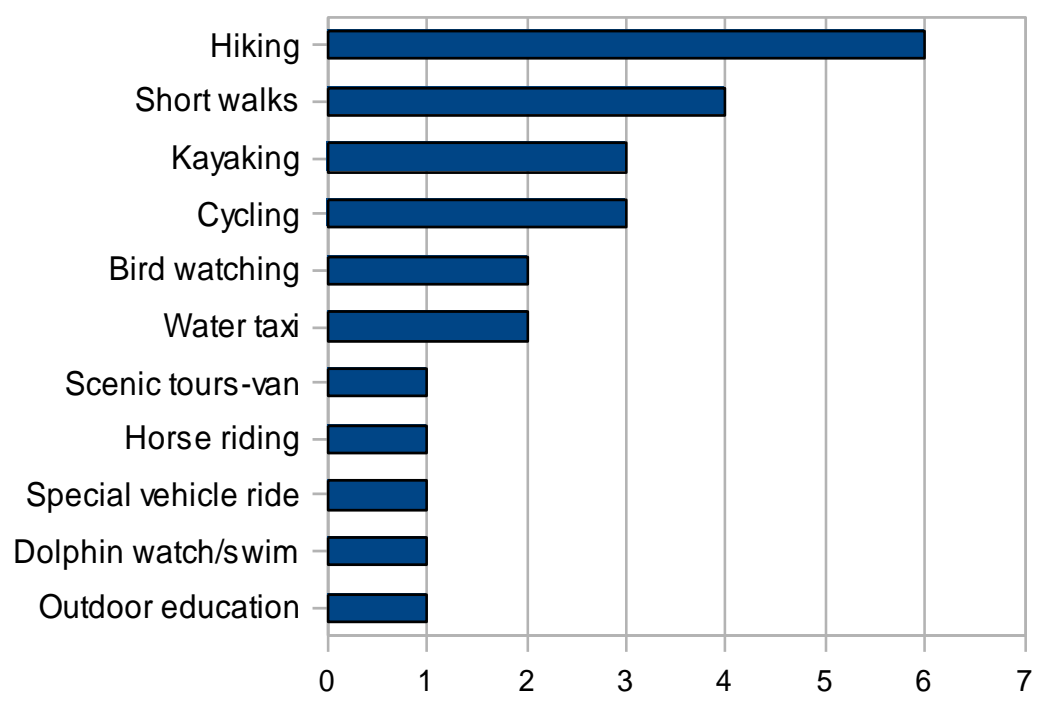


Three different field trips between August and October 2009 were necessary to be able to conduct all the interviews face-to-face. Interviews lasted between 35 and 90 minutes. Interviews were then transcribed and coded in order summarize the data and look for patterns. According to Punch (2005) "for analysis directed at discovering regularities on the data, coding is central." The primary codes used are related to the two groups (tour operators and DoC managers), as well as to the four research objectives: views on importance and benefits of interpretation, actions to develop interpretation capabilities of tour operators; challenges and constraints in developing and assuring quality interpretation practices; and views on their relationship regarding the concession system. Secondary codes are related to the different characteristics within each group: activity type, place of operation (setting), office location (base), and business size of the tour operators; and work coverage (local, regional, or national) of DoC managers. Tertiary codes were identified as the data was analyzed, and these were the different groups of issues or themes identified within each research objective.

\section{Participant Observations:}

Since the research objectives had to be reviewed due to limitations explained at the beginning of this chapter, the participant observations lost much of its original purposes, which was to include the perspectives of tour guides and to analyze their practices during guided tours. Nevertheless, the two participant observations conducted allowed the researcher to have an idea of the interpretation practices of two very experienced senior guides. Special attention was paid it their use of effective interpretation principles (TORE: Thematic, Organized, Relevant, and Engaging), as well as in their skills to tell stories, and in their use of supporting materials. The participant observations took place on the following guided tours: a scenic day tour (van) from Nelson to Golden Bay, and an aquataxi half-day tour in Abel Tasman National Park. 


\subsection{Analytical Framework}

The analytical framework presented below (Figure 3.7) was employed to guide the data analysis process, and the presentation of the findings. It relates the four research objectives to the two stakeholders investigated. Different characteristics of tour operators, such as: guided activity offered (nature walk, kayaking...), setting of operation (locality and type of protected area), office base (local x outside), and business size were identified and compared, albeit to a small extent due to the small sample sizes. DoC managers at the different spatial/hierarchical levels (local, regional, and national) were targeted in order to include and compare their different perspectives.

Figure 3.7: Analytical Framework

\begin{tabular}{|c|c|c|}
\hline \multicolumn{3}{|l|}{ PHASE II } \\
\hline \multicolumn{3}{|l|}{ PHASE I } \\
\hline Research Objectives & $\begin{array}{c}\text { Tour Operators (TOs) } \\
\text { activity / setting / base / size }\end{array}$ & $\begin{array}{c}\text { Resource Managers (DoC) } \\
\text { local/ regional / national }\end{array}$ \\
\hline \multicolumn{3}{|l|}{$\begin{array}{l}\text { Views on the importance and } \\
\text { benefits of interpretation }\end{array}$} \\
\hline \multicolumn{3}{|l|}{$\begin{array}{l}\text { Actions to develop TOs' } \\
\text { interpretation capabilities }\end{array}$} \\
\hline \multicolumn{3}{|l|}{$\begin{array}{l}\text { Challenges and constraints in } \\
\text { developing and assuring quality } \\
\text { interpretation practices by TOs }\end{array}$} \\
\hline $\begin{array}{l}\text { Views on their relationship and } \\
\text { on the concession system }\end{array}$ & & \\
\hline
\end{tabular}

The data analysis was conducted for each phase separately, and the findings are presented separately, first the national survey (chapter 4) then the case study (chapter 5). The different objectives were analysed and are presented sequentially, from top to bottom, as indicated by the vertical arrow on the left of the diagram. Within each objectives different issues identified were classified in themes to facilitate analysis and comparisons. The tour operators are addressed first, followed by DoC's managers, as indicated by the horizontal arrows. In the discussion chapter a comparison of the findings of the two phases is presented. 


\subsection{Research Strengths and Limitations}

One of the major strengths of the research is the mixed method approach which gave breadth and depth to the investigation. The national survey provided insights into the national picture and the case study enabled a more detailed investigation of the issues and their causes. However, limited resources and timing of the field work hampered a potentially more comprehensive study, and forced the reduction of the intended objectives and scope. A summary of the specific strengths and limitations of each phase of this research is outlined below.

\section{PHASE I (National Survey)}

\section{Strengths:}

> E-mail census survey: easy, fast, and low-cost distribution and retrieval;

> Assess the situation in different regions of the country - get the big picture;

> DoC's distribution: important official support (gate keeper), and allowed anonymity of participants;

> Mix of quantitative and qualitative data: comprehensive analysis identification and explanation of patterns, conditions, and issues; and

> Findings reveled issues to be explored in depth in the next phase, and informed case study choice.

\section{Limitations:}

> DoC's distribution: researcher lost control over the process, and ended up with one week period for responses instead of the planned two; and

$>$ Low response rate, particularly from tour operators does not allow generalizations or look at regional patterns. 


\section{PHASE 2 (Case Study)}

\section{Strengths:}

> Support from DoC Head and Regional offices facilitated access and collaboration of DoC staff and tour operators;

$>$ Interviews allowed in-depth investigation of issues;

$>$ Field work in low tourism season was good to find businesses owners/managers; and

> Working in a diverse setting, with different categories of protected areas, and a variety of guided activities allowed a broader understanding of issues, and comparisons to be made.

\section{Limitations:}

$>$ Field work in low tourism season was not conducive to finding tour guides and to do participant observations; and

> Working only in one region (conservancy) did not allow comparisons with other regions and the findings are restricted to that context. 


\section{Findings of National Survey}

This chapter presents the findings of the national survey sent to the two stakeholders guiding concessionaires (tour operators), and resource managers (DoC concessions managers). It follows the order expressed in the analytical framework (Fig 3.7), addressing the four research objectives consecutively. Each objective is addressed first for the tour operators then for DoC managers.

\subsection{Perceptions on the importance and benefits of environmental interpretation}

In order to assess the significance of interpretation, the two stakeholders were asked to choose one of the following three statements that best described their work:

( ) interpretation is a major part of my guiding services / concessions related work

( ) interpretation is a minor part of my guiding services / concessions related work

( ) interpretation is not part of my guiding services / concessions related work

Therefore, "significance of interpretation" here relates to these statements above, which express the proportion of effort and/or time spent with interpretation issues during tour operators' guiding services, and DoC managers' concessions related work.

For most tour operators that replied to the survey (26 out of 33 ) interpretation is a major part of their guiding services, for a few $(n=5)$ it is a minor part, and for a small number $(n=2)$ it is not part of their services (Figure 4.1a). The situation is quite different for DoC managers that replied to the survey: for most (9 out of 14) interpretation is a minor part of their concessions related work, for a few $(n=3)$ interpretation is not part of their work, and only for two of them interpretation is a major part (Figure 4.1b). 
Figure 4.1: Significance of interpretation to tour operators' and DoC managers' work

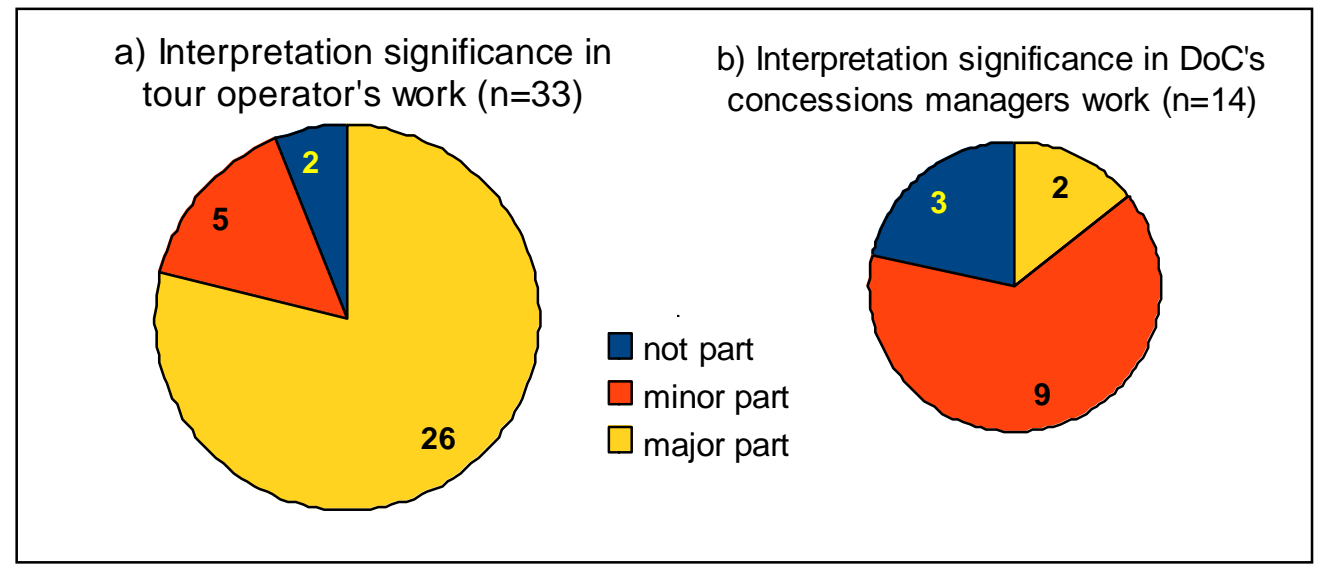

Table 4.1 relates the significance of interpretation to tour operators' services with the different types of guiding activities offered. The total number of activities is higher than the number of respondents since many tour operators offer more than one activity. Most operators that offer nature walks (20 out of 23), and all that offer wildlife watching $(n=7)$, ship or boat cruises $(n=4)$, kayaking $(n=2), 4$ wheel drive $(n=1)$, and tractortrailer tour $(n=1)$ replied that interpretation is a major part of their guiding services. Among the five operators who replied that interpretation is a minor part of their guiding business, there are two that operate river boarding, one that operates scenic tours, one that offers nature walks, and another that operates adventure activities (rafting, abseiling, and mountain biking). One of the tour operators that answered that interpretation is not part of his work, provides transportation services, and is waiting for a walking permit. That operator commented that he is "not being allowed to interpret areas of cultural significance as requested by local iwi and DoC." The other tour operator that answered that interpretation is not part of his work provides rafting, hunting and animal control services. The researcher suspects that this operator thought that the term interpretation referred to language translation, since he replied that “customers speak English”, despite the fact that two clear definitions of interpretation were provided with the questionnaire. 
Table 4.1: Significance of interpretation to tour operators per activity type

\begin{tabular}{|l|c|c|c|c|}
\hline ACTIVITY & Major part & Minor part & Not part & TOTAL \\
\hline Nature walk & 20 & 3 & 0 & $\mathbf{2 3}$ \\
\hline Wildlife watching & 7 & 0 & 0 & $\mathbf{7}$ \\
\hline Ship or boat cruise & 4 & 0 & 1 & $\mathbf{4}$ \\
\hline Coach or van tour & 2 & 1 & 1 & $\mathbf{4}$ \\
\hline Rafting & 2 & 1 & 0 & $\mathbf{4}$ \\
\hline Kayaking & 2 & 0 & 0 & $\mathbf{2}$ \\
\hline River boarding & 0 & 2 & 0 & $\mathbf{2}$ \\
\hline Mountain biking & 1 & 1 & 1 & $\mathbf{2}$ \\
\hline Hunting or fishing & 1 & 0 & 0 & $\mathbf{2}$ \\
\hline Abseiling & 0 & 1 & 0 & $\mathbf{1}$ \\
\hline 4 wheel drive tour & 1 & 0 & 0 & $\mathbf{1}$ \\
\hline Tractor-trailer tour & 1 & 0 & $\mathbf{1}$ \\
\hline
\end{tabular}

When significance of interpretation to tour operators was related to business size (Table 4.2), most of the micro-enterprises (fewer than 5 employees) replied that interpretation is a major part of their services, two replied that it is a minor part of their services, and only one replied that interpretation is not part of his/her guiding services. The same pattern was found among the small enterprises (6-49 employees). The larger operators, two medium enterprises (50-99 employees) and one large (100+ employees), replied that interpretation is a major part of their services.

Table 4.2: Significance of interpretation to tour operators (per business size)

\begin{tabular}{|l|c|c|c|c|}
\hline SIZE (employees) & Major part & Minor part & Not part & TOTAL \\
\hline 0 (working proprietor) & 2 & 2 & 0 & $\mathbf{4}$ \\
\hline $\mathbf{1 - 5}$ & 11 & 0 & 1 & $\mathbf{1 2}$ \\
\hline $\mathbf{6 - 9}$ & 7 & 0 & 1 & $\mathbf{8}$ \\
\hline $\mathbf{1 0 - 1 9}$ & 3 & 2 & 0 & $\mathbf{5}$ \\
\hline $\mathbf{2 0 - 4 9}$ & 0 & 1 & 0 & $\mathbf{1}$ \\
\hline $\mathbf{5 0 - 9 9}$ & 2 & 0 & 0 & $\mathbf{2}$ \\
\hline $\mathbf{1 0 0 +}$ & 1 & 0 & 0 & $\mathbf{1}$ \\
\hline TOTAL & $\mathbf{2 6}$ & $\mathbf{5}$ & $\mathbf{2}$ & $\mathbf{3 3}$ \\
\hline
\end{tabular}


When significance of interpretation to DoC managers was related to their roles (concessions supervisor or area manager) (Table 4.3), only one of the four concessions supervisors replied that interpretation is a major part of his concessions related work, the others replied that it is a minor part. Among the area managers a similar situation was found with most managers considering interpretation a minor part of their work. The only difference compared to concessions supervisors, was a small group of area managers who replied that interpretation was not part of their work.

Table 4.3: Significance of interpretation to DoC managers (per role)

\begin{tabular}{|l|c|c|c|c|}
\hline ROLE & Major part & Minor part & Not part & TOTAL \\
\hline Con. Supervisor & 1 & 3 & 0 & 4 \\
\hline Area Manager & 1 & 6 & 3 & 10 \\
\hline TOTAL & $\mathbf{2}$ & $\mathbf{9}$ & $\mathbf{3}$ & $\mathbf{1 4}$ \\
\hline
\end{tabular}


The stakeholders were asked to rank how important they think interpretation is to themselves, to the other party, and to visitors (tourists). Most DoC managers and tour operators in the survey regarded interpretation as important or very important, but both perceived it as less important to the other party (Figure 4.2).

Figure 4.2 Importance of interpretation to each stakeholder and to the other party

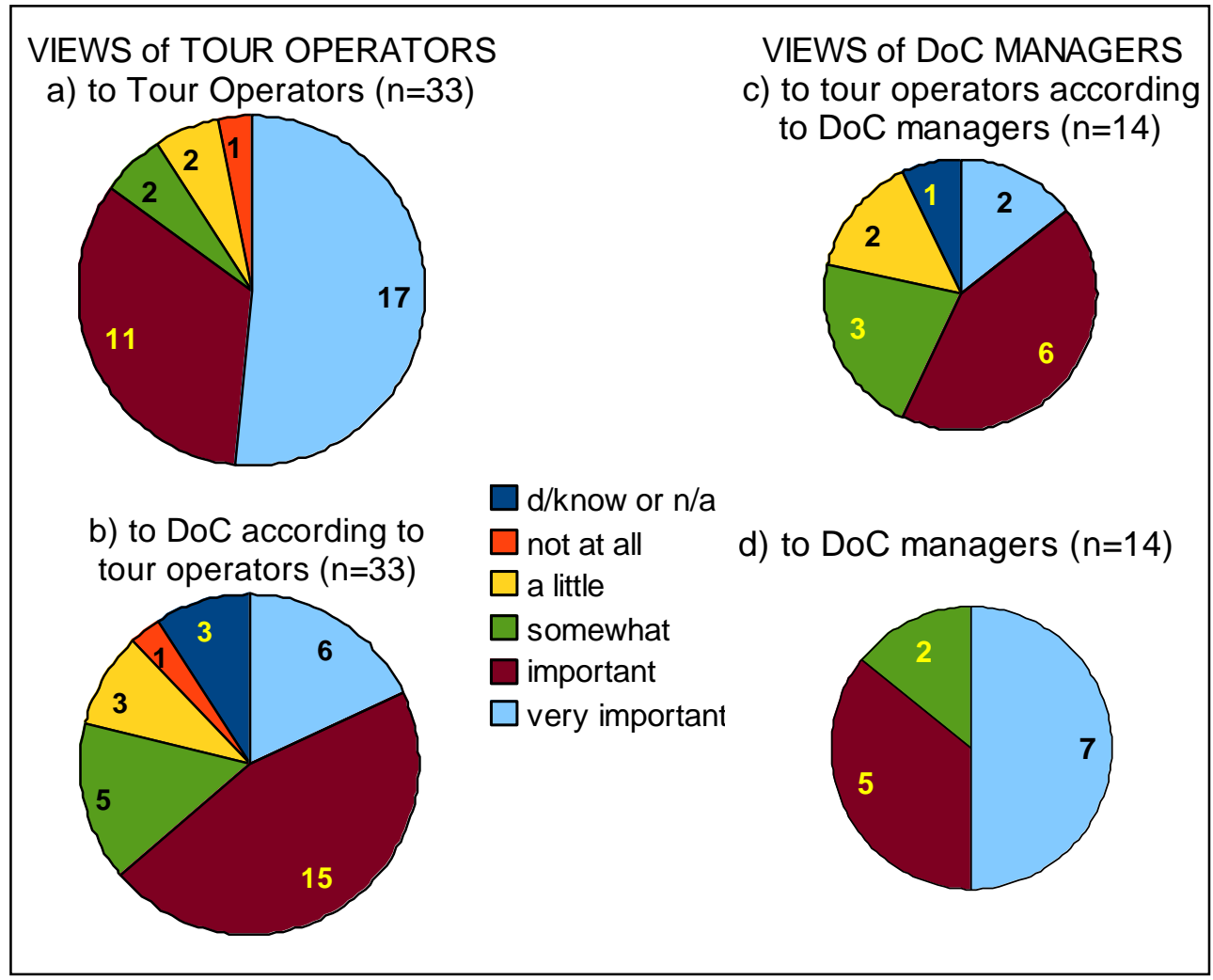

Tour operators and DoC managers had similar perceptions of the importance of interpretation to visitors (clients or tourists), most of them thought that interpretation is important or very important to visitors (Figure 4.3).

Figure 4.3 Importance of interpretation to visitors according to each group

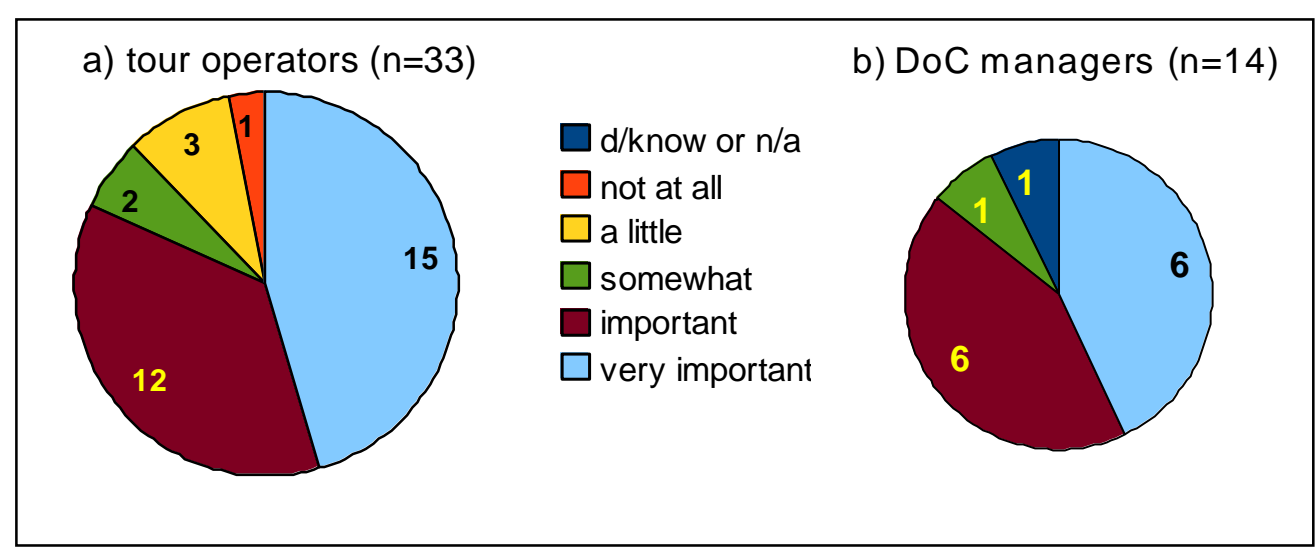


Some tour operators commented that the importance of interpretation to visitors varied according to their profile. It was mentioned that international visitors and older people were more concerned with interpretation. One tour operator commented that many international visitors have an inquisitive nature, and noted that "the international visitor has a greater understanding of our flora, fauna and Maori culture." Another tour operator pointed out that "the older the client, the more importance is attached to interpretation and understanding. ”

The stakeholders were asked to indicate what the main benefits or outcomes of interpretation are in their view. Tour operators indicated a number of interpretation benefits or outcomes that can be classified into four broad categories related to the beneficiaries:

$>$ the visitor experience;

$>$ the environment;

$>$ socio-cultural aspects; and

$>$ economic aspects;

Tour operators replied that interpretation informs, involves and entertains visitors, and that it enriches their experiences, making them memorable: "providing a memorable, unique, and all-round experience helps us provide a lasting experience." Operators commented that interpretation provides understanding and appreciation of the environment, creating awareness and connection with the natural heritage. One operator noted that interpretation encourages mental and emotional stimulation of guides, increasing their satisfaction with the job. Another operator pointed out that interpretation allows "different cultural understandings of the natural world." Tour Operators also pointed out that interpretation adds quality and value to their product, increasing business reputation and guides' earnings. 
DoC managers comments were also classified into four categories, and only the last one differed from those indicated by tour operators:

$>$ the visitor experience;

$>$ the environment;

$>$ socio-cultural aspects; and

$>$ the organization.

Some DoC managers indicated that interpretation benefits the visitor experience by making it more meaningful and enjoyable, adding value to it. A DoC manager wrote that interpretation provides "appreciation, education, understanding, enjoyment, which are the essential ingredients of a meaningful experience."

According to DoC managers interpretation benefits the environment by promoting: understanding of conservation issues; good environmental practices; conservation ethic; appreciation of heritage values; support for protection; and conservation outcomes. As one DoC manager indicated, these benefits or outcomes are connected, he wrote that interpretation promotes "visitor appreciation of the values, which ideally leads to understanding and hopefully support for their protection."

One DoC manager pointed out that interpretation also promotes socio-cultural benefits by "sharing an understanding about Maori cultural values and history"

Finally, other DoC managers noted that interpretation benefits the organization (DoC) by promoting public understanding and support for the Departments directions and objectives. Interpretation "fosters public support for DOC's objectives." 


\subsection{Actions employed by both stakeholders to develop the interpretation capabilities of tour operators}

The stakeholders were asked to indicate what actions they have undertaken to develop and support the interpretation capabilities of tour operators and to assure quality interpretation practices. Tour operators reported adopting a variety of actions or strategies to develop their interpretation capabilities, these were classified into five categories:

$>$ studying the literature;

$>$ preparing supporting materials;

$>$ consulting third parties;

$>$ recruiting qualified guides; and

$>$ training guides.

Tour operators reported using different types of literature to inform their interpretation programs, from DoC brochures, to history books, and scientific studies:

"We are conservationists primarily and have a very good understanding of NZ's natural ecology. We have been studying this for many years. The documentation we use is usually the latest in scientific studies."

Some tour operators commented that they have build databases of information that form the basis of their interpretation. They have also prepared supporting materials such as manuals, information sheets, and translation sheets.

Tour operators commented that they have consulted with different people to build their interpretation programs, such as: DoC staff, indigenous people (Maori), and local experts: "I have spoken with the DOC staff and knowledgeable Maori to build interpretive stories that satisfy the inquisitive nature of many international visitors." 
Some operators indicated that they try to recruit qualified or skillful guides in order to provide quality interpretation services. They mentioned the criteria for selecting new guides, they want people who are: knowledgeable, dedicated, outgoing, and passionate; and who have: formal qualifications, good interpersonal skills, and interpretation skills: “Employ guides that have a passion for outdoors and skills to provide interpretation."

Some tour operators reported providing in-house training in order to upgrade their guides' interpretation capabilities. They cited different training topics, such as: public speaking, interpretation techniques, and cultural and environmental aspects: "Guides learn cultural and environmental aspects when training up on tours, they must accompany a qualified guide on the tour before being able to lead."

Tour operators were asked to indicate which interpretation resources, from a list provided, they have and use. Two specific interpretation resources published by DoC were included in that list: the Interpretation Handbook and Standards (Figure 4.4), and the interpretation toolkit Conservation Revealed (Figure 4.5).

Figure 4.4: DoC's Interpretation Handbook and Standards (cover)

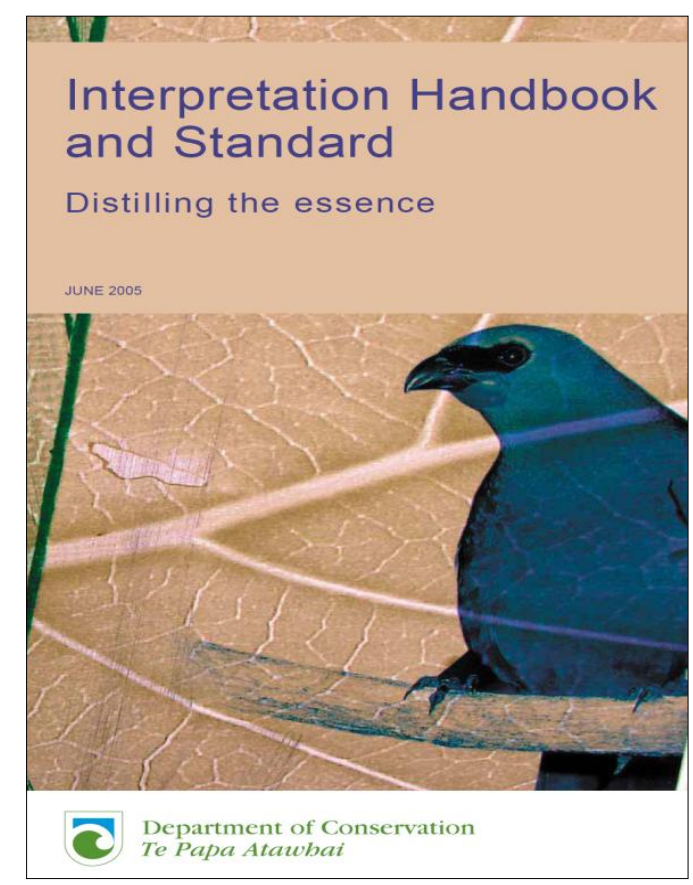


The Interpretation Handbook and Standards was published by DoC in 2005 with the collaboration of many DoC staff and top external interpretation specialists, such as: Professor Sam Ham from Idaho State University (USA), and Professor Betty Weiler from Monash University, Melbourne (Australia).

"The DoC Interpretation Handbook and Standard is a 'how to' guide developed for DoC staff, volunteers and concessionaires involved in interpretation. This handbook is designed to assist DOC staff and others translating the conservation vision into action by developing effective messages and stories about New Zealand's natural and cultural inheritance and its preservation. It provides best practice guidance about communicating clearly, planning interpretation, and guided and self-guided techniques." (DoC, 2005, emphasis added).

The handbook not only set standards for the interpretation provide by DoC, but also for the tour operators that hold guiding concessions:

"For many operators there are also requirements to deliver information to clients about appropriate minimal impact behaviour and provide accurate and relevant interpretation." (DoC, 2005 p.59 emphasis added)

Figure 4.5: DoC's interpretation toolkit Conservation Revealed (CD cover)

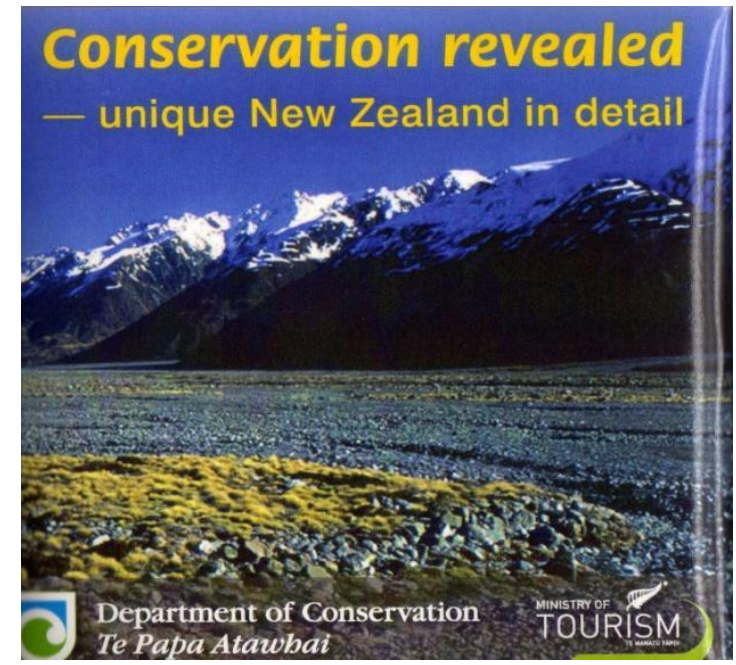

The interpretation toolkit Conservation Revealed was published by DoC in 2006 with funding from the Ministry of Tourism, its original name was Explore New Zealand. This material contains a large collection of fact sheets about New Zealand's protected areas, 
fauna and flora, (DoC, 2006c). Initially, hard copies of this toolkit were sold to tourism operators, now DoC sells a CD for $\$ 12.95$ containing all material, and it is also available on DoC's website for free download. In the toolkit's foreword, the former Minister of Conservation, Chris Carter, indicated the main target audience and the purpose of this interpretation resource:

"The collection provides tourism concessionaires operating in DOC managed areas with accurate and up-to-date information about New Zealand's special places and extraordinary wildlife. Its purpose is to help tourism operators explain to visitors a little about New Zealand's natural bounty, the work we do to save it, and what visitors can do to help."

Also in the toolkit's foreword the former Minister of Tourism Damien O'Connor pointed out the importance of reliable information for high quality visitor experiences:

"Research tells us that our ideal visitor wants high quality experiences and looks for ways to engage with us, as people, and our environment. Our ideal visitor wants activities that offer beautiful scenery, and interaction with our natural environment, culture and history. Well-researched information, such as contained here, is crucial to supporting these types of experiences."

According to the survey responses, the most common interpretation resources possessed and used by tour operators are manuals prepared specifically for their guides, and field guides or other printed interpretation materials (Figure 4.6).

Figure 4.6: Interpretation resources possessed and used by tour operators $(n=33)$

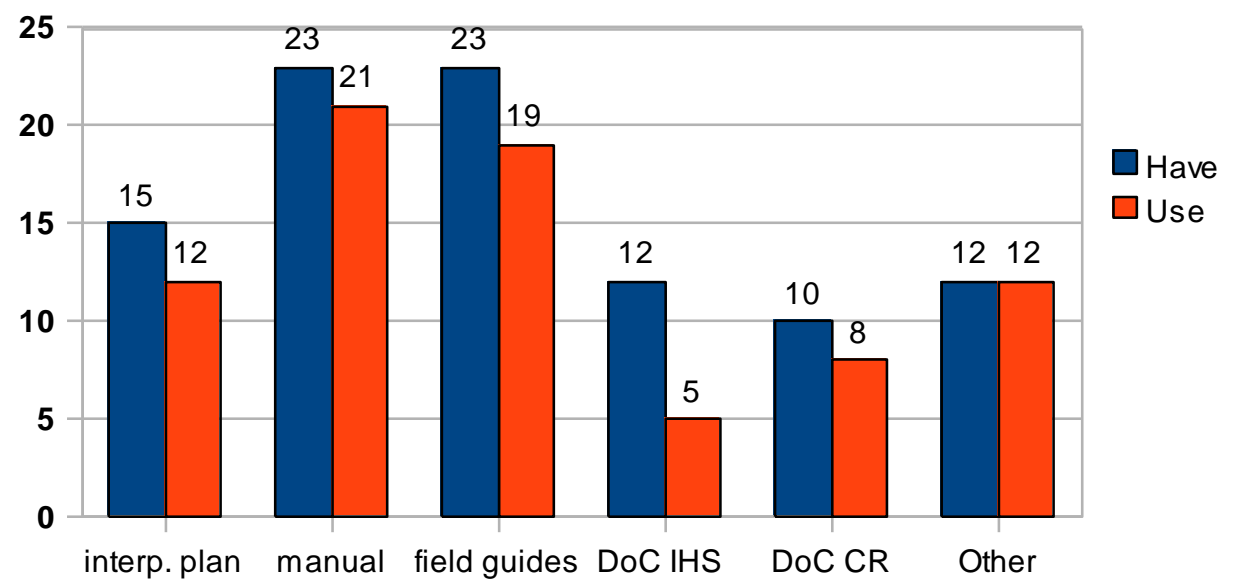


Almost half of the respondents $(n=15)$ have interpretation plans, and 12 make use of them. Slightly more than one third $(\mathrm{n}=12)$ have DoC's IHS Interpretation Handbook and Standards, but less than half of those $(\mathrm{n}=5)$ make use of it. Slightly less than one third $(n=10)$ have DoC's CR Conservation Revealed, and the majority of those $(n=8)$ make use of it. Finally, more than a third $(n=12)$ replied that they have and make use of other interpretation resources, such as: skilled and knowledgeable guides, historic books, local characters/experts, information passed by ancestors and other guides (word of mouth), DoC's brochures, and scientific studies.

DoC's actions to support the interpretation practices of tour operators were assessed from two perspectives: tour operators and DoC managers were asked to identify DoC's actions. Then, both stakeholders were asked how satisfied they were with DoC's interpretation support. Tour operators mentioned many different types of interpretation support provided by DoC. The most common DoC support action cited was the provision of publications, followed by personal contact, training, on-site interpretation panels, updates upon request, regular updates, visitor centres, and website information. While some operators indicated that DoC should provide more regular updates, others pointed out the usefulness of regular updates:

"Locally the Albatross Centre puts out great update mailings that give a good overview of activity in the Peninsula area which is very useful."

Mediation with indigenous people (Maori) was cited by one tour operator. However, it was not clear whether the support was coming from DoC, or if the operator was questioning it, since he left the word "mediated??", and in another part of the questionnaire he mentioned the problem of getting consent to tell Maori stories.

A few tour operators replied that they have had no support from DoC regarding 
interpretation, one of them commented that:

"once the initial concession application document is filled in, there seems to be no further interest from DoC regarding interpretation from guiding concessionaires."

Another operator from that same group had a contrasting view:

"I don't feel it is a role of DoC to assist commercial operators in this way. I would rather they stuck to their core role of conserving New Zealand's natural heritage."

DoC's interpretation toolkit Conservation Revealed was the most cited publication provide by DoC. However, tour operators that participated in the national survey expressed different opinions about the toolkit. Some operators praised the quality and usefulness of that resource, while others contended that the information provided was too generic, and noted that something more specific would be of greater assistance.

To get the support providers perspective, DoC managers' were asked to indicate their department's actions in supporting the interpretation practices of tour operators. Seven categories of actions were reported, six of which matched with those identified by tour operators: provision of publications, on-site interpretation panels, personal contact, review of operator's interpretation material, visitor centres, website, and training.

Again, the most cited publication was DoC's interpretation toolkit Conservation Revealed. On-site interpretation panels were cited by two DoC managers, one of them pointed out that they are in the process of developing such material in partnership with a tour operator: "Currently we are working with an adventure tourism operator to develop track and camping facilities which will include interpretation."

Tour operators and DoC managers were asked to rate on a five point scale their satisfaction with DoC's support to interpretation and explain their rating. Figure 4.7 
shows the proportions and absolute numbers. Four tour operators indicated that they were totally satisfied with DoC's support, one of them stated: "I cannot over-emphasize the support our organization receives from DOC. Their assistance with interpretation is excellent." In contrast, no DoC managers were totally satisfied with DoC's support to interpretation. More than half $(n=19)$ of the tour operators and half $(n=7)$ of DoC managers were much or somewhat satisfied with DoC's support to interpretation. One DoC manager commented that DoC has provided good support to tour operators:

"In my view the Department has provided an excellent resource in the form of the interpretation resources (handbook \& fact sheets) now available for free on the DoC website. There has also been a message provided to concessionaires that DoC is interested in supporting them to develop and deliver quality interpretation."

Figure 4.7: Tour operators' and DoC managers' satisfaction with DoC's support to interpretation

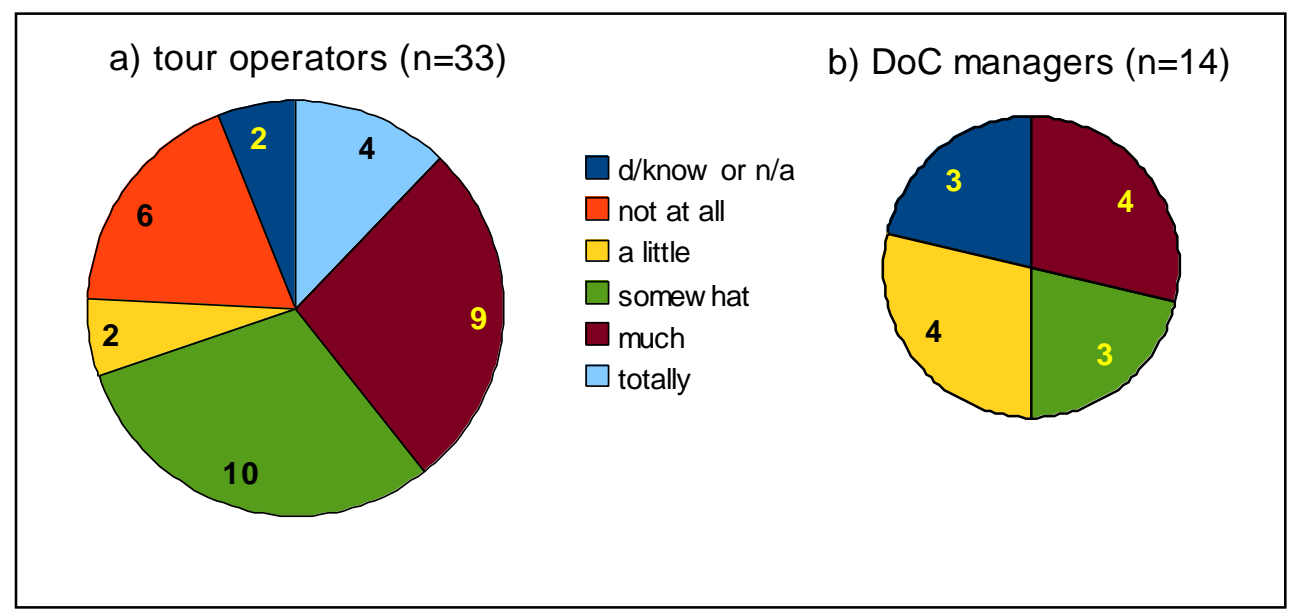

Approximately one quarter of the tour operators $(n=8)$ and DoC managers $(n=4)$ were just a little or not at all satisfied with DoC's support. One DoC manager commented:

“We could be doing a lot more in a 'partnership' sense in helping tourism operators to have high quality information and support. This could be through providing resources, or training or just showing support in monitoring. "

One tour operator proposed that:

"they [DoC] could do more to promote and encourage operators of the benefits of upskilling their guides on interpretation principles and practice. They could 
be more active in developing and promoting interpretation qualifications such as the ATTTO interpretation unit standards."

When asked to indicate the actions taken to assure quality interpretation practices by tour operators, DoC managers cited three different quality assurance actions. The most common assurance action mentioned by DoC managers was putting conditions or directives related to interpretation in concessions contracts and management plans. These conditions regard the inclusion of biosecurity instruction, approval of interpretation material by DoC and by indigenous people (Maori):

"Conditions are included in most guiding concessions requiring the concessionaire to speak with iwi to ensure their stories and interpretation is relevant and correct."

Reviewing operator's interpretation material and monitoring of concessionaires were mentioned by some DoC managers. The former was also classified as a support action, as one manager indicated: "approve and improve interpretation content." The only monitoring technique described was the use of incognito assessors (mystery shoppers): "Staff in civies [plain clothes] or known member of public engaged to be a tourist to observe and listen to quality of interpretation." However, monitoring was indicated to be a discretionary activity, done only occasionally, if ever. A DoC manager noted:

"There is no target set and thus it becomes a discretionary activity, and unfortunately in DOC, at area level at least, discretionary activities often fall over."

DoC managers were also asked what proportion of guiding concessions in their area delivers quality interpretation that meet the standards set out in DoC's Interpretation Handbook and Standards (DoC, 2005). Figure 4.8 shows that the majority of DoC managers $(n=9)$ replied that they do not know the answer to this question, and a few explained that the reason was insufficient monitoring. One manager stated that: 
"I am not able to answer this question, as we do not have a sufficiently thorough monitoring or assessment system in place to gauge a response to this question."

Figure 4.8: Proportion of guiding concessions that deliver quality interpretation that meet DoC's standards according to DoC managers

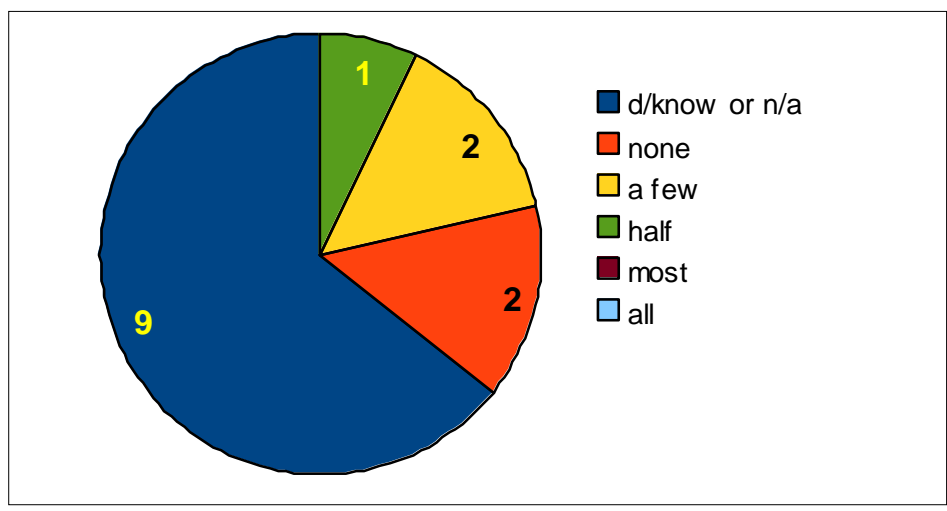

Two DoC managers replied that no guiding concessionaire meet DoC's interpretation standards, one argued that "I'm not aware of any guiding concessionaires where it would be required or appropriate", and the other stated that "concessionaires would not be aware of the Handbook." Two DoC managers answered that a few concessionaires meet DoC's standards, however one of them noted that "it's hard to know, comment on without auditing all the operations." Only one DoC manager answered that half of the concessionaires meet DoC interpretation standards, he pointed out that:

"many concessionaires visit our area as part of a South Island circuit. Local concessionaires are better known and we hear about the service they provide. Have not got the same contact or information sources for those visiting."

No DoC manager replied that most or all concessionaires meet DoC interpretation standards.

\subsection{Challenges and constraints faced by both stakeholders in developing and assuring quality interpretation practices by tour operators}

The stakeholders were asked to indicate what challenges and constraints they face in developing and assuring quality interpretation practices by tour operators. The 
challenges and constraints mentioned by tour operators were classified into seven distinct categories:

> guides' knowledge, communication skills and attitudes;

$>$ updating information;

$>$ recruiting and retaining qualified guides;

$>$ training guides;

$>$ lack of business;

$>$ conflict with the nature and pace of activity; and

$>$ restriction of cultural interpretation.

The most frequent challenges cited by tour operators in developing and assuring quality interpretation practices were related to guides' knowledge, communication skills, and attitudes. The large amount of knowledge required was mentioned by three operators, and this was caused by the spacial scope of businesses (across the country), as well as by the diversity of clients' interests: "Having a wide knowledge to cater for the diverse interests of clients, eg.: mining, Maori history, politics, transportation, farming... .". One tour operator pointed out the difficulty in getting guides to understand that interpretation is the main part of guiding: "Getting staff to recognise interpretation as the main part of their job, not the driving of the vehicles on tour." Some operators commented on the challenge of maintaining guides' motivation or enthusiasm throughout the year.

The second largest category of challenges and constraints reported was obtaining up-todate information and the difficulties in getting current, factual, and accurate information. One operator indicated the importance of up-to-date information, and listed the different types required:

"Keeping the stories fresh and for marine animals keeping up with updates on research, seasonal changes, breeding successes, and legislation changes/proposals." 
The third largest category of challenges or constraints indentified was recruiting and retaining qualified guides. Good communication, knowledge, passion and people skills were mentioned as attributes hard to find. One operator indicated the difficulty of finding guides that perform well in many different roles, and argued that another skill, boat skippering, was more important than interpretation for his business. The problem of high turnover of tour guides was mentioned by three tour operators.

Other categories of challenges and constraints were less frequent in the responses, but reveal the diversity of issues faced by tour operators: training, lack of business, conflict with the nature and pace of activity, and restriction on cultural interpretation.

Three tour operators replied that they have no challenges or constraints in developing quality interpretation, attributing it to the small size of the business, and their good relationship with DoC.

DoC managers reported five types of challenges and constraints in supporting tour operators' interpretation, and assuring quality practices:

1. resources restrictions;

2. lack of priority;

3. lack of interest by tour operators;

4. availability of interpretation resources; and

5. obtaining agreement from indigenous people (Maori).

Resources restrictions were the most frequent constraint faced by DoC managers, and it includes limitations of time, human resources, and funding. One DoC manager commented on the time constraint to deal with concessionaires' interpretation, and indicated the tasks that could otherwise be carried out: 
"The main challenges and constraints are setting aside sufficient time to devote to matters related to interpretation. These would include tasks such as following up on monitoring and checking interpretation resources created by concessionaires (for accuracy, quality and so on), for monitoring of how interpretation is being delivered ("secret shopper" trips and so on), and for ensuring concessionaires are taking advantage of available resources and are delivering an accurate and quality service for visitors."

Closely related, the second most cited constraint was the lack of priority to deal with interpretation: "other issues pertaining to concessionaires have higher risks and are priority work." One DoC manager commented that a challenge or constraint is: "knowing that they [tour operators] have an interest in delivering quality interpretation as part of their business." Another commented that the availability of interpretation resources is a constraint: "not having good conservation interpretation to provide to them, mainly due to the effort required from staff to provide it." It was also pointed out

that gaining agreement from indigenous people is a challenge: "gaining agreement from iwi [Maori tribe] in regard to storytelling."

Two DoC managers replied that they have had no challenges or constraints in developing and assuring quality interpretation practices by tour operators. One of them explained that he was not involved with the concessions assessment process, while the other wrote that he has not had any situations to deal with. Challenges and constraints cited by DoC managers were classified into five categories.

\subsection{Perceptions towards the concession system}

Tour operators and DoC managers were asked to point out the main issues, both positives and negatives, in holding and managing guiding concessions respectively. A relatively large number of comments were provided, and these were classified into many different categories within the two major groups - positive and negative issues. 
There were 74 comments from tour operators about DoC's concession system, which were classified into 7 positive and 12 negative aspects. Tour operators cited almost twice as much negative $(n=48)$ comments compared to positive ones $(n=26)$. Business credibility and advantage was the most common aspect in the positive group. One tour operator commented that it is "great for clients to know you have been audited through the concession process and therefore are a quality operator." Another operator pointed out that the concession system "maintains standards for tourism." The second most common positive aspect cited by tour operators was the legal access to the Conservation Estate provide by the concessions. The third largest category of positive aspects was the support to DoC and to the environment provided by the concession system, not only financially but also in helping to control the negative impacts of tourism and recreation in the Conservation Estate. One tour operator's comment describes in detail how DoC's concession system helps to control the negative impacts of tourism/recreation in protected areas:

"It ensures operators have a framework, which they must operate within thereby protecting the environment. Provides a mechanism to control negative effects of the use of the DOC estate. When you are applying for a concession you need to think through how you are going to operate and mitigation measures you need to put in place to reduce the impacts of your proposal."

The fourth largest category of positive aspects reported by tour operators was the support they get from DoC. Finally, safety standards, and protecting the visitor experience were commented by one operator each. One operator argued that "Concessions regulate areas from over use and misuse by non-concessioned groups down-grading the experience for guided and non guided visitors alike." 
Complaints about the concessions processing was the largest category $(n=17)$ in the negative aspects cited by tour operators. It was referred to as costly, lengthy, bureaucratic, and confusing:

"The concessions are expensive, and even renewals take a very long time. Our most recent renewal took over 18 months from submission to approval, and there was no issue with the application, it was accepted as submitted. This is an excessively long time for a simple renewal."

The second largest category of negative aspects $(n=9)$ was DoC's alleged poor law enforcement, which allows for unfair competition with illegal operators that do not hold concessions. This aspect seemed to be causing a great deal of resentment with some operators. One operator commented that:

"DoC doesn't enforce the requirement for all operators to have a guiding concession. Therefore, I'm paying my guiding fees and annual concession licence, implementing my safety plan and abiding by the conditions, while my opposition/competitor is not paying, has lower cost structures, and then undercuts my operation with cheaper quote/price!"

Other negative aspects, identified, were: poor communication and involvement; DoC's lack of understanding of business; and short concessions tenure. In relation to the former aspect, one operator wrote that:

"DoC doesn't take much notice of its concessionaires. As a business contributing to the cost of maintaining the DoC estate in NZ, and abiding by all the conditions to prevent damage or decline in its quality, I don't feel I have much of a voice at all in policy or procedure for those DoC areas we utilise."

In relation to DoC's understanding of business, a tour operator commented that " $D O C$ does not understand commercial challenges in running a commercial organisation." In relation to the tenure, one operator explained that "short permit period (5 years) makes business future uncertain." 
Other less frequent negative aspects, highlighted by a few operators, were: restrictive party size; unfair treatment; obtaining agreement from indigenous people to be able to tell their stories; and allocation of concessions revenues. Comments about unfairness were related to the free access that free independent tourists (FIT) get to the Conservation Estate, while guided tourists have to pay. In relation to the allocation of concessions revenues, one operator stated that "money generated from us taking people out to the Reserve is not prioritised on the area." Finally, there were some negative aspects that were commented on by one tour operator, these were: disapproval of the tendering process as a management approach; conflict with tour operators that do not hold concessions; and concern with excessive levels of tourism on protected areas.

There were 28 comments from DoC managers about DoC's concession system. They provided many more negative comments or difficulties $(n=24)$ compared to positive ones $(n=4)$. The positive aspects of the system indicated by DoC managers were:

$>$ it provides opportunities and quality experiences to visitors;

> it establishes a partnership in looking after the environment;

$>$ it assures quality services; and

$>$ there is a good relationship with tour operators.

A comment from a DoC manager illustrates the importance of concessionaires to DoC:

“Concessionaires are our eyes and ears on conservation land and meet far more visitors than we ever can expect to. Having their buy-in is significant and we hugely value the relationship."

Among the negative aspects or difficulties pointed out by DoC managers, the majority of the comments referred to limitations in management procedures and tools:

"clear and meaningful concession documents";

"tools for consulting with iwi over Maori stories";

"efficient application process so that decisions can be made more quickly on applications"; and "efficient systems to ensure legal obligations are being met." 
This last item, systems to ensure legal obligations, includes limitations in monitoring, which comprised half $(n=5)$ of the comments of this category. The second most frequent negative aspect or difficulty cited by DoC managers were resources restrictions, including lack of time and funding. One DoC Area Manager explained that "recreation concessions are just one aspect of an area's community relations programme managers tasks, time is the constraint."

Other less frequent negative aspects or difficulties cited by DoC managers were: occasional negative comments about DoC from tour operators to visitors; lack of information or statistics; difficulty in providing enough support to tour operators; poor quality of information provided by tour operators; difficulty in attracting high quality tour operators that have the resources to be sustainable in remote areas; payment issues with concessionaires; health and safety issues; and compliance with concession conditions (trip and passenger limits).

\subsection{Conclusions}

The national survey revealed that many tour operators and DoC managers have a good understanding of interpretation, particularly of its benefits. However, while interpretation plays an important role in tour operators' services, it is a low priority for DoC managers' concessions work.

The survey revealed many different actions employed by both stakeholders to develop and support the interpretation capabilities of the tour operators, but the levels that those actions are being undertaken in the different regions are not clear. The survey revealed that tour operators and DoC managers face a number of challenges and constraints to develop and support the interpretation capabilities of tour operators and to assure 
quality interpretation practices. The main challenge both stakeholders face are related to human resources. Tour operators have difficulties in recruiting and retaining qualified or skillful tour guides, and DoC managers have little time available to deal with interpretation support and monitoring.

The survey revealed a number of positive aspects within the concession system, but the participants provided many more comments on the negative aspects or difficulties. Although the response rates of the survey were too small to have a clear national picture, and to identify regional patterns, it seems that there is a wide range of needs, practices and challenges across the country.

The national survey allowed the identification of the attitudes, actions and constraints faced by both stakeholders, but it did not provide explanations for the situations encountered. This is the main reason for undertaking a second phase in this research, an in-depth investigation via a case study to reveal the reasons for the occurrence of these situations. 


\section{Findings of the Case Study}

This chapter presents the findings of the case study conducted in Nelson-Marlborough Conservancy with the two stakeholders: 13 tour operators (guiding concessionaires), and 9 DoC managers. The chapter follows the order expressed in the analytical framework (Fig 3.3), addressing the four research objectives consecutively. Each objective is addressed first for the tour operators then for DoC managers.

The chapter begins by presenting the findings about the attitudes of the stakeholders towards interpretation. Their perceptions on what interpretation is, and what its purposes are will be presented, followed by their views on the importance of interpretation. In this study, 'purposes' and 'benefits' of interpretation are similar concepts. In the following section, the stakeholders actions to develop the interpretation capabilities of tour operators are reported. The next section presents the challenges and constraints faced by them in developing and assuring quality interpretation practices by tour operators. The following section shows the findings about the stakeholders' views about their relationship, as well as their attitudes toward the concession system. The final section sums up the findings from this case study.

\subsection{Attitudes towards interpretation}

In order to assess tour operators' and DoC managers' understanding of interpretation, they were asked to explain what it is, and to indicate its main purposes or benefits. The stakeholders were also asked how important they think interpretation is to their services, and to rank its priority compared to other main services they provide. 


\subsubsection{Tour operators' attitudes towards interpretation}

Tour operators interviewed mentioned that interpretation is about providing information to visitors related to the place they are visiting, describing, explaining, and revealing meanings about the natural environment, the local history and culture. Most tour operators listed a variety of topics that they interpret. One of them listed different topics, and summarized interpretation:

"We focus on the natural history of the fauna and flora of the area, the social history, and then of course the landscape history, the geology and morphology of the area. So, interpretation for us is huge, it's wide encompassing, but if you gonna distil it down to one small thing, it's basically bringing the track to life."

One operator pointed out the importance of interpreting the culture and history of the indigenous people (Maori) in New Zealand, he commented that visitors know little about it and are fascinated by it.

A couple of operators mentioned that interpretation is more than just laying out facts, it's about telling stories. One of them described how he creates a narrative:

"As you walk along and talk about the broad-leaved, for example, you would say: this is a broad-leaved, and it's the favourite plant of the deer, and the deer industry was amazing in New Zealand. So, one thread then goes into a whole story. So, we focus on telling stories rather than facts."

Most tour operators mentioned that the purpose of interpretation is to promote understanding and education about the natural and cultural heritage of the place. The purposes or benefits of interpretation identified by tour operators were:

$>$ to promote understanding and education about natural and cultural heritage;

$>$ to promote environmental awareness and conservation behaviour;

$>$ to explain the value of protected areas;

$>$ to instruct proper behaviour in protected areas; 
$>$ to add value to guided trips; and

$>$ to deliver an expected product.

One of the operators that indicated that education is the main purpose of interpretation, explained that understanding more about ecology is essential to nature conservation throughout the world. He highlighted that New Zealanders needed to understand more about their country's ecology:

“...ecology is so important for the future of the planet, and without understanding it, we don't feel we can actually save what's left. And this is an educational component within what we do, and New Zealanders specially need to understand about our natural ecology."

Other tour operators commented that the purpose of their interpretation practices is to promote environmental awareness and conservation behaviour:

"The whole idea of us doing this is so the outdoors has a positive impact on people. So when an environmental issue comes up in their neighbourhood, wherever that is, they will have this feeling, an empathy for the environment. They will go: I want more trees, I want to look after that bird."

One operator mentioned specifically that interpretation helps to explain the value of the Conservation Estate to different stakeholders. Another operator added that interpretation also serves to explain to visitors how to behave properly in protected areas.

One operator that offers guided walks said that the purpose of interpretation is to add value to the trip, and that unguided visitors miss out by not having this:

"It's to add value to the trip. In the Abel Tasman specifically I watch thousands of people walking pass, and they're enjoying the country side, they're the scenery, they're enjoying being in the forest, but they haven't got a clue about what they are seeing. I'm convinced that those people that are walking unguided from end to end they had a wonderful day, but they missed out on so much."

Another tour operator made a similar point, and explained that personal (guided) interpretation enables him to reveal unperceived elements and meanings to visitors. One operator argued that, from a business perspective, interpretation is part of the 
product delivery, and that it must be delivered at the levels that visitors expect. $\mathrm{He}$ concluded that the purposes of interpretation are education and product delivery:

"It's a business, they pay us money to deliver a product, so we have to deliver that product up to the level of their expectations. So, interpretation in business is about education and delivering a product."

All tour operators that participated in the interviews said interpretation is very important to their guiding services. About half of the operators mentioned that interpretation is the point of difference in their business. However, despite the high importance operators place on interpretation, other aspects of their services were often seen as more important, with safety as the most important aspect, followed by trip organization. Other aspects such as visitor enjoyment, marketing, and promotion were also mentioned as more important than interpretation issues. A few operators pointed out that visitors' expectations regarding interpretation varies a lot, those who offer cycling activities mentioned that their clients are more concerned with the activity itself.

One tour operator explained that interpretation is the main point of difference in his business since all other aspects of the product are similar among competing companies:

"I think it's really important. That's the main difference, a lot of the companies have the same clients, they have the same water taxis, they do the same trips. So, the main difference is the interpretation that they receive."

Another operator that works with cycling tours pointed out that interpretation "makes the difference between an average guide and a good guide."

Safety and organization were mentioned by most tour operators as the most important aspects of all types of guided activities, kayaking, cycling, horse riding, and walking:

"Obviously we're an outdoor type of experience, and we operate in the water, so safety is priority and then customer experience would come second to safety."

"Organization is paramount, safety is second, and interpretation is third. When there's a safety issue, interpretation is no longer important." 
Only one operator affirmed interpretation and education as his first priority, out of the sample studied, this operator was the most focused on ecology and conservation. He argued that safety and organization are basic services sought by clients when booking a guiding service, and that many companies provide this. He noted that his point of difference is having interpretation and education as first priority.

One tour operator did not want to distinguish between the priorities of the different aspects of his guiding business. He pointed out that interpretation together with safety, organization, marketing and promotion are all important aspects:

“Well, marketing and promotion are fairly important, because without customers, you've got no one to provide with the interpretation. As far as the tour side of things goes, it's very important, but there are other things you have to do before you can get people on the tour.”

Two tour operators that offer bicycle tours explained that safety and operational issues get more attention than interpretation. One of them also pointed out that his clients' main motivation is the cycling activity, and he suggests that they do not expect much interpretation: "I guess I'll make a point: our clients are predominantly coming on our trip for the activities rather than necessarily looking for high interpretation."

A few other operators also noted that visitors' levels of expectations regarding interpretation varies a lot. One operator that offers cycling and kayaking noted that international visitors expect more interpretation than domestic visitors. Another operator that offers wildlife watching, explained that they provide the best interpretation they can, and visitors can choose how much they hear, and he indicated that interpretation is part of the whole package, or product. 


\subsubsection{DoC Managers' attitudes toward interpretation}

Most DoC managers that took part in the interviews stated that interpretation is about passing on information, and explaining the natural and cultural features of the place.

One DoC manager referred to those features as conservation values, and he noted that tour operators can specialize in different topics:

"Interpretation is explaining what are the conservation values of that place, and they can be biodiversity values, which can be plants, animals, fish or marine mammals in that place, the scenic values, the geological values, and the cultural values as well. ... I guess you can specialize on different aspects of that."

After giving a long list of possible topics, one DoC manager concluded:

"...I guess interpretation is making a place come alive in the imagination of the people that are experiencing, giving a little bit more depth to their experience."

Most DoC managers commented that the main purpose of interpretation is to promote understanding about the natural and cultural heritage. DoC managers cited a number of purposes or benefits of interpretation:

$>$ to promote understanding about the natural and cultural heritage;

$>$ to do conservation education;

$>$ to promote support to conservation and to DoC;

$>$ to control impacts of visitors in protected areas;

$>$ to enhance the visitor experience;

$>$ to provide economic benefits to businesses; and

$>$ to promote the New Zealand tourism industry.

A few managers mentioned that interpretation provides meaning, and enhances the visitor experience. One of them stated that "the main purpose is simply to produce a good experience for the client." One DoC manager pointed out that the purpose of interpretation is to instigate peoples desire to learn more about the place they are visiting: "Well I think it's a little bit like a spark plug, you know, where you try and 
spark in people's imagination a yearning to learn a little bit more." He also stated that interpretation helps visitors engage with and appreciate the environment - through learning about the uniqueness of the place:

"It's to build engagement, to get people to build empathy for the environment and to understand the context of where they're at. ... That is interpretation, it's digging down into the details, learning what drove those early pioneers, or the forces that shaped this country into the unique place it is."

One DoC manager pointed out that through interpretation tour operators are able to pass on information about the trip, the activity, and the place they are visiting. He also argued that visitors go on guided trips to learn, therefore guides should be knowledgeable. Another manager noted that good interpreters can enhance the visitors experience, and as a consequence can benefit the New Zealand tourism industry by means of word-ofmouth referrals or promotion:

"The interpreters have got a huge responsibility, because if people go away with a good experience, not only are they going to be more enlightened about New Zealand, but also they're going to pass on that information to other people. And really, In a country that relies heavily on tourism, it's really important that people get the right stories, and that they get a good experience"

One DoC manager stated that tour operators that hold DoC concessions provide a useful service for DoC by informing and educating visitors about nature conservation, about proper conduct when visiting natural areas, and ultimately provoking environmental awareness and better behaviour.

Another DoC manager suggested that DoC should put more emphasis on interpretation to build public support for conservation actions and for the Department. He argued that the lack of public understanding about DoC leads to criticism, low esteem, and budget cuts in a department that is fundamental to the country and to the tourism industry. 
A DoC manager at the national level commented that the Department has done quite a lot in terms of interpretation, and they are proud of that. He also pointed out the benefits of interpretation to visitors, to businesses, and to the country:

"I think we are very proud of our interpretative products that we deliver, especially the ones that we can say that we produced in partnership with others, and helped them to deliver. That was fantastic, that made New Zealanders and overseas visitors alike really happy with the experience. We're very proud of that, and if it provides economic benefits to the business and ultimately to the country as a result, so much better.”

DoC managers that participated in this case study stated that interpretation is very important, fundamental, or critical to meaningful visitor experiences. However, they all noted that interpretation plays a minor role, if any, in their concessions related work, and in DoC services in general. They said that other priorities consume the majority of their time.

DoC managers were asked how important interpretation is to deliver meaningful experiences to visitors, and all but one replied that it is important or very important. One manager stated that interpretation has became more important since more people are living in urban settings, and having less contact with nature. However, one manager argued that interpretation is not an essential element for meaningful visitor experiences, and he reported that visitors to his area have a full range of attitudes toward interpretation, from antipathy to appreciation:

"I don't think interpretation is essential for people to have a meaningful experience. I mean, even being in places, experiencing just the smell, the stillness, the quiet, I think those are all valid experiences, and don't need interpretation to be useful, meaningful, or a good experience for people visiting a site. It isn't essential, and some people prefer not to have any interpretation. It is sort of clutter, more noise... Whereas other people think it enriches their trip, 
they find out something, they know more about the site, have a more in depth experience. So, you get the full range."

A comment from one area officer exemplifies the common view among the DoC managers interviewed, that although interpretation is regarded as very important, there are other higher priorities in the Department of Conservation:

"I see it as a very important role that the department provides. However, it's definitely not the top priority. My most important role is to ensure the ongoing survival and sustainability of those habitats, and processes, and nature really."

Another area officer pointed out that DoC's own interpretation is not much of a priority, and that tour operators' interpretation is even less:

“Interpretation hasn't been as much a priority for DoC as it could be. I guess I feel DoC doesn't give DoC's own interpretation sufficient importance, let alone worrying about what concessionaires provide."

A DoC manager at an area office believed interpretation deserves a higher priority within DoC, although he perceived that they have started to work on it in his area. He argued that public support for DoC is not wider because interpretation has a low priority. Another manager at the regional level commented that DoC is changing its culture, being less bureaucratic and more outcome oriented, and recognizing interpretation and conservation advocacy as an important outcome:

"one of those outcomes is embedding conservation in the hearts and minds of the people of New Zealand and of people who visit it."

\subsection{Actions to develop the interpretation capabilities of tour operators}

Both stakeholders were asked what actions they have undertaken to develop the interpretation capabilities of tour operators, and what sources of information they have used or provided. They were also asked if they have provided or participated in any interpretation training. 


\subsubsection{Tour operators' actions to develop their interpretation capabilities}

Tour operators that participated in this study have employed a variety of actions to develop their interpretation capabilities, including:

1. recruiting qualified and/or experienced guides;

2. studying the literature, and keeping a collection available to tour guides;

3. providing in-house trainings and manuals for own guides;

4. participating in external trainings;

5. consulting with DoC and the Ornithological Society;

6. learning from local community, clients (tourists), and other operators;

7. consulting with indigenous people (Maori);

8. building experience and practice; and

9. undertaking monitoring and evaluation off their services

Tour operators reported consulting a number of different sources of information to give content to their interpretation program, including:

$>$ DoC's brochures;

> DoC's interpretation toolkit Conservation Revealed;

> DoC's newsletter What's Up DoC?;

> management plans of protected areas;

$>$ books and field guides;

$>$ scientific research;

> internet, including DoC's website;

$>$ DoC officers and specialist;

> conservation organisations: Ornithological Society, and Forest \& Bird;

> clients who are involved in environmental sciences.

Some tour operators mentioned that recruiting qualified and/or experienced guides is the first step to be able to deliver quality interpretation. However, according to them this is a big challenge in New Zealand (see more detail in section 5.4.1). In order to overcome that difficulty, other actions such as providing information and training are employed by tour operators to improve the interpretation capabilities of their guides. 
All types of tour operators, large and small, mentioned that they have bought and read books about New Zealand's nature and history. A small operator that offers scenic van tours and short nature walks commented that before he started guiding a couple years ago he spent a whole year researching and reading before he felt comfortable to start taking people on tours. Another small operator, who has been guiding long nature walks (tramping) for more than fifteen years, pointed out that they are constantly studying:

"As we say, our knowledge is layer upon layer, and we're constantly reading. It's right down to study the books on New Zealand's natural ecology and read, and read, and that's amazing what you can pick up. It's just reading and learning."

One large operator that offers kayaking and aquataxi tours in Abel Tasman National Park mentioned that DoC's handbook A parkfor all seasons: the story of Abel Tasman National Park is a basic literature for their guides:

“DoC's handbook about Abel Tasman National Park, is a basic one that all guides are provided with at the beginning of the season, so they read about the facts, and how the conservation estate was established."

However, that handbook was last published in 1990, and it is not available any more. One tour operator commented that she appreciates DoC's brochures, but she argued that tour operators should have more access to free brochures. One operator that works with cycling tours commented that he includes some DoC brochures in a folder of information carried during their trips. Most tour operators pointed out that they keep a collection of books, field guides and other literature, and make it available to guides.

Tour operators were asked if they are aware and have DoC's interpretation toolkit Conservation Revealed and DoC's Interpretation Handbook and Standards. Most of them replied they know and have the former, but only one said he has the latter. Most operators think the information in the interpretation toolkit is too superficial, but one operator commented that he appreciates it. He noted that the toolkit covers many 
different topics and provides accurate information:

"It's very well structured, and if you want to double check on something it becomes a very easy reference point,... there is a section on flora, a section on fauna, a section for each different reserve or national park. So, for accuracy it's very good. Because one of the issues I had was that a lot of the history books would have different stories."

On the other hand, one operator replied she was not aware of DoC's toolkit. When the researcher told her that it is available in DoC's website she commented that "you have to access all that sort of stuff, DoC is certainly not forthcoming with commercial operators, in handing out information."

The only operator that reported having a copy of DoC's Interpretation Handbook and Standards said he did not make use of it since he has too much to read, and he was satisfied with the quality of his interpretation practices already.

One operator pointed out that management plans of protected areas are also a good source of historical information. Another operator said he receives DoC's e-mail newsletter What's up DoC?, and there he can find out about new publications. Most tour operators said they make little use of DoC's website. Some commented that they use it for purposes other than getting interpretation information, such as: hut booking, or getting information about the Conservation Board meetings. One operator said he uses DoC's website a lot, but he also noted that there are two or three native animals and plants websites that are actually better than DoC's. Another operator said he consults the Ornithological Society, and Forest \& Bird websites. 
Medium and large operators reported that they have structured annual training at the start of the season, and that they provide company manuals to their guides. The smaller operators rely mostly on the previous knowledge and skills of their guides, and on external training. The operators that offer adventure or sport activities, such as: kayaking, and cycling spend most of the training on the activities and on safety issues, but all have some interpretation included as well.

An operator that offers long guided walks described his annual training and the extensive material made available to his guides:

"We spend a whole week at the start of each season, even the returning guides, on going through the education of interpretation. They are given a massive guide's manual and we've got an informal book case back at the office where people can go, and it has the natural history, social history, and all that."

An operator that offers kayaking trips in Abel Tasman National Park explained that his training is a mentoring program where new guides accompany senior guides, and gradually they get to guide larger parts of the trips.

An operator that specializes in wildlife watching said he gives written commentary to his guides about the wildlife a month before the tourism season. When asked how he makes sure guides know the material, he replied he asks them to talk about each species, but he expects them to put in their own words. Another operator said she provides the guides a long list of questions, and expects them to go away and learn by themselves:

"So, we encourage them to do their own research, to find their own answers, to deliver it in their own way, but the questions create the base of the essential information that they must provide."

The two most cited training providers mentioned by the tour operators were the polytechnic institutes in Nelson, Christchurch, and Greymouth on the West Coast. One tour operator had studied at Nelson Marlborough Institute of Technology, and another 
operator had studied at the Outdoor Pursuit Centre in Turangi, both more than ten years ago. Those operators and others that have hired guides that came out of those institutes commented that those trainings focus more on the outdoor activities rather than on interpretation.

However, a couple of operators were not satisfied with the quality of the guides that graduated from of those institutes. One operator that offers nature walks with emphasis on ecology and conservation believes that polytechnics instructors have limitations on interpretation training: "they actually haven't got enough of the knowledge." Another operator with long experience in cycling tours pointed out that he has not employed guides that come out of the polytechnics courses because they do not meet his needs: "I thought that the polytechnic should be a good place to find guides, but it's been very mediocre. In my view, most of the people who come out of those courses don't have the characteristics I need - life experience, ability to tell a story, sense of humor, and passion."

One the other hand, one of the operators that studied in a polytechnic and that works with kayaking thinks that the interpretation training in those institutes is good enough. He argued that those courses can teach interpretation techniques, but the content or the information of interpretation should be sourced by the guides themselves:

"I think it should be up to the individuals, once they settle on a place that they want to work, to take it upon themselves to source that information, whether they get that through the company they work for, or the library, or the Internet."

Tai Poutini Polytechnic in the West Coast is emphasising interpretation in its Certification in Ecotourism program, and it has been working closely with the tourism industry. Recently, it provided a nature guide training course to the renowned operator Real Journeys from Fiordland (Ecotourism NZ, 2010). 
Only two tour operators that participated in this study took part in the interpretation training workshop provided by DoC in 2006 (more details in section 5.3.2), and they appreciated the opportunity. One operator reported that many years ago he participated in a short training session provided by DoC to kayak guides in Abel Tasman National Park. He said DoC staff talked about stories and rules, and he found that very useful. He suggested DoC should run those every year for new guides. Another operator said he used to take part in DoC's summer holiday programs, he commented that those programs were really good and popular. He noted that DoC doesn't run those programs in Nelson-Marlborough Conservancy any more, and he believes this is due to lack of staff. He also noted that those programs were also important for DoC's public image. That same operator also said he had been to a couple short workshops offered in Nelson, he did not recall who provided those, but found them too superficial. When asked if the workshops should be longer and have more depth, he suggested that first there should be an assessment of what types of trainings tour operators need.

Many operators commented that they would appreciate if DoC could provide more trainings or workshops on different topics, such as: fauna, flora, and geology. Some also suggested that during those training sessions DoC should go over regulations and conservation issues as well. A tour operator that works with marine mammal watching in the Marlborough Sounds said DoC should address all tour operators, including those that do not hold concessions - but still interact with marine mammals:

"DoC mentioned a few years ago that they really need to sit with all the operators and go over the rules and regulations for dolphin watching, and they never did. So, it's a bit frustrating."

Most tour operators pointed out the difficulty in participating in trainings during the peak season (summer), and outside their area. One operator commented that May or September would be the best time, and that the training should be just one day long. 
Another tour operator suggested that DoC's interpretation workshop should be mandatory to guiding businesses: "I think you should only be able to guide in a region if you attended that interpretation workshop." On the other hand, two medium size operators argued that it is not DoC's role to provide training to tour operators. One of them argued that DoC doesn't have all the knowledge, and it is the company's job to do training. The other operator pointed out that providing a professional service is part of the competition among businesses, and that DoC should not interfere with that:

"DoC provides the facilities and it's up to the concessionaires to be providing a professional service. And the ones that provide the most professional service, and that covers interpretation and all other things, are the ones that will do well. So, I don't see it as DoC's job to cross over into that commercial area."

A small operator commented that he might be interested in interpretation training only if it is about interpretation techniques: "... if it is how to interpret rather than what to interpret I might be interested."

Most tour operators commented that DoC staff are helpful when approached. An operator at Abel Tasman National Park commented that DoC is very accessible:

"You can always ring, or if you see Doc staff in the national park they're always pretty friendly and helpful, you feel like you can approach them."

One operator that works at Farewell Spit Nature Reserve, an important bird sanctuary, said he participates in annual meetings with DoC and the Ornithological Society:

"We try and keep up to date with the what the Ornithological Society are doing in regard to the birds and their counts and things. We use whatever opportunities we can to keep abreast of new developments."

A large tour operator that offers kayaking and aquataxi tours commented that DoC sends out a staff member every year to speak to their guides specifically about marine mammal issues. Two tour operators that undertake nature conservation initiatives, on habitat restoration and native species recovery, pointed out that their close contact with DoC officers during those initiatives allow them to learn a lot. 
A small operator that came from another country many years ago, commented that he gets a lot of information and stories from the local community where he operates:

"I'm not from here, but I've found that the local Golden Bay people are tremendously helpful about giving me background in giving these stories."

Another small operator with significant experience in nature walks commented that he still learns from the clients (tourists) who are involved in environmental sciences:

"We often attract people who are involved in environmental sciences, and we get taught a lot ourselves."

Two operators mentioned that they have gone on other operators' tours in New Zealand and abroad in order to observe and learn with their interpretation practices.

The only condition in guiding concessions contracts in the study area regarding interpretation is the requirement that tour operators must consult with tangata whenua (local indigenous people) before telling their stories. However, most tour operators affirmed that they do not consult with Maori, some argued that they only provide information that is in public domain, hence there would be no need for consultation. One operator argued that there is no need to consult since there were no Maori tribes in the area he operates - Kahurangi National Park. He also explained that he only talks about history and does not deal with Maori stories and spiritualism. One operator said he talks to Maori people to get correct information, but he said he does not do that because it is a condition in his concession contract, he said he had done it before DoC existed.

The largest tour operator that participated in this study is a iwi-owned business, and therefore has access to Maori interpretation:

"A representative for Wakatu, which is the local iwi, comes over and does interpretation for the guides at the beginning of the season, and spends a couple of days, and offers the Maori perspective on living in the area." 
One tour operator that offers guided walks pointed out that experience, spending time in the natural environment, is one of the most important ways to develop interpretation. Another operator that offers kayaking trips made a similar point, and explained how practice builds up confidence and the ability to communicate with visitors:

"I've been kayaking in the park as a guide for ten years now, and I definitely think I'm way better at it now than I was ten years ago. I'm not talking about my physical skills, but more stuff like reading different situations and getting a feel for them. So, I do think that a lot of it is practice, and having the confidence to go out and talk to people."

A large tour operator explained that in their business they have a "ladder of seniority", and as guides get more experienced they get to guide longer tours:

"Obviously with those extended tours you have to have a whole suitcase full of information, and tricks, and interesting facts about the area to entertain people for that length of time."

Not all tour operators interviewed have structured monitoring and evaluation procedures of their services. Some said they rely on e-mail feedback from clients, others have visitors books where they collect commentaries at the end of the trips. A couple of operators said they do not do visitor surveys because they do not want to bother clients. Only a few operators reported undertaking visitor evaluation regularly:

"At the end of the trip, the guests are asked to fill out a guest evaluation form, and as part of that we ask them how was the interpretation, or how was the guide's knowledge and interaction with the group."

One operator commented that he has recently felt the need to monitor and evaluate his guides' interpretation performances as the company grew and the team got larger. 


\subsubsection{DoC managers' actions to develop the interpretation capabilities of tour operators, and to assure quality interpretation practices}

DoC managers reported a variety of actions employed by them or the Department to support and develop tour operators' interpretation capabilities, and to assure quality interpretation practices by the operators, including:

providing or indicating literature: DoC's interpretation toolkit Conservation Revealed, and DoC's brochures; and internet sites: DoC, Ornithological Society, Forest \& Bird, and Project Jonah;

$>$ providing on-site interpretation panels;

$>$ offering training: interpretation workshop (2006), and occasional trainings about particular topics and regulations related to specific protected areas;

$>$ indicating DoC specialists that can provide specific information, and providing updates about DoC's conservation work;

$>$ reviewing interpretation material of tour operators;

$>$ accompanying tours and providing personal interpretation (only in Maud Island Scientific Reserve);

$>$ putting conditions related to interpretation in the concessions contracts;

$>$ sanctions and incentives to promote compliance with concessions conditions;

$>$ monitoring and evaluating tour operators' interpretation practices; and

$>$ supporting other organizations to raise interpretation quality nationwide.

These will each be discussed in more detail using quotes from the DoC interviwees. Some of those actions are not primarily aimed at tour operators but at visitors, such as: brochures and on-site interpretation panels, but they also support tour operators' practices. Visitor centres are other major interpretation resources provided by DoC, but they may not directly support the interpretation practices of tour operators, and were not cited by DoC managers or tour operators interviewed.

Not all the actions listed above are employed everywhere. Actions employed by local DoC managers varied in type and frequency in the different areas studied: Marlborough Sounds, Motueka (Abel Tasman National Park), and Golden Bay. As a DoC manager at 
the national level pointed out, there are different situations across the country with different needs and levels of interest:

"You have to remember that DoC is a decentralized organization, so what you will see in one region versus another may vary, and that heavily depends on relationships and levels of interest and knowledge in the key people on the ground. It also depends on need. Because in some areas you have more active tourism community, a lot more operators, a lot more tourism investments happening, so what happens in one place versus another may be different strictly based on need, and just activity level."

That same manager explained that at the national level they provide universal tools, such as DoC's Interpretation Handbook \& Standards, and DoC's interpretation toolkit Conservation Revealed. He also commented that DoC organized one interpretation training to tour operators in different parts of the country a few years ago, and are now planning an online (distance) interpretation training for DoC staff and tour operators.

In 2006 DoC published an extensive interpretation resource aimed at tourism concessionaires, the toolkit Conservation Revealed, described in section 4.2. A DoC manager that processes concession applications at the regional level said she notifies concessionaires that DoC's toolkit is available. However, another manager that has the same function said he has not notified operators about the toolkit, and justified that he has not been advised to do so, but he also pondered that it should be done:

"Nobody suggested that we should be doing that, but there might well be a case to say: here are the sources, this is where you can go if you want information to interpret your activity. If we've got it, we should tell them where it is."

When asked how the tour operators perceived the interpretation toolkit, a DoC manager at the regional level commented that they did not evaluate that, but he has heard that some operators have found it too superficial. 
DoC publishes a large collection of brochures about the protected areas, and many other topics, such as: wildlife, cultural heritage, conservation, and tracks. Most are available for free, and the larger ones are sold for a small price, from \$1 to \$3. A DoC manager commented that he recommends the brochures to tour operators, but he has received feedback saying that they are more appropriate for tourists. DoC also publishes large maps (Parkmap) of protected areas or groups of protected areas with much information on the reverse side, these cost $\$ 19$ and are basically a substitute for the old national parks handbooks. However, none of the managers interviewed nor the tour operators mentioned these maps. According to a DoC staff, the Department terminated the publication of the whole series of handbooks about New Zealand's national parks because it was too time consuming and expensive to keep updating them. He argued that there are now many other books available about the parks, plus the internet as a source of information. Nonetheless, he believes there is potential for the handbook concept, but he noted that DoC would need a partnership with a private publisher with a strong enough sales volume. A DoC area manager commented about one of those handbooks:

"There are other sources of information, there's a small book published by DoC about Abel Tasman National Park called "A Park for all seasons”, a field guide, it's no longer published, it's a good book and provides enough information."

Most DoC managers interviewed were not aware of DoC's publication Interpretation Handbook and Standards, described in section 4.2. Two area managers said they had seen it, but did not make use of it, and did not indicate it to tour operators. A DoC manager at the regional level who was not aware of this publication suggested that it would probably be relevant to the concessions processing work since it sets standards. A manager at the national level recognized that many DoC staff are not aware of this publication, and explained that staff turn over and changing of roles is part of the reason 
why. He commented that there is a need to promote the publication internally:

"When we do the next round of training, then probably that would be an opportunity to refresh the Handbook, and put it in front of them again, and say: hey, this thing is really good and you should be using it, and make sure they realize the tool is there."

That manager also commented that, although the handbook is not well known, it is the standard for DoC staff and concessionaires, and it should not be discretionary. However, he believes the standards set out there are not applied particularly for concessionaires.

A couple of DoC managers said they indicated DoC's website to tour operators. One said there is a lot of useful information there, and another commented that it is a good place to find up-to-date information. An area manager commented that it is hard to find information in DoC's website, but he noted that it is improving:

“It's just starting to get better. It's a very big website, and I still find it pretty hard to navigate around parts of it myself, but generally speaking, if you're persistent you can get good information on just about anything. "

That same manager said he advises tour operators to search for information on the internet, and he indicates websites of independent conservation organisations, such as: Forest and Bird, New Zealand Ornithological Society, and Project Jonah, this last one for information on marine mammals.

A DoC manager at Golden Bay said they provide different levels of on-site interpretation, some sites with frequent panels and others with few or none. He argued that this caters for different visitor's preferences, some like the panels and others find them an interference. A tour operator in that area noted that the Forestry Service used to put small signs identifying the plants along short forest trails, and that they were very useful, but DoC has discontinued that practice. However he acknowledge that DoC has provided good levels of on-site interpretation, and track marking: 
"I think it's important to have signage, and I think that the level that DoC has in

New Zealand is good, and of course their track marking is excellent as well."

A DoC manager in Marlborough Sounds said there are few panels on the Queen

Charlotte Track because they are too expensive, approximately NZ\$2,000 each, and because they do not last long due to harsh weather conditions. Nonetheless, DoC has recently (2006) invested in a new interpretation panel at Ship Cove Scenic Reserve, on a historical site at the north end of the Track (Figure 5.1). It took a few years between planning, consulting the public (local indigenous people (Maori), Captain Cook Society, and other areas of DoC), getting the resources $(\mathrm{NZ} \$ 38,000)$; and putting those panels in place. According to the Interpretation Network New Zealand (INNZ, 2008), and local tour operators, the panels are very good and visitors appreciate them.

Figure 5.1: DoC's interpretation panels at Ship Cove - Marlborough Sounds.

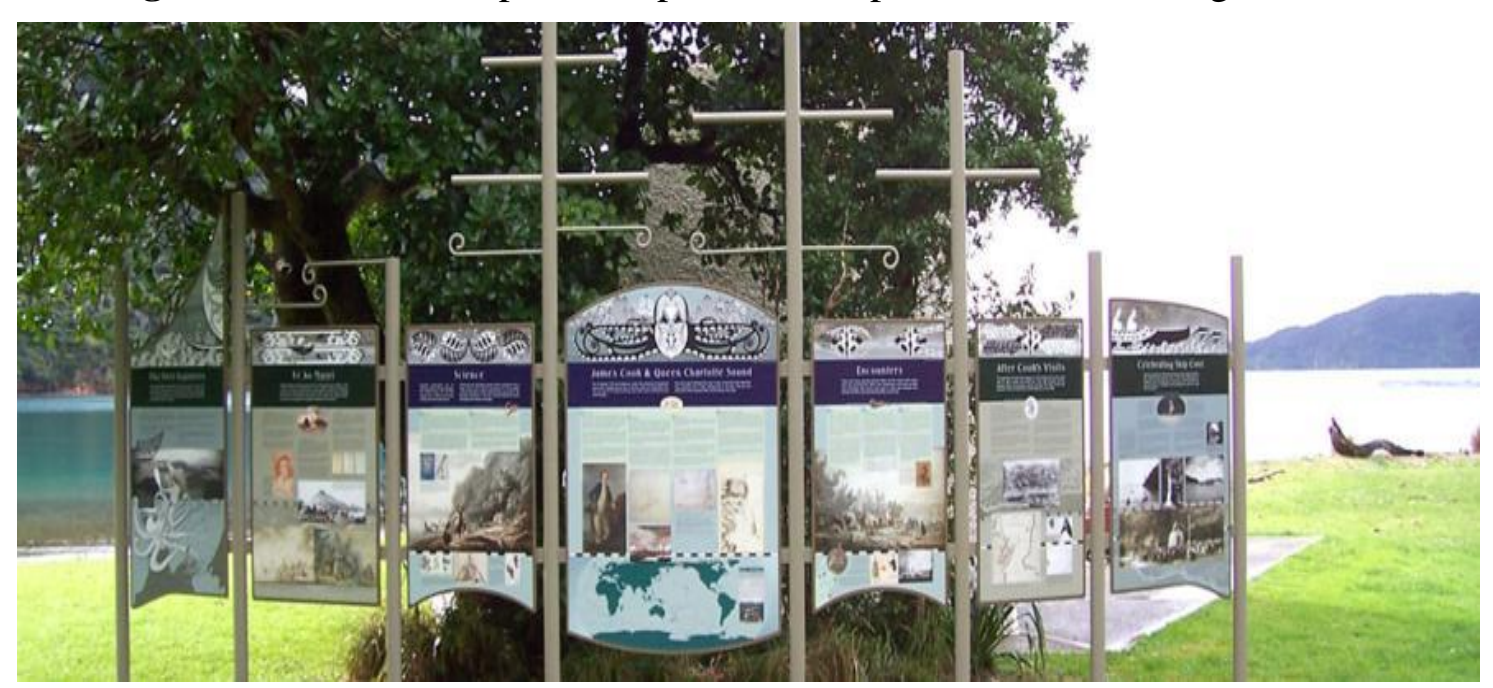

Although DoC's work with on site-interpretation and signs is widely praised, there is still demand for more signs and shortage of resources. One tour operator complained that he has requested DoC for an interpretation panel for an important historic site, but DoC replied that it did not have the resources.

In 2006 DoC provided a one day interpretation training workshop to tour operators and guides in the following locations: Christchurch, Motueka, Greymouth, Dunedin, Te Anau, Queenstown, Napier, Rotorua, Twizel, and Fox Glacier. DoC received a funding 
grant from the Tourism 2010 Strategy, from the Ministry of Tourism to run the workshops. The Aviation, Tourism and Travel Training Organisation (ATTTO) also collaborated on the project to ensure the training was aligned with their, and the New Zealand Qualifications Authority's (NZQA) standards. The workshops were offered to tour operators free of charge, on a first-come first-served basis, for up to 20 people in each location. DOC concessionaires were given priority places on the workshops. Approximately 160 tour operators and tour guides participated in the workshops. Participants had to cover the costs of the hard copy of the information folder, DoC's interpretation toolkit Conservation Revealed, which was released during the workshops. An external specialist (Steve Broni) was contracted to deliver the training, which was focused on interpretation techniques rather than on contents or topics. A DoC manager of the Nelson-Marlborough Conservancy office, at the regional level, accompanied one of those workshops, and described what was being taught:

"they could tell you how to tell stories, they could tell you how to make them attractive, and how to make the people wanna listen, and how you get people involved in what they are doing."

That manager commented that taking part in the training had helped him with his work managing guiding concessions because it gave him a good idea what the tour operators should be doing. However, when asked if he thought that DoC area managers should do a similar training, he replied they would need it only if they had some responsibility for ensuring the quality interpretation practices of guiding concessionaires.

The tutor provided a copy of the report and evaluation of that interpretation training workshop, and according to that, the overwhelming majority of the participants (more than $90 \%$ ) appreciated the training and would recommend it to others. However, no other similar training, focused on interpretation techniques, has been offered by DoC to tour operators since then - four years ago. 
DoC area managers from Golden Bay and Motueka areas have organized trainings to tour operators about specific topics and regulations in their areas. Tour operators that operate in Farewell Spit Nature Reserve are invited almost every year to bring their guides to an one-day training with DoC's botanist or zoologist. The DoC manager responsible for that area commented that this is a way for DoC to share information, and make sure tour guides are providing accurate interpretation. However, smaller tour operators that work in other protected areas managed by that same DoC office have not been offered a similar training opportunity. The manager explained that they have focused on the larger operators that work at Farewell Spit. Moreover, he commented that he has not received requests from the smaller operators regarding interpretation support. He noted that with the prospect of more businesses operating in Kahurangi National Park, if bicycle tours are allowed in the new management plan, they will probably organize similar trainings for that park as well.

A DoC manager at Motueka reported that before five years ago they used to meet every spring, just before the peak of the tourism season, with tour operators, boat skippers, and guides that worked in Abel Tasman National Park for a day training where they would talk about the park's organization, regulations, and emergency procedures, and they would also bring specialists to talk about specific topics:

"One year I brought a Maori elder to talk to them. I brought our DoC archaeologist in, and he spoke to them about all the historical values associated with the coast, you know, where the early pioneers were, and where the early Maori settlements were. I had our bird specialist come in another year, and he talked a little bit about birds. And another year I got the whale guy to come and talk about marine mammals."

That manager commented that he was very passionate about those training sessions, but some difficulties caused him to cease them - (discussed in section 5.6).

No trainings have ever been provided by DoC to tour operators in the Marlborough Sounds area. A DoC manager there agreed that trainings for new concessionaires would 
be helpful, but he also argued that information is easily available nowadays, and that some operators may know more than DoC. Nonetheless, that area office has been able to provided close personal support to tour operators that hold guiding concessions, by providing updated information on DoC's conservation projects, and helping to identify interpretation opportunities. The manager also commented that they have been proactive in supporting new guiding initiatives in the area helping applicants through the concession process.

A DoC manager at the regional level explained that when tour operators ask for support on interpretation, he indicates DoC specialists that they can talk to, but he noted that this happens rarely. When asked why he thinks that concessionaires rarely consult with DoC staff about interpretation matters, he stated that: "I think it's because we don't offer it, and they probably don't know it's available." He also explained that DoC staff can decide if they can afford the time to deal with interpretation issues, and that most are willing to collaborate, but they have limited time available to provide greater support.

A DoC manager in the Marlborough Sounds area commented that he often engages with tour operators to discuss regulation and to exchange information. He provides updates about native species recovery programs carried out in a couple islands (scenic and scientific reserves), and some operators provide information about the marine mammals that they are watching, According to that manager, "there has been a good exchange of information." A similar situation occurs in Golden Bay area where the small community allows for frequent engagement and information sharing between DoC managers and tour operators:

"Over a period of the year, we'll have numerous conversations with some of our concessionaires about things of mutual interest, and so there is information sharing between us and our concessionaires on a reasonably regular basis." 
Two managers from the Marlborough Sounds area commented that occasionally they review interpretation material of tour operators to check accuracy:

"some of the things we have done is help collaborate with them with some of their interpretation and information that they have, they'll sometimes come to us and run things past us to make sure that it's correct."

Only in one place in the whole Conservancy, on Maud Island Scientific Reserve in the Marlborough Sounds, DoC provides a staff member to accompany guided tours and deliver commentary. The island is only open to the public for a restricted number of trips which are operated by one concessionaire. There is a biosecurity check and no bags are allowed on the island to avoid invasion by alien species. The presence of endangered and fragile species is the reason for greater visitor controls and support. DoC staff not only accompany the tours, but before tours they also capture some rare animals, such as: the ground weta, the flex weevil, and the giant snail to show to visitors. According to a local DoC manager this is called a showcase island, and visitors appreciate it very much:

"We get a lot of good feedback with that, and I'm sure part of the success with that is that we've got DoC guys on the boat, and they advertise it as such."

According to DoC concessions managers at the regional level, the only condition related to interpretation included in the guiding concessions contracts is the requirement for the tour operators to consult with local indigenous people (Maori) before telling their stories. This condition has been recently added in the management plan of Waikoropupu Springs, a sacred place to Maori and important tourism attraction in the region. Those managers explained that having well defined conditions in the management plans of protected areas facilitate the processing of concessions applications. However, according to them this condition still has not been enforced, they do not have any 
formal procedure established for monitoring compliance, and they do not know the levels of compliance. One of them noted that this is a recent condition, and that they have just started to ask tour operators to contact local iwi (Maori tribes).

One of the regional managers described a case where a concessionaire wanted to consult the local iwi through telephone or internet because his office was far from the area, but the local iwis did not accept that, they want to have personal contacts in order to build better relationships with tour operators:

"They're really keen to get a face to face meeting, and as they stressed at the meeting I had with them, their issue really is around building a better relationship with the operators that are going to operate in an area that's so important to them."

DoC managers were asked if there were other conditions included in the concessions contracts regarding interpretation other than the requirement to consult with indigenous people. Just one manager recalled that there is usually a condition about accuracy and quality of the interpretation, but noted that it would be difficult to apply:

"There is usually a condition in there that concessionaires provide accurate, and I guess in essence we do require concessionaires to provide good quality interpretation of their activity. That's kind of loose words because it's not accurate, and defined what good quality interpretation is, so if it come to one contest whether an interpretation is of good quality, I wouldn't know what we would do."

Another DoC manager at the regional level pointed out that the conditions in the concessions contracts must be testable:

"The legal things in there are very tight. They have to be testable, so if you say you have to do quality interpretation, then what's the measure? How do you demonstrate if one hasn't breached that condition? We're very careful of not putting conditions that can't actually be detected." 
A couple of DoC managers expressed the concern of adding more conditions in the concessions contracts, they argued that this would make the application process more lengthy, the compliance monitoring more complicated, and that it would also upset tour operators. One of them argued that there are too many conditions in the contracts already. Two managers argued that the quality of interpretation should be controlled by the market forces, the businesses that do not provide good services would fail:

"If somebody is running an operation, and they are not doing it properly, then presumably they will fail, and that's the market saying no. If they really want to succeed, they are going to have to do it anyway. So, I don't know if we should be interfering into that level of the administration of these things, or if we should be telling concessionaires what they can and can't do in that sort of detail."

A DoC manager suggested that setting standards for qualification of tour guides would be an alternative, and an easier condition to be verified than the quality of interpretation delivered. However, he commented that DoC prefers not to deal with that, and that they are recommending tour operators to be Qualmark accredited, presuming that it sets standards for tour guides and interpretation services. He commented that Qualmark accreditation will be a standard condition in recreation concessions in a couple of years.

When asked if there any sanctions or incentives to promote compliance a DoC manager at the regional level said that the major sanctions would be suspending or canceling a concession if someone did something that they should not, but in Nelson-Marlborough Conservancy that has not happened. As for incentives, he explained that after 2012, when most existing concessions expire, DoC is planning to offer longer tenures of 15 years in the renewal processes. This is an old demand of the businesses, but in order to get that, the pre-requisites will be: tour operators will have to be Qualmark accredited, and they will have to have clear compliance records. So, according to him: "that is a very strong incentive to not play around and take chances." 
DoC managers said they are not expected to monitor interpretation practices of tour operators, but they usually do it while monitoring compliance with concessions conditions. DoC managers indicated two formal procedures for monitoring tour operators' practices: participant observation on tours by "mystery shoppers", and interception of guided groups inside protected areas. A manager noted that monitoring has been intensified in areas particularly under stress, like Abel Tasman National Park:

"We're putting in place much more rigorous monitoring methods over the last couple of years, so we're actually getting people out into the field, talking to every group that they see, ensuring that they actually have a permit, and that they're behaving in a responsible manner."

According to DoC (2007), there is a condition that can be included in the concessions contracts allowing DoC to send an officer to accompany the concessionaires' activities, at no expense to the Department, to assess their services. In this study area, only in Farewell Spit Nature Reserve this monitoring method has been employed regularly. However, DoC has paid for staff members to accompany the activities so that tour operators are not aware that there is an assessor taking part. The assessments are carried out by DoC staff from another office that go on the tours disguised as tourists (mystery shoppers). A DoC manager at the regional level commented that it does not make sense to expect that concessionaires should pay for the assessors' participation, according to him the monitoring method would loose its efficacy. Assessments have been carried out once a year with the two largest tour operators that work at Farewell Spit Nature Reserve. Occasionally, this method has been used in the Marlborough Sounds as well, particularly to assess marine mammal watching operations. The assessments focus on checking if operators are complying with the conditions of their concessions contracts, but they also include evaluating the interpretation provided by the guides, as well as the comments made about DoC. Tour operators are aware that assessments will happen, but 
they don't know when, and they receive a report afterwards. DoC managers that coordinate this monitoring in their area offices are satisfied with the performance of the tour operators, but one of them recalled one instance where the report pointed out some inaccuracies, and he had to correct the information being provided by the operator.

DoC managers also rely on eventual feedback from tourists about the experience they have had on guided tours. A DoC manager in the Marlborough Sounds area commented that he often meets tourists in the visitors' centre or around town and asks them about their experiences. Another manager recalled one instance that a tourist complained about the careless behaviour of one tour operator in relation to native birds, he then contacted the operator to discuss the matter.

A DoC manager at the local level pointed out that in small towns DoC staff get to know the local operators and their guides quite well. On the other hand, he noted that he usually does not get to engage with operators that are not locally based, and does not know much about their services. He also commented that DoC actually puts more effort in monitoring tour operators that are acting illegally, without concessions:

"So we do monitor illegal operators that are coming in. That's where most of our monitoring occurs, when in actual fact we should be monitoring the concessionaires that we've got."

According to DoC managers they have never assessed the quality of the interpretation provided by tour operators during the visitor surveys carried out by the Department. Most of DoC's visitor monitoring effort in the past has been concentrated on measuring the negative impact of concession operations on independent visitors. At the beginning of 2008 DoC started a new approach, assessing who was using the concessions (guiding, water taxi, accommodation, and gear hire), and whether they were satisfied with the services in Abel Tasman National Park. However, DoC only assessed overall satisfaction, and interpretation practices were not specifically targeted (DoC, 2010). 
A DoC manager at the national level commented that DoC has been working with other organizations, to raise the profile of interpretation in New Zealand:

"At the national level we have been working closely with other organizations, to try to raise the quality, providing opportunities outside DoC. Things like Interpretation Network NZ, the heavy involvement by DoC in the 2009 national interpretation conference as a corporate sponsor. That is all about trying to be supportive of the professionalization of this discipline, and to make it widely available to people. We also work closely with training providers like ATTTO, and NZQA where I am on a review team, under the tourism certificate."

He also mentioned that DoC has worked with the National Services Te Paerangi, which is based at the National Museum of New Zealand Te Papa Tongarewa, providing interpretation training opportunities for DoC staff.

When asked how satisfied he was with DoC's support to tour operators' interpretation, a DoC manager at the regional level argued that what the Department has done is good since there is no objective or outcome set for this:

"In terms of it not being central to what we do, what we did was good. I think we have to be clear: at the Department there is no objective. So, I think the department is doing as much as it can do, in so far as the outcome is not in itself to follow up, not to support the concessionaires."

\subsection{Challenges and constraints to develop and support the interpretation capabilities of tour operators, and assure quality interpretation}

The stakeholders were asked to indicate and comment about the challenges and constraints they have faced in developing and supporting the interpretation capabilities of tour operators. DoC managers were also asked about the challenges and constraints they have faced in assuring quality interpretation practices of tour operators. 


\subsubsection{Challenges and Constraints faced by tour operators in developing and to maintaining their interpretation capabilities}

Tour operators that took part in this study reported a number of challenges and constraints to develop and to maintain their interpretation capabilities:

$>$ recruiting good guides;

$>$ retaining good guides;

$>$ having enough time and resources to provide or to participate in trainings;

$>$ finding and delivering reliable information;

$>$ guides interactions with clients; and

$>$ balancing the activity element with the interpretation.

Recruiting and retaining good guides were the most common challenges faced by tour operators in developing and maintaining their interpretation capabilities. Four operators commented that recruiting good guides in New Zealand is very difficult. "That's the hardest thing I have to do, is to source guides, not just any guides, I want really good guides. "A medium size operator that works with cycling tours commented that he needs guides with a range of characteristics and abilities: hold a P2 license to drive small buses, availability to go on trips that last up to 19 days, good people skills, ability to cook, life experience, sense of humour, passion, and ability to tell a story. He then noted: "I think it's quite hard to get guides who have got interpretation skills as part of a package." A small tour operator that works with nature walks commented that guides have not invested much on their interpretation skills: "they usually haven't spend the time and effort that I've spent, and so you have to accept people for what they are."

Half of the tour operators interviewed said that retaining the guides is a big challenge. Most of them argued that the main difficulty is that guiding is seasonal work. A small operator commented:

"The hardest thing about keeping them is the sporadic work. You know, you are full on in the summer months, and in the winter you can't keep people employed. And that's probably the biggest challenge." 
Large businesses have the same problem on a larger scale, as noted by a kayak and aquataxi operator in Abel Tasman National Park:

"Well, there's no work in the winter time, and we need two hundred staff in the summer time, so how can we possible manage a business? It's extremely difficult. Yes, that's one of the major challenges."

One operator commented that another difficulty in retaining guides is the low payment they get in New Zealand. He claimed that guides in Australia make twice as much money than in New Zealand, and argued that a lot of good guides move out: "I think that we do loose a lot of people overseas, guiding as well. The sort of person that would be a good professional guide."

A tour operator that works with horse riding commented that she finds it hard to motivate the guides to come back after the first season. She explained that most guides start motivated, but once they see that the work is really hard, they usually do not come back for a second season. A dolphin watching operator commented that he is happy when he gets people guiding for three years, and noted that guiding is not a lifetime job: "If you get 3 years out of a guide it's pretty good. In the end it's not a lifetime job, most people wanna move on to something else." Another tour operator commented that guide turn over is another problem associated with the challenge of training guides: "you train people for correct interpretation, and they move on."

On the other hand, three operators said that they have not had problems retaining their guides. One operator, whose company has been working for sixty years in Farewell Spit, commented that four of his guides have been with him for more than ten years. One operator that works with cycling tours all over New Zealand said that his guides are very experienced, and that he can not afford to loose them, so he pays them very well:

"Our pay rates are such that guides can actually make a living from what we are offering them. We are probably one of the highest paying companies in New 
Zealand, and that's why we get almost 100\% return."

Another operator that works with cycling, kayaking and walking tours in the Marlborough Sounds area explained that company efficiency allows good earning for the guides and high return rates:

“We're very efficient, so it means that we don't hire a large pool of guides. We keep a very tight team of guides, and that means that they work hard, but they earn good money. We're very focused on them getting as much work as they can, so they come back next season."

One small operator commented that he spends too much time dealing with other issues, such as: accreditation schemes and DoC activity reports, that he has little time left for training his guides. Another small operator pointed out that he has limited time and resources to participate in external training courses and other extra activities.

Another small tour operator mentioned that he often finds contradicting information, and to overcome that he relies on DoC's interpretation toolkit Conservation Revealed: "It may be just the confusing avenues of information. So that's why I prefer to use the interpretation folder written by DOC. If it's in there I'll believe that, as opposed to some of the other stuff."

An experienced operator that specializes in ecology and conservation commented that tourists come to them with misleading perceptions about New Zealand's environmental situation, and that they have to correct that by telling the truth about the environmental problems of this country:

"They have been told that they're gonna go into New Zealand bush and they're gonna see all these lovely native birds. And what they've found? They've gone into the the bush, and the bush is empty."

He also mentioned that New Zealand's clean and green image, and the $100 \%$ Pure campaign are not truthful, and that tourists that are more environmentally oriented soon perceive that. 
Another young tour operator commented the importance of being honest when telling stories, and the need to make sure that the factual information provided is accurate:

"I guess the biggest thing is, if you are telling a story that's not truthful, I think it's important that people know that it's not truthful. I guess the main thing that if you are talking as though something is true or factual then to make sure you get the facts right."

One tour operator that works with kayaking tours pointed out that guide interaction with clients is a challenge. He commented that new guides with little experience sometimes are too abrupt with clients and tend to boss them around. He then explains to the guides that the clients are there for a good time, and they have to relax and be more patient. $\mathrm{He}$ noted that: "It's more about not what they say, but how they say it."

A tour operator that works with cycling tours pointed out that his challenge is balancing the activity element (bicycle riding) with the timing of the interpretation. He explained that there is a big emphasis on the activity, and that often the interpretation element is marginalized or forgotten. He said he understands the importance of interpretation, he has sent his guides to interpretation trainings, but recognizes that he still needs to do more to improve that part of the visitor experience.

\subsubsection{Challenges and constraints faced by DoC managers in supporting the interpretation practices of tour operators, and assuring quality interpretation}

DoC managers identified a number of challenges and constraints in supporting the interpretation practices of tour operators and assuring quality interpretation:

$>$ Lack of resources (financial, human, and time);

> Lack of professional development of DoC staff on interpretation;

$>$ Lack of structures and outcomes related to interpretation support and monitoring; and

$>$ Lack of conditions for tour guides' qualification in the concessions contracts. 
Lack of resources (financial, human, and time) is the main constraint faced by DoC managers in supporting the interpretation practices of tour operators and assuring quality interpretation. DoC managers at all levels, national, regional and local, pointed out that the lack of resources is a constraint of the Department as a whole. One of the managers commented that DoC's mandate is too large for the available resources:

"The problem that DoC has is that it's charged with doing much more that it can possibly do with the resources that it has, across the board, whether you're talking about ecosystems management, information delivery, recreation planning, whatever it is."

In his view all DoC services suffer from resource constraints, whereas another manager suggested that interpretation services have less resources than other services due to other priorities related to the management of environmental threats. The latter also pointed out that resource allocation decisions are politically driven, and that native bird recovery and pest control are priorities at the moment in New Zealand, leaving education, interpretation and visitor services with little resources.

One manager at the national level pointed out that if DoC staff could spend more time to support tour operator's interpretation practices, they would be able to help in many different ways:

"If staff that were in charge with looking after concessions, and looking after their interpretation practices had more time to devote to that, I have no doubt they would be happy to work closer with them to improve their product, maybe as simple as providing them with printed resources, and pointing them in the right direction, could be as far as going with them on tours, giving them tips, doing observation and things like that, so it's really about people and the amount of time they have devoted or set aside to do this work, that's the biggest limitation I think."

An area manager in Golden Bay area pointed out that he has limited time to spend with tour operators' interpretation support and monitoring because he is involved with a range of activities: 
"I'm the only person here that might have a task to do that, and my time is limited by the range of activities I'm involved in, so it's kind of a decision about how much time I want to spend doing that, which in reality is not much time."

However, that manager said he has few tour operators and guides working in his area, and that he is satisfied with the levels of support and monitoring he has been able to maintain, and with the quality of the services being provided by the operators.

In the Motueka area, where most of the tourism of Abel Tasman National Park is based, there is a contrasting situation. There are much larger levels of tourism in this area and hence greater needs for support and monitoring. However, DoC's interpretation training previously offered by the area office has ceased partially due to time limitations, despite the high levels interest, experience, and capability of local DoC staff.

In the Marlborough Sounds area, time again is a constraint to monitoring tour operator's services. A DoC manager noted that the high number of operators, both with and without concessions, the diversity of activities involved, and the large area make monitoring very complex and time consuming. He also pointed out that this is not a priority of their work, and he would need a new directive and more funding from the Department to be able to do such monitoring:

"It definitely is a worthwhile thing, but it's a little bit fringe of what we're actually here for, and unless there was a directive and extra funding to allow that to happen, it would be hard to just fit it in."

A former DoC social researcher pointed out that lack of resources and low priority are DoC managers' main constraint in giving greater support to tour operators' interpretation practices: "It's really the combination of reduced funding and how interpretation is seen as a discretionary item and not a core item." 
A DoC manager at the national level commented that in order to give greater support to tourism operators' interpretation capabilities, DoC needs to invest first in professional development of its own staff. He commented that many DoC staff do not necessarily know all the benefits of interpretation and even if the Department gave time to staff, and copies of DoC's Interpretation Handbook and Standards, they still would not be able to make much progress forward without having greater knowledge about interpretation themselves. According to him:

"providing them [DoC staff] with the knowledge and the skills necessary to be able to talk about this [interpretation], and articulate it well to their managers and to other parties is really key. This places them in a leadership role, which is very important."

One of the managers reported that in 2006 he had the opportunity to participate in a two day interpretation training workshop delivered by Professor Sam Ham (Idaho State University - USA), a world leader in interpretation. The workshop which focused on thematic interpretation, was held in the Museum of New Zealand Te Papa Tongarewa in Wellington, and was sponsored by DoC and the National Services Te Paerangi. The manager said the training was very good, and that DoC should provide more opportunities like that. He noted DoC provides a range of trainings to its staff, but not as much on interpretation:

"It isn't being given a huge amount of emphasis in the department. I mean, we do computer training, we do health and safety training, and we do fire training and stuff like that, but interpretation training it's not done particularly frequently. And over the years it has probably declined."

However, he pondered that since DoC has phased out providing personal interpretation itself, like guided walks in the former Summer Programs, the need for DoC staff to have those skills is a lot less now. However, the manager at the national level pointed out that the main purpose of providing DoC staff with more interpretation training would be to 
enable DoC to support tour operators and other groups:

"It's investment in the staff, but not necessarily so they could be delivering interpretation themselves. In this model that we're talking about, where we are working with others, the investment on the staff has more to do with supporting communities than it does producing our new products."

According to a DoC manager at the regional level DoC does not have proper structures nor stipulated outcomes to deal with tour operators' interpretation practices. He commented that if DoC decides to get more involved in supporting and monitoring tour operators' interpretation practices, it will be necessary to set up organizational structures and clearly specify the desired outcomes.

A DoC manager at the regional level pointed out that there are no stipulated standards for tour guides' qualifications in the concessions contracts, apart from first aid. He believes setting standards would assure quality guiding, but concessionaires need to understand and agree with new standards:

"Tourism is a very vital part of New Zealand economy, and we can't afford to have somebody who is delivering a service of poor quality. So, I'd like to see some standards introduced, but concessionaires have to understand the reasons why we are doing that, and not fight against it."

A DoC manager questioned the viability and fairness of setting conditions regarding tour guide's proficiency or skills in the concessions contracts:

"How do you judge a person to be the right person or the wrong person to do a job like that? Do you base it on their academic qualifications or do you base it on their experience and time in an area, or you know, on the fact that they can speak a language or you know, it'd be pretty hard. I don't see how we could. We can't tell people [tour operators] how they can employ their staff, I don't think."

A DoC manager at the local level indicated that the lack of a legal requirement making guides trainings mandatory is a constraint. He commented that one of the reasons he 
gave up offering interpretation trainings to tour operators was the low attendance rates.

He explained that it was difficult to find time when all guides could participate since the tour operators had different starting periods, and many of the guides arrived in the peak tourism season and were not available for training then. He argued that making such trainings mandatory would solve the problem of attendance, and it could increase the credibility of the country's tourism industry:

"We haven't formalized it to the extent where we've made it necessary or mandatory or highly desirable, but I can see a time when maybe it should be. Then it helps to build, I guess, the credibility of the New Zealand tourism product."

That same manager pointed out that DoC is incorporating Qualmark accreditation in the concession system in order to raise the quality of services provided by tour operators. He said he expects Qualmark to include criteria related to interpretation:

"One of the things that we're trying to do is raise the quality standards of the concession operators. And part of that is through Qualmark, and interpretation would be one of the things that they're scored on: whether in fact they provide interpretation training for their staff, do they provide information, and will they select some of their guides that have a passion for interpretation. They haven't developed it at this stage to that extent, but those are the sort of things that I would like to see in there."

\subsection{Views on their relationship and on the concession system}

The stakeholders were asked how they viewed their relationship, and what the positive and negatives aspects of the concession system were. Their relationship is largely influenced by those aspects.

\subsubsection{Tour operators' views on their relationship with DoC and on the concession system}

Views on the relationship with DoC: 
The great majority of the tour operators interviewed reported having good relationships with DoC managers, particularly at the local level where there is closer contact. The relationships at the regional level, with DoC's conservancy office, are mostly about concessions processing, and the often lengthy process is a major source of distress. Difficulties with the concession system are discussed in more detail in the next section. Tour operators did not report having any relationship with DoC at the national level.

Tour operators noted that their relationship with DoC has improved, and most praised DoC's work in general, acknowledging its large mandate and limited resources. The work of the Concessions Supervisor based in the regional office was widely appreciated, particularly for his efforts in keeping contact, listening to tour operators, and adopting a proactive attitude. However, there were also reports of a number of difficulties in the relationship between tour operators and DoC managers.

A few operators indicated that communication levels with DoC managers could be improved. One operator pointed out the importance of communication:

"Communication is key to good relationships. You can solve all problems if you have communication. If the relationships are good it means the business is good."

Although good levels of informal meetings and communication were reported, particularly at the local level, many tour operators felt the need for regular and more structured meetings with DoC. Operators suggested DoC should hold regular meetings at the beginning and at the end of the tourism season. One operator in the Marlborough Sounds argued that due to high staff turnover it would be very important for DoC to hold annual meetings at the beginning of the tourism season to make sure everyone knows what the rules are, and to give orientation related to interpretation. Another operator pointed out the different functions of the pre and post annual meetings 
(briefing and debriefing): at the beginning of the tourism season the meeting should be focused on guides' training, and at the end it should be an evaluation of the season.

One operator praised DoC's work, and commented that the Department has improved its understanding and attitudes towards businesses:

"I think that DoC does a very good job. They have their constraints, but with what they are doing they do it very well. They have improved enormously over the last 10 or 12 years. They are getting a better idea of commerce, they are not as anti-business as they used to be."

However, another operator believes that some DoC staff are still against businesses:

"I think that there's this thought that as soon as you are a commercial operator in the park, you're raping the system, you shouldn't be there. And that's very much the feeling you get from some DoC people."

One operator disapproved of DoC's incognito monitoring system (mystery shopper) feeling that it showed mistrust. Another operator expressed resentment because DoC had changed its position regarding a specific action they had agreed upon, causing him to loose investments and trust in DoC.

Positive aspects of the concession system according to tour operators:

Tour operators mentioned a few positive aspects about the concession system:

$>$ provides legal access to protected areas;

$>$ protects from random competition;

$>$ enhances business reputation;

$>$ avoids overuse of protected areas; and

> guarantees quality of visitor experience.

A couple of tour operators commented that a concession is a privilege, and it provides a 
legal access to be able to work in the Conservation Estate: "Without it we wouldn't be able to run the business in the Park."

Some tour operators pointed out that the concession system protects them from random competition. One operator commented that:

"It enables us to work in an environment where someone can't just come along, at any time, and set up a company next door to us; unless they sort out a concession with DoC, and that takes some time and investments."

A few tour operators noted that a concession enhances the business' reputation, and it provides an advantage over other businesses. One operator commented that:

"I think that when people see concession holders they say: ok, these people have a concession they must be pretty switched on about what they are doing, and the overall tour will be better than the guy that doesn't have one."

A few tour operators mentioned that the concession system helps to avoid overuse of the protected areas, minimizing the impacts on the environment and on heritage values. One operator commented that "it's a system where people are getting the use that they can, but without the park getting over run."

A tour operator pointed out that the concession system is a mechanism used by the government to guarantee the quality of visitor experience. Another operator commented that "it keeps the services at a professional level."

Negative aspects of the concession system according to tour operators:

Tour operators indicated a number of negative aspects or difficulties with the concession system:

Little support to interpretation;

Lack of consistency in DoC's support to interpretation;

$>$ Lack of standards to interpretation;

$>$ Lengthy concession processing;

$>$ Insecurity of present concessions;

Short tenure; 
$>$ DoC's support to businesses economic viability;

$>$ Costs and business growth restriction;

$>$ Limited concessions and tradable quotas;

$>$ Lack of monitoring commercial activity limits;

$>$ Lack of consistency in marine mammal permits;

$>$ Lack of charges and controls over tour operators that drop off tourists in protected areas; and

Differential treatment of guided versus unguided visitors.

A few operators commented that DoC should provide more support to interpretation. A couple of operators commented that if the Department was more efficient in some of its process it would have more resources to spend on interpretation support. A tour operator in Golden Bay believes the local DoC office needs a bigger budget for interpretation:

"DoC needs a bigger budget for DoC's interpretation, they need to have a bigger budget for information. Because that's what we're all selling, and they take their concessions fees."

That same tour operator argued that the money paid by the concessionaires to DoC should be invested in the areas they operate:

"This needs to be seen to be going back into the areas, not just going up to Wellington and being absorbed by the government. I get quite annoyed at that actually. The guys [DoC managers] in the base here are struggling."

Another operator in Golden Bay said he has asked DoC for an interpretation panel for an important historic site, but DoC replied that it does not have the resources.

Two small tour operators commented that DoC used to have regular annual meetings with the tour operators in Golden Bay and Motueka areas. However, according to those operators the meetings in Golden Bay have not happened every year, and in Motueka (Abel Tasman National Park) the meetings were discontinued many years ago. Moreover, in both areas DoC has maintained greater contact with the larger tour 
operators, leaving the smaller operators with little support.

One operator pointed out that the concession system sets no standards for interpretation:

I think that it does need to be something with interpretation in there. Is it at a basic standard? Is it at a basic level?

All tour operators that participated in the case study have had their concessions for a number of years, so the issues related to concession processing did not come up frequently. Only one tour operator commented on a new concession he has applied for. It is for a new journey program that covers multiple conservancies, and this seems to be the main reason why it has taken so long:

"I started the process seven months ago, and I haven't got anywhere. It's incredibly frustrating. Massive bureaucracy, a nightmare, and they claim that a One Off is a really easy and quick one. It's unbelievable!"

The operator also commented that he thought that by having a very long and good relationship with DoC things would be easier.

A small operator pointed out the insecurity of present concessions, and the risk of big companies overtaking if a tender process for granting concessions is introduced:

"The negative is that you could lose it on a review, and we really need it reinforced that we are not going to be put out. And we really need that security. And that really worries me, that the next director general might say that we're going to have a tender system, and all you end up with are big companies operating. And I think they're heading that way."

Another tour operator explained that assurance in the continuity of a concession is important when getting bank loans to invest in the business:

"That is a huge thing for tourism. We have to be able to go to banks with assurance that we will still have a business at the end of our concession period, 
and that it will be rolled over."

A couple of tour operators felt that the present concession tenure is too short. One tour operator commented that DoC should provide greater support to concessionaires since they contribute a lot to the local economy and to the protected areas where they operate:

"I think concessions should be for a longer term. I think there should be more support given to concessionaires. I think as a concessionaires we contribute a hell of a lot to the region and to the park that we operate in."

One tour operator commented that until recently DoC did not care for businesses economic viability, increasing competition and diminishing market share by granting new concessions. He also commented that there is not a single clause in his concession contract where DoC has any responsibility back to him:

"DoC has never held any responsibility to me as a concessionaire, they don't even have the requirement to advise me of a new concessionaire coming in to do the same activity as I'm doing."

However, the operator pointed out that the situation is changing, and DoC has set limits to commercial activity in Abel Tasman National Park, and is planning to do the same in the Heaphy Track in Kahurangi National Park. Although the main reasons to set those limits are related to controlling the impacts on the environment and on the visitor experience, they also benefit the present concessionaires by avoiding new competition and increasing the value of the existing concessions:

"My concession now is becoming valuable. I can sell that concession, whereas before I couldn't sell that concession because it was too easy for new people to get new concessions."

Another operator commented that DoC can help to guarantee the value of his concession by enforcing the legislation and curbing illegal tour operators that do not hold concessions:

“...having DoC do something about making sure my costs actually can be 
translated into a value. And they can only do that by stopping everybody, so that's enforcement. You know: I pay, they enforce"

One operator pointed out that there is a significant cost in getting a concession, and that the limits imposed in the concession forbids his business from growing:

"The negatives is that it's not a cheap exercise to have one, and things like the growth of your business is governed by the concessions you have."

One tour operator commented some areas have very limited concessions and many times the existing quotas are not being used. He argued that those quotas should be tradable so that other tour operators can use them. This system has been recently implemented in Abel Tasman National Park.

One operator commented that DoC has not monitored the new quotas set to commercial activities in Abel Tasman National Park:

"There's been no monitoring since the issuing of packets. So that would be my major concern at the moment: is that people who have been allocated a certain percentage of the activity stick to that percentage."

One tour operator commented that DoC has different marine mammal permit policies for different regions, and he believes that is not justified nor fair:

"The biggest problem we have with DoC is the marine mammal permits, because what is allowed here is not what is allowed elsewhere. And that's frustrating because, speaking of interpretation, we have to tell people we're not allowed to swim with Hector's Dolphins here in the Sounds, but you can do it down in Akaroa. They are not consistent with certain policies, and that makes me crazy."

That same operator also pointed out that many tour operators that provide water transport in the Marlborough Sounds engage improperly with dolphins: 
"These other guys that don't actually have a permit, that run people out to resorts, they have no idea what the regulations are, it's just like a big free for all out there in the water, as far as driving around dolphins."

He commented that some of those tour operators have Opportunistic Permits, which means they can stop to watch dolphins if they see them on their destined route. However, according to him they often will go way out of their course, chasing dolphins, and driving right through them at speed. He pointed out that: "here in the Sounds there's absolutely no enforcement whatsoever, which makes me crazy."

One tour operator commented that in Motuara Island Scenic Reserve many tour operators that do not hold concessions just drop off tourists in the Island, while he has to pay for a concession to guide people there. He argued that the clients of those operators behave carelessly causing impacts on the Reserve, while his guides make sure visitors cause minimal impact and get good information. He believes that this situation is unfair:

"It seems totally backwards, they should be paying to drop people off that have no regard for the actual rules of the Island and all that, and yet it's the opposite... it's almost like we're penalized because we guide people on the Island, and that makes no sense whatsoever."

Two tour operators commented about the different treatment DoC gives to guided versus unguided visitors. One of them pointed out that unguided visitors or free independent travellers (FIT) get a free ride in New Zealand, while guided visitors have to pay to visit the Conservation Estate. He said this situation is unfair, and suggested that either everyone should pay, or no one should. The other operator commented that, in case of overcrowding, the current legislation only allows DoC to stop guided visitors:

"Concessionaires will always be the people that get stopped from doing something, and that's because if there's an issue of overcrowding or something like that, they can't stop the general public, so the only people they can stop are the guided visitors." 


\subsubsection{DoC managers' views on their relationship with tour operators and on the concession system}

DoC managers were asked how they viewed their relationship with tour operators, and if they had any suggestions to improve the concession system. Most relationships with tour operators occur at the local level, with DoC managers at the area offices, and generally they maintain good relationships. DoC managers indicated a few positive aspects of the concession system, but also some negative aspects or difficulties.

Views on the relationship with tour operators:

A DoC manager responsible for interpretation matters at DoC's Head Office in Wellington said that he usually does not engage directly with tour operators. At the national level DoC has been working with other organizations (Interpretation Network New Zealand - INNZ, the National Services Te Paerangi, the Aviation, Tourism and Travel Training Organisation -ATTTO, and the New Zealand Qualifications Authority NZQA) to provide opportunities and to raise the quality of interpretation in the country. Is terms of the relationship with tour operators, he noted that they rarely seek information from him:

"Every once in a long while I get requests from people coming directly to me saying: we want to know about certification, or professional organizations, where to go?"

That manager commented that the levels of engagement between DoC and tour operators at the regional level varies across the country, and that depends on needs, resources, and demand:

"There's that saying that the squeaky wheels gets the grease, and tourism operators that are really proactive, and are asking for things, and are engaged, they make a difference in getting the attention of the organization, and they often can get your attention and resources aimed at them." 
At the regional level, on Nelson-Marlborough Conservancy Office, where the concessions applications are processed, most DoC concessions managers rarely engage personally with tour operators, but they do exchange communications with tour operators while their applications are being processed. However, according to a DoC manager at that office, the Department wants them to build those relationships:

"While we're still process-focussed, there has been a push for this strategic direction, for us to get out there and start building the relationship with our clients, and we're doing that, but it's still within the constraints of following a process, rather than achieving an outcome and using whatever means to get there."

At the regional level the Concessions Supervisor actively engages with all tour operators during planning, monitoring, and training events. He commented that the main improvement in the way they have been dealing with concessionaires is moving from a reactive to a proactive mode of operation. He explained that in the past $\mathrm{DoC}$ was always trying to respond to endless demands and issues as they appeared, but recently they have concentrated on proactive and participatory planning, setting the desired outcomes and the necessary regulations to achieve them. The best example of that is the new management plan of Abel Tasman National Park, approved at the end of 2008, where a new system of quotas has been established in order to limit commercial activity in the Park. This system was intensely discussed with tour operators on a one to one basis in order to avoid conflicts, and to obtain their cooperation. The main goals were to enhance the quality of visitor experiences, to guarantee sustainable tourism businesses, and to improve the conservation of the natural resources. According to the Concessions Supervisor that experience has been very successful:

"We work very closely with the operators, the operators are open to us, and they make suggestions of how things can be changed, to the good of the whole park, and what we're achieving is sustainable tourism. By creating some ground rules we have a park that works, from four years ago a park that didn't work." 
At the local level DoC managers commented that they maintain good relationships with tour operators, and they reported that there are frequent informal contacts with tour operators that are locally based. A DoC manager in Golden Bay commented that there is a lot of information sharing during those contacts:

"Some of the concessionaires have relationships with staff in this office, either formally or socially. Over a year we will have numerous conversations with some of our concessionaires about things of mutual interest. So, there is information sharing between us and our concessionaires on a reasonably regular basis, certainly the ones that operate from Golden Bay area. I think there is quite a lot of information goes to and from on that basis."

That manager also commented that there are few businesses operating in Golden Bay, most small and locally based, and because of that they have been able to develop good relationships and high levels of trust. He speculated that in areas with more activity and where operators are not locally based, the relationships would be more difficult:

"I can imagine being in a site where we have a much higher level of concession activity, particularly of concessionaires that are based outside of your area and having a good relationship with concessionaires would be harder and also establishing good dialog, communication, or level of trust would be much harder."

The other two areas included in this study, Marlborough Sounds and Motueka, do have higher levels of tourism activity and concessions. A DoC manager in the Marlborough Sounds pointed out that he has a very close and good relationship with the local concessionaires, but he is not able to engage with the ones that are based outside his area, nor with the operators that do not hold concessions. In Motueka area, particularly in Abel Tasman National Park where most of the concession activity is concentrated, all tour operators hold concessions, and most are based in the area. A DoC manager in Motueka commented that personal engagement with tour operators is the main part of his concession work: "at an area level, most of the concession work that I do is focused around the day to day relationship with the operations on the ground." 
A DoC manager pointed out that in the past some DoC staff had an anti-business attitude, but he believes concessionaires are important DoC advocates, and this attitude has helped with his relationships with tour operators:

"When I first started working for the department, there were a lot of people that saw commercial operators as sort of the enemy. They were competing. But really, in actual fact, concessionaires who are providing a good service are some of our best advocates. Locally we've always had that attitude, and that is, I guess, why we get on so well with the operators."

Another DoC manager indicated that the key to a good relationship is being able to understand each others perspectives:

"It just requires I guess a better understanding about where each of them is coming from. So by us being able to tell commercial operators a little bit about what restricts us, you know, the national park legislation, management planning, the general policy for national parks and a whole range of things; and then it's us also understanding what's some of the constraints around business: turnover, and margins, fuel costs, market share, and advertising. They're all huge costs that put a lot of pressure on businesses and they are all trying to stay viable."

On the negative side, two DoC managers commented that there has been a couple of instances where tour operators have criticized DoC to tourists, either because of restrictions of access or charges that they have had to pass on to tourists.

Positive aspects of the concession system according to DoC managers:

DoC managers indicated a number of positive aspects about the concession system:

$>$ it enables DoC to transfer to private sector a service that is not its core role;

$>$ it allows information and interpretation delivery to a wider public;

$>$ it helps to mitigate visitor impacts in protected areas; and

$>$ It helps to control activities, and to assure quality visitor experiences. 
A couple of DoC managers commented that the concession system enables DoC to pass on to the private sector a service that is not part of its core role. One DoC manager noted that DoC does not have the resources to invest in guiding:

“We don't have the resources to do the job ourselves, then we've got to make sure that the public get the very best possible service, and generally speaking you get that here."

Another DoC manager commented that concessionaires help DoC to provide information and interpretation to the public:

"From DoC's point of view, having concessionaires interpreting their walks or trips is useful for us, cause it's a way of getting information to people that we might not get in touch."

The same manager pointed out that the concession system helps DoC to mitigate the impacts of visitors in protected areas without the personal involvement of DoC staff:

"By having concessionaires taking people we can assure that visitors to Farewell Spit are adhering to a code of standards, and to the conditions we set to the concessionaires. So, we have the ability for the people to visit the site without actually having to do the management of those people ourselves."

A DoC manager pointed out how the concession system helps to control activities, and to assure quality visitor experiences:

"In Abel Tasman, we have a really good situation where we've now got better control over activities on the water and foreshore, we've got a new-style management plan which talks about our outcomes for place, and that's all about trying to manage it for a particular experience, if you've got a remote zone you don't see as many people..."

Negative aspects or difficulties of the concession system according to DoC managers: DoC managers commented on a number of negative aspects or difficulties of the concession system: 
$>$ lengthy concessions processing;

$>$ lack of standards for quality guiding services; and

> low levels monitoring (quality of services provided by concessionaires).

A couple of DoC managers commented on the lengthy concession processing, which is the cause of many conflicts with tour operators. A DoC manager explained why some processes take such a long time:

"I think that the ones that are particularly difficult are concessionaires that want multi-conservancy concessions, and so then there's a consultation right across all the conservancies, and down to area offices. And by the time it goes all the way to the bottom and back up again it takes months, which it shouldn't be, and I don't find that acceptable at all."

To minimize that problem DoC is implementing a new category (Conforming NonNotified Process) to streamline the process by not requiring consultation with DoC area offices. According to a DoC manager this category will be implemented in places that are not of particular concern, and where concessions use is indistinguishable from overall visitor use. He explained how this process works:

"They call it Conforming Track Schedule, which is saying these tracks, these sites, so long as you meet certain conditions, which is things like party size, might be frequency of visit, or something like that, if you meet those criteria then you are in. ... So, I expect in the next year or so we will be able to provide a quicker service."

Presently, only the safety standards are well established in the concession system through the requirement of audited safety plans. A couple of DoC managers commented that they would like to see more standards introduced in the concession contracts in order to assure quality services, and indicated that this will be done through Qualmark:

"I think, in future there may be more standards that will be put into those concession agreements, which they'll have to aspire to. One of them, for the kayakers out here will be to meet the Qualmark standards. And that will drive the quality for us." 
One manager pointed out the need to have standards for guides' qualifications:

"It would be nice to have some kind of measure of some kind of qualification to guiding. To me, I recognize that concessions on conservation land are a big part of New Zealand tourism industry, and there has to be same standards there."

Another Doc manager commented that in the future a tender process will be introduced in Abel Tasman National Park, and that will help to assure quality operators:

"In the future we're going to get into a situation of competitive tendering for guiding opportunities in the Abel Tasman. And that'd be one way which we'd be able to differentiate good operators from not-so-good operators. If a good operator is good business acumen, has given good return, has a sharp P.R. campaign, and has got good trained guides, has demonstrated good environmental practice, a whole range of things like that."

A DoC manager noted that monitoring has not been a big part of the concessions process, and that most of it has been concentrated on checking if commercial activities are properly authorized, rather than assessing the quality of the services provided by existing concessionaires: "a critical part is measuring business satisfaction, and we haven't yet developed that bit." A DoC manager at the Marlborough Sounds commented that a difficulty in monitoring is that there are many tour operators in his area that do not hold concessions, but drop people off in protected areas:

"A lot of the operators merely drop people off, and they don't guide them, so that doesn't constitute a concession. So, that's quite a difficulty for us to manage, because it's hard to keep track of who all the commercial operators are."

He said that they are trying to solve that problem, but there are legal constraints. He also acknowledges that this situation is a source of conflict with the existing concessionaires:

"We have been trying to close that anomaly, but we haven't had much luck because of the different by-laws that we have to work by. And there are indeed our own policies, within our own act, that we are basically guided by. And that does cause a conflict with some of the operators who are concessionaires" 


\subsection{Participant observations}

Since it was possible to do only two participant observations during guided tours, the findings are not representative, but they provided some insight into interpretation practices in the study area. The two guides observed were senior guides, one was the only guide and owner of a small tour operator that offers scenic tours and short walks throughout Nelson-Marlborough Conservancy, and the other was a guide and skipper for a large tour operator that offers aquataxi tours around Abel Tasman National Park. The guides were very experienced and knowledgeable, and provided a fine service. However, neither guides made use of effective interpretation principles such as TORE: Thematic, Organized, Relevant and Enjoyable. The guides spent most of their time telling isolated facts and failed to make use of strong themes and narratives. Neither guides attempted to identify particular interests of their audiences, nor to make connections between the objects of interpretation and the audiences' background. The guides also failed to engage the audiences by asking questions, or promoting interactivity. Finally the guides did not provide much information about the significance of the protected areas visited, nor about the conservation efforts to maintain and enhance those areas. Although the tours observed were generally entertaining, the educational aspect was reduced, and no memorable messages or ideas were passed on to the audiences.

\subsection{Conclusion}

The case study allowed an in-depth investigation of the attitudes, actions and challenges faced by the two stakeholders in developing and assuring quality interpretation practices by tour operators. The interviewees demonstrated different levels of understanding about interpretation. While all participants were able to list a number of benefits of interpretation, only a few commented about the techniques of interpretation. The 
findings from the participant observations reinforced the perception that many tour guides do not fully understand the principles of effective interpretation, and are missing the opportunity to deliver more memorable and educative visitor experiences. The reason behind that deficiency seems to lie in the fact that few tour guides have had interpretation training, and their practices are based mostly on natural communication abilities and experience.

Nonetheless, both stakeholders concur that interpretation is an important aspect to guided tourism activities in protected areas, and to the visitor experience. Half of the tour operators interviewed pointed out that interpretation is the point of difference of their businesses. However, other aspects of their services were ranked as more important than interpretation, namely: safety and organization (logistics) of the trips. DoC managers revealed that although they value interpretation, it is not a priority nor a requirement of their concessions related work.

Collectively, the stakeholders reported a wide range of actions to develop and support the interpretation practices of tour operators and to assure quality interpretation. Most of the actions reported by the operators were related to providing information and training to their guides. Many different sources of information are used by them to inform their interpretation programs. DoC has provided different types of material that support the interpretation practices of tour operators, such as: on-site panels, brochures, maps, website, and a comprehensive interpretation toolkit. DoC has also provided some good training opportunities, but some of those have been discontinued and others have not been offered on a regular basis. The three areas investigated, Marlborough Sounds, Motueka, and Golden Bay have had different levels of interpretation support and monitoring from DoC. 
The stakeholders have faced a number of challenges and constraints to develop and monitor the interpretation practices of tour operators. Tour operators face a major challenge in recruiting and retaining qualified tour guides. The main reasons are the low availability of guides with multiple skills, and the seasonality of the tourism businesses. Some operators find it difficult to provide and participate in trainings due to lack of time and resources. Lack of time, and difficulties in timing and attendance are some of the difficulties faced by DoC in order to provide training opportunities to tour operators. Lack of time and resources, as well as lack of clear conditions and standards in concessions contracts are the main constraints DoC face in order to monitor the interpretation services provided by tour operators. DoC managers that deal with concessions at the local level explained that they have many other competing roles, and that they have very limited resources and time to deal with interpretation support and monitoring.

Overall, tour operators and DoC managers have good relationships in NelsonMarlborough Conservancy, particularly at the local level. However, some individual dissatisfactions were detected, mostly from the tour operators, these were related to: incognito monitoring, change in agreement, lack of support, lack of monitoring, inconsistency in permits, and lengthy concession application process. Another important factor affecting their relationship is the location of the tour operators' offices, those that are based at the area where they operate have a closer and better relationship with DoC.

The stakeholders reported a number of positive and negative aspects about the concession system. Tour operators identified many more negative aspects than positive ones, but DoC managers comments were more balanced. Both stakeholders indicated that the system helps to protect the environment and to assure quality visitor 
experiences. Tour operators pointed out that it provides legal access to protected areas, enhances their reputation, and protects them from random competition. DoC managers noted that the system enables DoC to transfer to the private sector a service that is not its core role, and it allows information and interpretation delivery to a wider public.

On the negative side, both stakeholders commented about the lengthy concessions process. However, the new management plans for protected areas containing well defined outcomes for visitor management, and clear parameters for concession activity have facilitated the concessions process. Moreover, DoC is implementing a new category of concession that will streamline the process. Other deficiencies of the system noted by both stakeholders were the low levels of monitoring, and the lack of standards for quality guiding services. Tour operators were concerned with the short tenure and the insecurity of the present concessions. Finally, a couple of tour operators commented that the concession system is unfair since it imposes charges on guided tourists, but not on free independent tourists; and also because many tour operators without concessions just drop off visitors in protected areas without any controls or charges. 


\section{Discussion and Conclusion}

This chapter compares the attitudes, actions and challenges reported by guiding concessionaires (tour operators) and resource managers (DoC concessions managers) in the two phases of the research - a national survey in New Zealand and a case study in Nelson-Marlborough Conservancy. It brings together and compares the findings of the two phases, using the four objectives as a structure. This chapter also relates the findings back to the literature reviewed, and presents the implications of the findings for the management of guiding concessions and their environmental interpretation, as well as for future research.

The major strength of this research was the mixed method approach which added breadth and depth to the investigation. The national survey allowed the identification of existing conditions and issues, providing insight into the situation at a national level; while the case study enabled a more detailed investigation of the issues and their causes.

\subsection{Perceptions on the importance and benefits of environmental interpretation}

Most tour operators and DoC managers, both in the national survey and in the case study, demonstrated good understanding about interpretation, particularly about its purposes and benefits. Some of the most common expressions used by the participants to describe its purpose, such as: to promote understanding about the place, and to provide meaningful experiences, are key aspects of interpretation indicated in the literature (Tilden 1977; AHI 2009). Most interpretation benefits indicated by tour operators, in both the national survey and case study, were also indicated by DoC managers. Both stakeholders mentioned a number of benefits of interpretation to the visitor experience, to the environment, and to socio-cultural aspects. However, while operators pointed out the economic benefits of interpretation, DoC managers indicated 
that it helps to promote conservation advocacy and public support to the Department. Both stakeholders were actually indicating that interpretation helps them to achieve their organizational goals: economic returns for tour operators, and heritage conservation for DoC. Indeed, this is one of the main purposes of interpretation according to the literature (Weiler, 2005; Ham and Weiler, 2005; NAI, 2009). Most of the benefits of interpretation reported by the participants in this research fall into the first three of the four broad categories identified by Ham and Weiler (2005, p. iv). Those categories are:

$>$ enhancing visitor experiences;

> strengthening public relations;

$>$ protecting the site from visitor impacts; and

> protecting visitors from on-site hazards.

However, none of the participants indicated that interpretation also helps to protect visitors from on-site hazards. Apparently they do not realize that this is the case when they provide briefing instructions prior to the activities. Tour operators and DoC managers also reported some interpretation benefits that do not fall into any of the four categories identified by Ham and Weiler (2005), these were: the economic benefits to businesses and to the tourism industry, and the socio-cultural benefits to indigenous peoples and tour guides.

In the national survey most DoC managers and tour operators regarded interpretation as important or very important, but both perceived it as less important to the other party. For most tour operators that replied to the survey, interpretation is a major part of their guiding services, whereas for most DoC managers it is a minor part of their concessions related work. The case study revealed a similar situation, but it also enabled identification of other competing priorities. Despite the high importance with which tour operators regarded interpretation, other aspects of their services were often ranked 
as more important, with safety as the most important aspect, followed by trip organization. Nonetheless, half of the tour operators interviewed pointed out that interpretation is the point of difference in their businesses. DoC managers interviewed pointed out that there are no outcomes expected from them regarding interpretation support, and it is considered a discretionary activity that gets little attention due to other priorities. However, some DoC managers argued that the Department should put more emphasis and resources into interpretation support to tour operators, since they are providing an important service that has been transferred from the government to the private sector.

Most participants in both phases of this study emphasised the content aspect of interpretation, citing the different topics, such: as fauna, flora, history, and indigenous culture. Some tour operators also indicated that good interpretation should focus on telling stories rather than facts. However, few participants demonstrated understanding about the principles of effective interpretation, such as TORE: Thematic, Organized, Relevant, and Enjoyable (Ham in DoC, 2005). Few participants commented about specific techniques necessary to deliver quality interpretation, such as: the use of strong themes; the use of organized narratives; the exploration of relevant topics to the audience; and the engagement of the audience through questioning and interactivity.

\subsection{Actions employed by both stakeholders to develop the interpretation capabilities of tour operators}

The national survey and the case study revealed that both stakeholders have undertaken a range of actions to develop the interpretation capabilities of tour operators. Most actions employed by tour operators were matched by corresponding DoC supporting actions. Part of the literature and internet sources used by the tour operators to inform their interpretation programs is provided by DoC, such as: the interpretation toolkit 
Conservation Revealed, DoC's brochures, and DoC's website. Some of the tour guides' training opportunities were provided by DoC, such as: the interpretation workshops in 2006, and the annual trainings in some conservancies and areas. Parts of the supporting material prepared by tour operators were based on DoC's information, and at least some have been reviewed by DoC managers. Finally, DoC managers are among the third parties consulted by tour operators.

While the results from the national survey may give the impression that all the actions reported to develop tour operators' interpretation capabilities are widespread, the case study revealed that different areas experience different levels of action. While DoC's office in Golden Bay has been able to maintain frequent contact with tour operators and to provide training almost every year, the Marlborough Sounds and Motueka offices have not. The lower levels of concessions activity in Golden Bay have made it possible for DoC to maintain greater levels of support and monitoring compared to the other two areas. Distinct environmental characteristics, as well as different quantities and types of protected areas have affected the needs and the levels of support and monitoring. The greater quantity, variety, and dispersal of protected areas in the Marlborough Sounds have made DoC's support and monitoring even more complex and challenging.

The national survey revealed a range of satisfaction levels with DoC's support to interpretation. A few tour operators indicated that they were totally satisfied with DoC's support, but no DoC manager was totally satisfied with DoC's support. More than half of the tour operators and half of DoC managers that participated in the survey were much or somewhat satisfied with DoC's support. Approximately one quarter of the tour operators and of the DoC managers that took part in the survey were just a little or not at all satisfied with DoC's support to interpretation. In the case study it was possible to 
gain some insight into the reasons for the levels of satisfaction with DoC's support. Tour operators that have closer relationships with $\mathrm{DoC}$, such as the ones that are locally based, and those that participate in conservation projects have received greater support and are more satisfied. Most DoC managers argued they are satisfied because interpretation support is not an expected outcome of their roles, and the levels they have been able to provide is good enough under these conditions. However, some DoC managers commented that there is much room for greater support, and if the Department gave them a new directive then the current levels are not good enough.

In the national survey and in the case study DoC managers mentioned three types of actions to assure the quality of tour operators' interpretation practices: putting conditions in concessions contracts; monitoring tour operators' services; and, although rarely done, reviewing tour operators' interpretation materials. The case study revealed that the only condition related to interpretation included in all guiding concessions contracts is the requirement for tour operators to consult with indigenous people (Maori) before telling their stories. However, according to tour operators and DoC managers there are no formal mechanisms established to do that consultation, nor to verify if it has been done. Only one DoC manager mentioned another condition in the concessions contracts related to the accuracy and quality of the interpretation, but he noted that there are no parameters to judge that, and it would be difficult to apply it. A DoC manager suggested that including a condition about tour guides' qualification could provide some assurance to quality interpretation. Finally, a few DoC managers commented that Qualmark accreditation will probably become a requirement for all concessionaires, and they are hoping that it will include criteria for interpretation standards. 
Due to the low levels of monitoring, most DoC managers in the national survey were not able to comment on the quality of the interpretation delivered by tour operators. The case study revealed that only in the Golden Bay area, more specifically in Farewell Spit Nature Reserve, has there been periodic evaluations of the services provided by tour operators with the use of mystery shoppers. In the other two areas investigated, Marlborough Sounds and Motueka, DoC managers noted that through informal contacts with tour operators, guides, and tourists they have been able to assess the services provided, and they reported satisfaction with the quality of the services delivered by the local operators. However, one local DoC manager pointed out that he does not have contact with tour operators that are based elsewhere but operate in his area, and that he has not been able to assess their services.

\subsection{Challenges and constraints faced by both stakeholders in developing and assuring quality interpretation practices by tour operators}

The national survey and the case study revealed that the lack of human resources is the greatest constraint faced by tour operators and DoC managers to develop tour operators' interpretation capabilities. However, while DoC's constraint is caused by the lack of time to deal with interpretation support due to competing priorities, tour operators' constraints are caused by the difficulties in recruiting and retaining qualified tour guides. Tour operators pointed out the difficulty in finding tour guides who posses multiple abilities, including interpretation skills. The case study revealed that the seasonality of tourism activity is the main factor causing high turnover of tour guides.

Some tour operators noted that due to high turnover, annual training is necessary. However, both stakeholders reported difficulties with training. Small tour operators commented that limited time and resources is a major constraint to provide or to participate in training. DoC managers commented that other priorities leave them with 
little time and resources to organize training for tour operators and their guides.

However, there has been some successful training experiences, both at the national and local levels. The national survey identified the series of interpretation workshops provided in 2006 by DoC to tour operators with resources from the Ministry of Tourism. The case study revealed that DoC's area office in Golden Bay has held meetings, almost every year, with local tour operators both for training and evaluation purposes. DoC's area office in Motueka had previously offered annual training in Abel Tasman National Park, but this has been discontinued due to resources constraints and difficulties in timing and attendance. Tour operators commented that other DoC conservancies (Southland and Canterbury) hold annual meetings. Annual pre-season training was the main suggestion from tour operators interviewed in the present study.

The national survey revealed that both stakeholders face some challenges related to cultural interpretation. They cited difficulties in gaining agreement from indigenous people (Maori) for tour operators to be able to tell their stories in Tongariro-Taupo Conservancy. It is important to note that Maori tourism in that region is an old and well established practice and that may be a factor for this resistance. In the case study region, where there is a much lower indigenous culture profile, there were no reports of such difficulty. The only place where this issue arouse in Nelson-Marlborough Conservancy was in Waikoropupu Springs where for a number of years there was a moratorium on concessions activity in the area due to Maori restrictions. However, the new management plan of the Springs has settled any disputes by emphasising the requirement for tour operators to consult with Maori before telling their stories. It is interesting to note that many tour operators that operate in Abel Tasman National Park are now owned by Ngai Tahu, an iwi (tribe) that is not from that region. 
Another constraint cited by some tour operators in the national survey was the difficulty in obtaining updated information from DoC, but this constraint was not detected in the case study. This could indicate that different conservancies have different levels of communication and information exchange between DoC and tour operators. In NelsonMarlborough conservancy, apart from some minor conflicts, the great majority of tour operators and DoC managers are satisfied with their communication levels.

\subsection{Perceptions towards their relationship and the concession system}

Perceptions on their relationship:

The national survey revealed some aspects of the relationship between tour operators and DoC managers, specifically the levels of satisfaction with DoC's interpretation support, a point already addressed, and their views on the concession system.

The case study enabled a deeper investigation of their relationship. At the national level there is very little contact between DoC managers and tour operators, most of the relationships at that level are with other organizations both from the public and the private sectors, such as: the Interpretation Network New Zealand (INNZ), the National Services Te Paerangi, the Aviation, Tourism and Travel Training Organisation (ATTTO), and the New Zealand Qualifications Authority (NZQA), in order to provide opportunities and to raise the quality of interpretation in the country.

\footnotetext{
A DoC manager at DoC's Head Office in Wellington pointed out that the levels of engagement between DoC managers and tour operators at the regional level vary across the country, and that it depends on needs, resources, and demand. At the regional level, in Nelson-Marlborough Conservancy Office, the Concessions Supervisor keeps good contact with tour operators throughout the conservancy, and he actively engages with all
} 
tour operators during planning, monitoring, and training events. His performance was praised by all tour operators interviewed. In this Conservancy DoC has improved the way it deals with concessionaires by adopting a proactive and participatory mode of operation. New management plans of protected areas are widely discussed with stakeholders, including concessionaires, avoiding misunderstandings and conflicts. The new plans include clear parameters for concessions activities, setting directives for sustainable commercial activities and quality visitor experiences.

A few dissatisfactions were detected in the interviews, most related to the lengthy concessions application process. DoC managers that work with this process argued that the new management plans that have clear directives regarding concession activities are helping to speed up concessions processing for those protected areas (Abel Tasman National Park, and Waikoropupu Springs Scenic Reserve). Furthermore, DoC is implementing a new concession category, Conforming Non-Notified Process, that will streamline the application process in places that are not of particular concern to DoC. Other dissatisfactions and resentments from tour operators in relation to DoC derived from the incognito monitoring process (one instance); a change of position in relation to an action proposed by one operator; and lack of proper enforcement and consistency of regulations regarding marine mammal watching. Most of those issues were dealt with at the Conservancy Office causing some conflicts in the relationships at the regional level.

At the local level, where there are closer contacts, most tour operators interviewed reported having good relationships with DoC managers. Operators commented that DoC staff are very supportive when approached, but they noted that most of the contact is initiated by them. DoC managers at the area offices also commented that they have good relationships with tour operators, they noted that they keep frequent informal 
contact with the operators that are locally based, enabling a lot of information sharing during those instances. However, they pointed out that they do not keep much contact with tour operators that are based elsewhere and just come by when on tours. Although good levels of informal meetings and communication were reported, many tour operators felt the need for more structured and regular meetings with DoC. One of the most common suggestions from tour operators were annual meetings, ideally two, one in the pre-season for guides training, and a second for evaluation of the season. Indeed, according to Wegner (2007) good levels of communication and collaboration is crucial for the development of cooperation between resource managers and tour operators.

According to some tour operators and DoC managers, DoC staff 's attitudes toward businesses have improved, and tour operators are now seen as important DoC advocates and partners in the provision of visitor services. One DoC manager pointed out that the key to a good relationship is good communication, and being able to understand each other's perspectives.

\section{Perceptions on the concession system:}

The national survey and the case study revealed a few similarities in the positive aspects of the concession system perceived by the two stakeholders. Both mentioned that the concession system establishes conditions for protecting the environment, one DoC manager even referred to this as a partnership. They also concurred that the concession system helps to assure quality visitor experiences. However, there were some differences in the positive aspects perceived by the two stakeholders, and these were related to their different perspectives. Tour operators commented that the concession system provides legal access to the Conservation Estate, as well as business credibility and a competitive advantage. DoC managers noted that the concession system enables 
DoC to transfer to the private sector a service that is not its core role, it helps to increase the opportunities for visitor experiences in the Conservation Estate, and it allows information and interpretation delivery to a wider public. DoC concession system is indeed the type of partnership between the public and private sector found in the literature (Cessford and Thompson, 2002; Bushell, 2005; TTF, 2007; McCool, 2009).

There were some similarities in the negative aspects of the concession system perceived by the stakeholders. In both phases of this research, tour operators and DoC managers indicated that the lengthy concessions process is major problem of the system. This issue was raised by many participants in the national survey, but only in the case study it was possible to understand that the lengthy processes are related to multiconservancies concessions, and also to the lack of clear parameters in conservation management plans. The case study also revealed that DoC has taken steps to improve the system. The new management plans for protected areas, specifically for Abel Tasman National Park and Waikoropupu Scenic Reserve, which have clear parameters for concession activity have facilitated the concessions processing. Moreover, DoC is implementing a new category of concession (Conforming Non-Notified Process) that is streamlining the process. These actions address some of the problems of the concession system indicated by Parr (2000).

In the national survey some tour operators complained about the lack of law enforcement, which allows for the presence of illegal operators without concessions and unfair competition with concessions holders. This view was matched by DoC managers' comments about their limitations in monitoring. However, this problem seems to be under control in Nelson-Marlborough Conservancy. Nonetheless, other negative aspects related to monitoring were detected in the case study, particularly the lack of assessment 
of the quality of the services provided by tour operators in most protected areas. Other issues related to DoC's monitoring raised by tour operators were: the lack of monitoring of the new quota system in Abel Tasman National Park, and the lack of monitoring of tour operators' behaviour around marine mammals in the Marlborough Sounds. The case study enabled to understand that those problems are caused by the overwhelming roles of DoC and the shortage of resources, rather than lack of will.

In the national survey both stakeholders commented on the difficulties related to the concessions condition that requires tour operators to consult with indigenous people (Maori) before telling their stories. A DoC manager indicated that there are no formal procedures for this consultation, and a couple of tour operators from Tongariro-Taupo Conservancy mentioned that they are facing difficulties in gaining such an agreement. In the case study region, the only place where there was a similar issue was in Waikoropupu Springs Scenic Reserve, but this has been settled with the new management plan. Tour operators are required to consult with the local iwi, but DoC managers pointed out that there are no standard mechanisms for consultation nor for assessing compliance.

A negative aspect cited by both stakeholders in the national survey, but with contrasting perspectives was related to the concessions conditions that limit party sizes. While some tour operators complained about the restrictive party sizes, a DoC manager pointed out the difficulty in getting some tour operators to comply with those limits. This issue did not come up in the case study.

The short tenure of concessions was criticized by a few tour operators in the national survey and the case study. In the case study it was possible to understand their concern: the insecurity of short tenures hampers bank loans and investments in the businesses. 
Finally, tour operators in both phases of the research argued that the concession system is unfair since it imposes charges on guided tourists, but not on free independent tourists (FIT); and also because many tour operators without concessions just drop off visitors in protected areas without any controls or charges.

\subsection{Implications for management}

The findings suggest that DoC could improve its support to tour operators' interpretation by holding annual training sessions in each area office, and this may well be the most cost effective action not only to support quality interpretation practices, but also to review regulations and to promote proper behaviour in protected areas. A suggestion for that training would be to structure it around three modules:

$>$ Relevant interpretation topics for each area (i.e.: birds in Farewell Spit, and marine mammals in Marlborough Sounds);

> Principles of effective interpretation (TORE: Thematic, Organized, Relevant, and Enjoyable); and

$>$ Regulations and minimum impact procedures.

Post season evaluation meetings with tour operators are also recommended in order to discuss existing problems and needs, and to plan improvements for the next season.

Another action that could improve the management of guiding concessions regarding the quality of their services, is the inclusion of conditions and standards in concessions contracts related to tour guide qualification. However, this would require extensive consultation with the tourism industry in order find the most appropriate way, and to avoid injustices. Experienced tour guides might not need further qualification, and it may be necessary to create a mechanism where their proficiency is verified and attested. An easier, and probably sounder alternative would be to make that DoC annual training, suggested above, a mandatory requirement for operators that hold guiding concessions. 
As Qualmark becomes part of the conditions of the concession system, it should include some criteria related to interpretation, as suggested by a DoC manager:

"Interpretation would be one of the things that they [tour operators] are scored on - whether in fact they provide interpretation training for their staff; do they provide information; do they make training opportunities available; and will they select some of their guides that have a passion for interpretation."

Another action that needs DoC attention is the promotion of DoC's Interpretation Handbook and Standards, both to tour operators and DoC managers. It is an excellent resource that provides guidance to the development and evaluation of interpretation programs, as well as standards that should be put in practice.

DoC is working closely with some key organizations to improve the interpretation practice in New Zealand, such as INNZ, ATTTO, and NZQA, but other organizations could also provide greater support to interpretation. The Ministry of Tourism could repeat and spread the experience of the interpretation training workshops provided in 2006, and some polytechnic institutes could upgrade their outdoor education curricula putting more emphasis on interpretation.

\subsection{Implications for future studies}

Due to limitations of this study it was not possible to assess the perspectives of two other critical stakeholders regarding tour operator's interpretation - the tour guides and the visitors (guided tourists). Future studies are necessary in order to properly evaluate the quality of the interpretation practices, the levels of satisfaction and needs of visitors, and the specific needs for interpretation support and training. Regional studies are necessary in order reveal the different levels of practices and needs throughout the country. A more comprehensive investigation could also reveal the perspectives of the 
various types of nature based tourism that operate in the Conservation Estate. It is likely that different activities have different practices and needs.

\subsection{Conclusions}

Although there is room for improvement in the levels of DoC support to and monitoring of the interpretation services provided by tour operators, it is important to acknowledge that DoC is the only organization that has provided extensive and permanent support to interpretation not only to tour operators, but also to all visitors of the New Zealand Conservation Estate. Although it was not part of this research to evaluate DoC's own interpretation efforts, it is obvious that it has done a great deal in the form of visitor centres, on-site panels, publications, and website. DoC's overwhelming roles and restricted resources explain its limited actions in supporting and monitoring tour operators' interpretation practices.

Finally, tour operators need to be more united and proactive, and other organizations, particularly from the tourism sector, must also be responsible for the development of environmental interpretation as a critical tool to enhance the quality of the services provided by tour operators. Ideally, the different organizations should work cooperatively with coordinated and integrated initiatives. This could increase the competitiveness of New Zealand's tourism industry, and promote the conservation of tourism attractions and the country's heritage. As pointed out by Moscardo (1988, p.11) "interpretation has the potential to make significant and substantial contributions to the development of a more sustainable tourism industry." 
Appendix I: Information sheet and questionnaire sent to guiding concessionaires (tour operators) during national survey

\section{INFORMATION SHEET - Interpretation Survey (1) - for Guiding Concessionaires}

\section{Project Title: Concession system as a mechanism to promote and assure quality interpretation practices by tourism operators and other guiding concessionaires in protected natural areas of New Zealand.}

Your participation is extremely important, and it will help to develop an understanding about the views, conditions and challenges faced by tourism operators and other guiding concessionaires in delivering quality interpretation in protected natural areas of New Zealand. You will find the survey questionnaires in the attachment, it should take no more than ten minutes to respond.

This survey is aimed at organisations that hold guiding concessions from the New Zealand Department of Conservation (DoC). This survey has been approved by DoC's Concessions National Manager who also helped to distribute it. However, this is an independent study, and response should be sent back to Victoria University.

\section{Please Send your response before $24^{\text {th }}$ June 2009 to:}

e-mail: tourism@vuw.ac.nz with the subject "Interpretation Survey"

or mail: Tourism Management - Victoria Management School - Interpretation Survey PO Box 600 - Wellington 6140

\section{or Fax: 044635180 with the subject "Interpretation Survey"}

The return of the survey questionnaire will be considered as consent to participate. Ethical approval to conduct this research was obtained from the Human Ethics Committee of Victoria University. All information given by respondents will be confidential, and DoC or anyone else will only see the final results which will be presented in an aggregated format, being impossible to identify individual sources of information. Moreover, in order to guarantee confidentiality, an administrator of Victoria University will be responsible for receiving the survey, deleting senders' addresses, forwarding responses to the researcher, and deleting all files in her computer right away without reading the responses. The administrator has signed a confidentiality agreement containing these conditions. All information received will be stored in a personal computer protected by password and will be accessible only to the researcher and his supervisor. After two years all information will be destroyed.

The results of this survey will be presented in my master thesis and will be available to the public at Victoria University, and it will be presented in academic or professional conferences and journals. A summary of the results will be sent to all guiding concessionaires and DoC concession managers by February 2010.

Important: The survey must be answered by the organisation's owner or manager responsible for the planning and management of the guiding activities and interpretation issues.

Thank you very much

\section{Contacts:}

Rogerio Dias (researcher) - Master of Tourism Management - Victoria University of Wellington Phone: 0211743026

e-mail: diasroge@student.vuw.ac.nz (please, do not send the survey response to this address)

Dr. Karen Smith (supervisor) Senior Lecturer, Tourism Management, Victoria University of Wellington Phone: 044635721

e-mail: karen.smith@vuw.ac.nz (please, do not send the survey response to this address) 


\section{Questionnaire for Guiding Concessionaires}

For comparative purposes l'd like to know a few details about your organisation:

1- In which conservancies does your organisation hold a DoC guiding concession? tick all that apply

( ) NATION WIDE ( ) Northland ( ) Auckland ( ) Waikato ( ) Bay of Plenty ( ) Tongariro/Taupo

( ) East Coast/Hawke's Bay ( ) Wanganui ( ) Wellington ( ) West Coast ( ) Nelson/Marlborough

( ) Canterbury ( ) Otago ( ) Southland

2- What type of organisation is yours? ( ) commercial ( ) not-for-profit

3- What is the size of your organisation (number of employees in the peak season): ( ) 0 (working proprietor) () 1-5 ( ) 6-9 ( ) 10-19 ( ) 20-49 ( ) 50-99 ( ) 100+

4- What are the types of guided activities offered/provided by your organisation in areas that you hold a DoC concession? (ie: kayaking, bird watching, nature walk...)

l'd like to know about your interpretation practices; interpretation can be defined as "primarily a communication process that helps people make sense of, and understand more about, your site, collection or event." (Association for Heritage Interpretation)

5- Choose one statement that best describes your guiding services:

( ) interpretation is a major part of my guiding services.

( ) interpretation is a minor part of my guiding services.

( ) interpretation is not part of my guiding services.

6- Overall, how important is interpretation to your organisation?

( ) not at all ( ) a little ( ) somewhat ( ) important ( ) very important

7- In your opinion, how important do most of your customers (people you guide) regard interpretation? ( ) not at all ( ) a little ( ) somewhat ( ) important ( ) very important

8- In your opinion, how important does DoC regard interpretation?

( ) not at all ( ) a little () somewhat ( ) important ( ) very important

\begin{tabular}{|l|l|l|}
\hline \hline 9- What type of interpretation material or document do you have/use? (tick all that apply) & Have & Use \\
\hline Interpretation Plan / Strategy (written document prepared specifically for your organisation) & & \\
\hline Manual or guidelines prepared specifically for your guides including interpretation material & & \\
\hline Field guides or other printed interpretation material (e.g. brochures, pamphlets) & & \\
\hline DoC's publication: “Interpretation Handbook and Standards” (2005). Printed or electronic. & & \\
\hline DoC's publication: “Conservation Revealed Fact Sheets” (2005). Printed or electronic. & & \\
\hline Other. Please state: & & \\
\hline
\end{tabular}


The next six questions are open ended and will take a little more effort. They are deliberately broad in order to collect as wide as possible views. Please, insert more space as needed.

10- In your view, what are the main benefits (outcomes) of interpretation?

11- What are some of the things, if any, your organisation has done to develop and improve its interpretation capabilities?

12- What are the main challenges and constraints your organisation faces in providing quality interpretation?

13- In what ways, if any, has DoC provided support to your interpretation practices?

14- How satisfied is your organisation with DoC's support regarding interpretation?

( ) not at all ( ) a little ( ) somewhat ( ) very ( ) totally

Please, explain your answer:

15- What are the main issues (both positive and negative) in holding a guiding concession from DoC?

Thank you very much for your participation. If you have any further comments, please continue below.

Please, return by $24^{\text {th }}$ June 2009 to tourism@vuw.ac.nz

Thank you very much. 
Appendix II: Information sheet and questionnaire sent to DoC concessions managers during national survey

\section{INFORMATION SHEET - Interpretation Survey (2) - for DOC Concession Staff}

\section{Project: Concession system as a mechanism to promote and assure quality interpretation practices by tourism operators and other guiding concessionaires in protected natural areas of New Zealand.}

Your participation is extremely important, and it will help to develop an understanding about the views and challenges faced by DoC's concessions staff in supporting and assuring quality interpretation practices by guiding concessionaires. You will find the survey questionnaires in the attachment, it should take no more than ten minutes to respond.

This survey is aimed at DoC's concessions staff. This survey has been approved by DoC's Concessions National Manager who also helped to distribute it. However, this is an independent study, and response should be sent back to Victoria University.

\section{Please Send your response before $24^{\text {th }}$ of June 2009 to: \\ e-mail: tourism@vuw.ac.nz with the subject "Interpretation Survey" \\ or mail: Tourism Management - Victoria Management School - Interpretation Survey PO Box 600 - Wellington 6140}

or Fax: 044635180 with the subject "Interpretation Survey"

The return of the survey questionnaire will be considered as consent to participate. Ethical approval to conduct this research was obtained from the Human Ethics Committee of Victoria University. All information given by respondents will be confidential, and DoC or anyone else will only see the final results which will be presented in an aggregated format, being impossible to identify individual sources of information. Moreover, in order to guarantee confidentiality, an administrator of Victoria University will be responsible for receiving the survey, deleting senders' addresses, forwarding responses to the researcher, and deleting all files in her computer right away without reading the responses. The administrator has signed a confidentiality agreement containing these conditions. All information received will be stored in a personal computer protected by password and will be accessible only to the researcher and his supervisor. After two years all information will be destroyed.

The results of this survey will be presented in my master thesis and will be available to the public at Victoria University, and it will be presented in academic or professional conferences and journals. A summary of the results will be sent to all guiding concessionaires and DoC,s concessions staff by February 2010.

Important: The survey must be answered only by concessions staff (area managers and concessions supervisors) without the input of other DoC officers. This is to understand the views of concessions staff alone.

Thank you very much

\section{Contacts:}

Rogerio Dias (researcher) - Master of Tourism Management - Victoria University of Wellington Phone: 0211743026

e-mail: diasroge@student.vuw.ac.nz (please, do not send the survey response to this address)

Dr. Karen Smith (supervisor) Senior Lecturer, Tourism Management, Victoria University of Wellington Phone: 04 463-5721

e-mail: karen.smith@vuw.ac.nz (please, do not send the survey response to this address) 


\section{Questionnaire for DoC Staff}

For comparative purposes, l'd like to know a little about your work, but this will not be used to identify any individual

1- In which conservancy do you work?

2- What position do you hold in DoC? ( ) Concessions Supervisor ( ) Area Manager

l'd like to know about your interpretation practices; interpretation can be defined as "primarily a communication process that helps people make sense of, and understand more about, your site, collection or event." (Association for Heritage Interpretation)

3- Choose one statement that best describes your concessions related work:

( ) interpretation issues are a major part of my concessions work.

( ) interpretation issues are a minor part of my concessions work.

( ) interpretation issues are not part of my concessions work.

4- Overall, how important is interpretation to DoC?

( ) not at all ( ) little ( ) somewhat ( ) important ( ) very important

5- In your opinion, how important do guiding concessionaires regard interpretation?

( ) not at all ( ) a little ( ) somewhat ( ) important ( ) very important

6- In your opinion, how important do most guided visitors regard interpretation?

( ) not at all ( ) a little ( ) somewhat ( ) important ( ) very important

7- How much support do you get from other DoC staff when dealing with interpretation issues of guiding concessionaires? ( ) none ( ) a little ( ) some ( ) much ( ) a lot

8- Approximately what proportion of current guiding concessions in your conservancy have special conditions related to interpretation in their concession contract?

( ) none ( ) $<25 \%$ ( ) $25-50 \%$ ( ) $50-75 \%$ ( ) $>75 \%$ ( ) all

9- Approximately what proportion of guiding concessions in your conservancy have formal (written) interpretation plans? ( ) none ( ) $<25 \%$ ( ) $25-50 \%$ ( ) $50-75 \%$ ( ) $>75 \%$ ( ) all

The next six questions are open ended and will take a little more effort. They are deliberately broad in order to collect as wide as possible views. Please, insert more space as needed.

10- In your view, what are the main benefits (outcomes) of interpretation?

11- What strategies, tools, and actions have been used by you as a concession manager to support and assure quality interpretation by guiding concessionaires?

12- What are the main challenges and constraints do you face as a concession manager in supporting and assuring quality interpretation by guiding concessionaires? 
13- How satisfied are you with DoC's support to guiding concessionaires regarding interpretation?

( ) not at all ( ) a little ( ) somewhat ( ) much ( ) totally

Please, explain your answer:

14- In your opinion, what proportion of guiding concessions in your conservancy deliver quality interpretation that meet the standards set out in the DoC "Interpretation Handbook and Standards"?

( ) none ( ) a few ( ) half ( ) most ( ) all

Please, explain your answer:

15- What are the main issues (both positive and negative) in managing guiding concessions?

Thank you very much for your participation. If you have any further comments, please continue below.

Please, return by $24^{\text {th }}$ June 2009 to tourism@vuw.ac.nz

Thank you very much. 
Appendix III: Interview schedule and semi-structured questionnaire used to guide interviews with guiding concessionaires during the case study

Concession system as a mechanism to promote and assure quality interpretation practices by tourism operators and other guiding concessionaires in protected natural areas of New Zealand

INTERVIEW SCHEDULE

(2) to Guiding Concessionaires

\section{RESEARCHER}

Rogerio Dias

\section{Contents}

1. Preliminary Explanations (Research Information Sheet and Consent Form)

2. Concessionaire's Profile

3. Interpretation

4. Concession System

5. Concluding Comments 
1) PRELIMINARY EXPLANATIONS - Research Information Sheet and Consent Form

1.1- Ask if the interviewee has received and read the research information sheet and research consent form. If not, then provide documents and allow time for him/her to read them.

1.2- Ask if the interviewee understands everything and if there are any doubts. Answer any questions posed by the interviewee.

1.3- Ensure that personal information will not be disclosed in the research outputs, but identity of participant organizations may be revealed in the resulting theses and publications.

1.4- Ask the interviewee if the interview can be recorded.

1.5- Ask the interviewee to sign the research consent form and return a copy to him/her. 
2) CONCESSIONAIRE'S PROFILE - For comparative purposes l'd like to know a few details about your organisation

2.1- In which conservancies does your organisation hold a DoC guiding concession?

( ) NATION WIDE ( ) Northland ( ) Auckland ( ) Waikato ( ) Bay of Plenty ( ) Tongariro/Taupo

( ) East Coast/Hawke's Bay ( ) Wanganui ( ) Wellington ( ) West Coast ( ) Nelson/Marlborough

( ) Canterbury ( ) Otago ( ) Southland

\section{2- How long have you hold a guiding concession from DoC?}

2.3- What type of organisation is yours? ( ) commercial ( ) not-for-profit

2.4- What is the size of your organisation (number of employees in the peak season):

( ) 0 (working proprietor) ( ) 1-5 ( ) 6-9 ( ) 10-19 ( ) 20-49 ( ) 50-99 ( ) 100+

2.5- What are the types of guided activities offered/provided by your organisation in areas that you hold a DoC concession? (ie: kayaking, bird watching, nature walk...)

2.6- What is your role in the organization?

3) INTERPRETATION - This section seeks to understand your organization's views and practices in relation to interpretation, as well as your relationship with $D o C$ in regard to interpretation issues. I realise you may not be a professional interpreter, but...

\section{1- How would you explain what interpretation is?}

- In your view, what is the main purpose of interpretation?

- In your view, how important is interpretation to deliver meaningful visitor experiences?

3.2- Who in your organization deals with interpretation issues (planning and management)?

- How do interpretation issues fit in your duties and priorities?

3.3- What are some of the things, if any, your organisation has done to develop and improve its interpretation capabilities?

- What sources of information do you use to inform your interpretation program? What are the challenges or difficulties in getting information?

- What are the main subjects or themes your organization interpret?

- What are the main messages your organization try to get across through interpretation?

- How do you deal with indigenous knowledge and tangata whenua consultation?

- What are the main techniques/principles of interpretation that you apply?

3.4- What are the main challenges and constraints your organisation faces in providing quality interpretation? 
3.5- What are the criteria you use to select your guides?

- How difficult it is to find and to keep good guides?

3.6- How do you monitor and evaluate the interpretation quality of your guided services?

- How satisfied are you with the interpretation performance of your organization?

- How much interpretation do you think your costumers expect?

- How satisfied do you think your customers are with your interpretation? How do you evaluate that?

3.7- In what ways, if any, has DoC provided support to your interpretation practices?

- Has your organisation ever requested support from DOC regarding interpretation?

- How satisfied is your organisation with DoC's support regarding interpretation?

- Has a DOC staff ever provided comment or feedback on your interpretation practices?

- Do you have any suggestions to improve DoC's support to your interpretation practices?

3.8- Has your organization ever had other external support to develop or improve your interpretation program and capabilities? If so, what type of support? by whom?

- If not, do you think other organizations should give support to guiding concessionaires' interpretation practices? If so, which ones? How?

3.9- Have you or anyone in your organization had any training on interpretation? If so, please give details (type? length? when? by whom?). Has that training helped you manage your interpretation program? Do you think your organisation needs more training on interpretation?

- Would you participate in a low cost interpretation training if $\mathrm{DoC}$ or any other organization offered one?

4) CONCESSION SYSTEM - This section seeks to understand how does the concession system works.

4.1- Are there any conditions in your concession contract related to interpretation management (plans, procedures, standards, skills, consultation, and monitoring)?

4.2- Are there any conditions in your concession contract related to guides' proficiency or skills? What are the types and levels of qualifications required? What are the emphasis (mandatory areas of expertise)?

- Do you think those conditions make sense?

- Are there any difficulties in conforming with those conditions?

- Were those conditions verified by DoC prior to your concession's approval? How?

- Were those conditions ever evaluated and enforced by DoC? How? How often?

4.3- How do you view the relationship of DoC and guiding concessionaires? 
4.4- Do you have any suggestions to improve that relationship?

\section{5) CONCLUDING COMMENTS}

5.1- Has your organization ever been consulted or invited to participate in the discussion and formulation of conservation strategies and plans, or concessions policies and regulations?

- How important do you think that is?

- If not, do you think you should have been invited? Would you have participated?

5.2- What are the main issues (both positive and negative) in holding a DoC guiding concession?

5.3- Are there any other points you would like to raise regarding interpretation and DoC concession system?

END 
Appendix IV: Interview schedule and semi-structured questionnaire used to guide interviews with DoC concessions managers during the case study.

Concession system as a mechanism to promote and assure quality interpretation practices by tourism operators and other guiding concessionaires in protected natural areas of New Zealand

INTERVIEW SCHEDULE

(1) to DoC Concessions Staff

\section{RESEARCHER}

Rogerio Dias

\section{Contents}

1. Preliminary Explanations (Research Information Sheet and Consent Form)

2. Staff's Profile

3. Recreation Concessions Work

4. Interpretation

5. Concession System

6. Concluding Comments 


\section{1) PRELIMINARY EXPLANATIONS - Research Information Sheet and Consent Form}

1.1- Ask if the interviewee has received and read the research information sheet and research consent form. If not, then provide documents and allow time for him/her to read them.

1.2- Ask if the interviewee understands everything and if there are any doubts. Answer any questions posed by the interviewee.

1.3- Ensure that personal information will not be disclosed in the research outputs, but identity of participant conservancy and area may be revealed in the resulting theses and publications.

1.4- Ask the interviewee if the interview can be recorded.

1.5- Ask the interviewee to sign the research consent form and return a copy to him/her. 
2) STAFF'S PROFILE - For comparative purposes l'd like to know a few details about your occupation.

\section{1- What position do you hold in DoC?}

- In which conservancy and area do you work as a concessions manager?

- How long have you been working at DoC? And with recreation concessions?

2.2- Can you please tell me a little bit about your background?

\section{3) RECREATION CONCESSIONS WORK}

\section{1- Can you please tell me about your work with recreation concessions?}

- What are your main duties as a recreation concession manager?

- What are the top three priorities?

- What are the three main challenges in managing recreation concessions?

4) INTERPRETATION - This section seeks to establish your views in relation to interpretation, and to understand the relationship of DoC with guiding concessionaires in regard to interpretation issues. I realise you are not a professional interpreter, but...

\section{1- How would you explain what interpretation is?}

- In your view, what is the main purpose of interpretation?

- In your view, how important is interpretation to deliver meaningful visitor experiences?

Obviously DoC does a lot in terms of interpretation. I am particularly interested in guiding concessionaires' interpretation practices and DoC's support and monitoring.

\section{2- Who within your area deals with concessionaires' interpretation issues?}

- Are there other DoC staff dealing with concessionaires' interpretation issues in your area?

- How do interpretation issues fit in your duties and priorities as a concessions manager?

4.3- What are the main messages do you think guiding concessionaires should get across to visitors in the conservation estate? Do you think most of them deliver that?

4.3- What are some of the things, if any, you have done as a concession manager to support guiding concessionaires' interpretation practices? (if none, what about DoC as a whole?)

- Have guiding concessionaires ever requested support from DoC regarding interpretation? How often? What is the type and level of demand?

- Do you recommend any particular sources of information to guiding concessionaires to inform their interpretation program?

- What are the main challenges and constraints DoC faces in supporting concessionaires' interpretation? 
- How satisfied are you with DoC's support to concessionaire's interpretation? WHY?

- Have you and DoC ever had external support to improve and monitor guiding concessionaires' interpretation practices? If so, what type of support? by whom?

4.4- How do you deal with the use of indigenous knowledge by guiding concessionaires, and tangata whenua consultation issues regarding interpretation?

4.5- What are some of the things, if any, you have done as a concession manager to monitor guiding concessionaires' interpretation practices?

- How satisfied do you think visitors are with the interpretation performance of concessionaires? Has DoC, the concessionaires, or anyone else carried out any visitor surveys to assess that?

- Have you ever provided feedback to concessionaires on their interpretation practices?

- What are the main challenges and constraints you face in monitoring their interpretation?

\section{6- Have you had any training on interpretation?}

- If so, please give details (type? length? when? by whom?).

- Has that training helped your work in managing guiding concessions?

- Do you feel you need more training on interpretation for your work as a concession manager?

4.7- Do you have any suggestions to improve DoC's support and monitoring of concessionaires' interpretation practices?

5) CONCESSION SYSTEM - This section seeks to understand how does the concession system works.

5.1- Are there any conditions in concessionaires' contracts related to interpretation management (plans, procedures, standards, consultations, and monitoring)?

5.2- Are there any conditions in guiding concessionaires' contract related to guides' proficiency or skills? What are the types and levels of qualifications required? What are the emphasis (mandatory areas of expertise)?

- Do you think those conditions make sense? Do they work?

- Are those conditions ever evaluated and enforced by DoC? How? (if not, WHY)

- What are the difficulties concessionaires face to comply with those conditions?

- Are there any incentives or sanctions applied to promote compliance with contract conditions?

\section{3- How does the concession assessment process work?}

- What are the main criteria assessed?

- Is interpretation and guiding skills included? 
- Is there an assessment framework? Can I see it?

- How often is it carried out?

5.4- Do you have any suggestions to improve the concessions system?

\section{6) CONCLUDING COMMENTS}

6.1- Is the presence of illegal (without a concession) commercial guided activities a problem in your conservancy/area? How does DoC deal with that?

6.2- Have guiding concessionaires and guides ever been consulted or invited to participate in the discussion and formulation of conservation strategies and plans, or concessions policies and regulations?

- If so, have they provided important inputs? (If not, WHY?)

6.3- Are there any other points you would like to raise regarding guiding concessionaires' interpretation practices and issues? 
Appendix V: DoC's messages accompanying the national surveys sent via e-mail.

Message on the e-mail body sent to guiding concessionaires (tour operators):

Dear Concessionaire,

Attached is an independent survey related to interpretation being undertaken by concessionaires. Interpretation is an explanation of the natural, cultural or historic values attached to places. It enables visitors to gain insight and understanding about the reasons for conservation and ongoing protection of our heritage.

This work has been developed by a Masters student (Rogerio Dias) from the Tourism Management Program of Victoria University of Wellington. He would appreciate your support by participating in a short survey as part of this study. DOC is providing logistical support but and this work is independent of the Department.

Attached is a document containing a information sheet and survey form. Please read the information sheet for further details of the study and for instructions about how to fill out the survey form. Please send your completed survey form directly to tourism@vuw.ac.nz. before the 24th of June.

All participants will receive a summary of the results at the end of the research, and anyone will be able to access the entire thesis through Victoria University.

Regards,

Gavin Walker

Visitor Services Manager

Department of Conservation

Message on the e-mail body sent to DoC concessions managers:

Area Managers and Concessions Supervisors,

Attached is an independent survey related to interpretation being undertaken by concessionaires and how DOC goes about supporting this activity.

This work has been developed by a Masters student (Rogerio Dias) from the Tourism Management Program of Victoria University of Wellington. He would appreciate your support by participating in a short survey as part of this study. DOC is providing logistical support but and this work is independent of the Department.

Attached is a document containing a information sheet and survey form. Please read the information sheet for further details of the study and for instructions about how to fill out the survey form. Please send your completed survey form directly to tourism@ vuw.ac.nz.before the 24th of June.

All participants will receive a summary of the results at the end of the research, and anyone will be able to access the entire thesis through Victoria University.

Regards,

Gavin Walker

Visitor Services Manager 


\section{References}

AHI - Association for Heritage Interpretation (2009). What is interpretation? Available:

http://www.ahi.org.uk/www/about/what is_interpretation/[19/03/2009]

ATTTO - Aviation, Tourism and Travel Training Organisation (2009). National Certificate in Tourism (Guiding) (Level 3). Available: http://www.attto.org.nz/tourism/qualification/national_certificate_in_tourism_guid ing_level_3/ [8/09/2009]

Ballantyne, R., Packer, J., and Hughes, K (2008). "Environmental awareness, interests and motives of botanic gardens visitors: Implications for interpretive practice." Tourism Management 29: 439-444

Balmford, A., Beresford, J., Green, J., Naidoo, R., Walpole M., and Manica, A. (2009). A Global Perspective on Trends in Nature-Based Tourism. Plos Biology. 7 (6):1-6.

Black, R. and Crabtree, A., ed. (2007). Quality Assurance and Certification in Ecotourism. Oxfordshire: CAB International.

Black, R. and Weiler, B. (2005). "Quality Assurance and Regulatory Mechanisms in the Tour Guiding Industry - A systematic review" The Journal of Tourism Studies 16 (1): 24-37.

Black, R. and Weiler, B. (2008). "Factors Facilitating and Inhibiting the Use of Research to Inform Interpretation Practice: A Case Study of Australian Protected Area Management Agencies.” Visitor Studies 11 (2): 163-180.

Booth, K. and Mackay, M. (2007). Tourism and Recreation in New Zealand's Natural Environment: A Bibliography and Research Synthesis. The Ministry of Tourism, Wellington, New Zealand. i + 89pp.

Buckley, R. (2004). Partnerships in Ecotourism: Australian Political Frameworks. International Journal of Tourism Research. 6: 75-83.

Bushell, R. (2005). "Building support for protected areas through tourism." In Friends for Life: New partners in support of protected areas, edited by J.A. McNeely. Gland, Switzerland and Cambridge, UK: IUCN, pp. 141-154.

Bushell, R. and S. F. McCool (2007). "Tourism as a Tool for Conservation and Support of Protected Areas: Setting the Agenda." In Tourism and Protected Areas: Benefits Beyond Boundaries, edited by R. Bushell and P.F.J. Eagles. UK: CABI International, pp. 12-26.

Cessford, G. and A. Thompson (2002). "Managing tourism in the New Zealand protected area system.” Parks, 12 (1): 26-36.

Creswell, J.W. (2003). Research design: Qualitative, quantitative, and mixed method approaches. Thousand Oaks: Sage Publications. 
Davies, B. (2003). "The role of quantitative and qualitative research in industrial studies of tourism." International Journal of Tourism Research 24 (3): 524-536.

DoC - Department of Conservation (2005). Interpretation Handbook and Standards. Available: http://www.doc.govt.nz/publications/aboutdoc/role/policies-and-plans/visitor-management/interpretation-handbookand-standard/ [15/01/09]

DoC - Department of Conservation (2006a). The Value of Conservation.

Available: http://www.doc.govt.nz/upload/documents/conservation/value-ofconservation.pdf [27/01/2009].

DoC - Department of Conservation (2006c). Interpretation resources - Conservation revealed. Available: http://www.doc.govt.nz/about-doc/concessions-andpermits/concessions/information-for-concessionaires/interpretation-resources/ [02/05/2009].

DoC - Department of Conservation (2007). Possible Special Conditions for Guiding Permits. Internal document provided by DoC's national concessions manager at the DoC Head Office in Wellington.

DoC - Department of Conservation (2009a). National parks visitor statistics. Available: http://www.doc.govt.nz/about-doc/role/maps-andstatistics/visitor-statistics-and-research/national-parks-visitor-statistics/ [8/10/2009]

DoC - Department of Conservation (2009b). DOC mission, vision and statutory mandate. Available: http://www.doc.govt.nz/about-doc/role/mission-vision-andstatutory-mandate/statutory-mandate/ [8/08/2009]

DoC - Department of Conservation (2009c). Visitor Strategy. Available: http://www.doc.govt.nz/publications/about-doc/role/policies-and-plans/visitormanagement/visitor-strategy/ [5/05/2009]

DoC - Department of Conservation (2009d). Concessions Statistics. Available: http://www.doc.govt.nz/about-doc/concessions-andpermits/concessions/concession-statistics/ [5/10/2009]

DoC - Department of Conservation (2009e). Protected Area Statistics. Available: http://www.doc.govt.nz/about-doc/role/maps-and-statistics/protected-areastatistics/ [15/11/2009]

DoC - Department of Conservation (2009f). Annual report for the year ended 30 June 2009. Available: http://www.doc.govt.nz/upload/documents/aboutdoc/role/policies-and-plans/annual-report-for-the-year-ended-30-june-2009.pdf [7/12/2009]

DoC - Department of Conservation (2009g). An Introduction to Concessions. Available: http://www.doc.govt.nz/upload/documents/aboutdoc/concessions-and-permits/concessions/introduction-to-concessions.pdf [15/09/2009] 
DoC - Department of Conservation (2009h). Tongariro National Park. Available: http://www.doc.govt.nz/parks-and-recreation/national-parks/tongariro/ [10/08/2009]

DoC - Department of Conservation (2009i). Conservancy Map. Available: http://www.doc.govt.nz/about-doc/structure/conservancy-map/ [15/12/2009]

DoC - Department of Conservation (2009j). Map of Nelson/Marlborough Conservancy. Available: http://www.doc.govt.nz/aboutdoc/structure/offices/conservancies/nelson-marlborough/map/ [20/12/2009]

DoC - Department of Conservation (2009k). Nelson/Marlborough. Available: http://www.doc.govt.nz/parks-and-recreation/places-to-visit/nelson-marlborough/ [06/08/2009]

DoC - Department of Conservation (2010). Results of Abel Tasman Coast Track Overnight Visitor Survey 2008. Internal document provided by DoC Head Office in Wellington.

Dudley, N. (Editor) (2008). Guidelines for Applying Protected Area Management Categories. Gland, Switzerland: IUCN. x + 86pp.

Duim, R.V.D. and J. Caalders (2002). "Biodiversity and Tourism - Impacts and Interventions." Annals of Tourism Research, 29 (3): 743-761.

Eagles P.F.J. and S.F. McCool (2002). Tourism in National Parks and Protected Areas. CABI: Wallingford.

Eagles, P.F.J., S.F. McCool, and C.D. Haynes (2002). Sustainable Tourism in Protected Areas: Guidelines for Planning and Management. IUCN Gland, Switzerland and Cambridge, UK. xv + 183p.

Eagle, P.F.J. (2002). “Editorial.” Parks, 12 (1): 1-2.

Ecotourism NZ (2010). Training. Available: http://www.ecotourismnz.com/ecotourism/training/ [02/02/2010]

Emerton, L., Bishop, J. and Thomas, L. (2006). Sustainable Financing of Protected Areas: A global review of challenges and options. IUCN, Gland, Switzerland and Cambridge, UK. $\mathrm{x}+97 \mathrm{pp}$.

Fennell, D.A., ed. (1999). Ecotourism: an Introduction. New York: Routledge.

Figgis, P. (2000). “The double-edged sword - tourism and parks.” Habitat Australia, October: $24-26$.

Grubb, T.R.J. (2007). "Exploring environmental management among tourism operators in New Zealand's Nelson/Tasman Region." A thesis submitted for the partial fulfillment of the requirements for the degree of Master's of Tourism Management at Victoria University of Wellington, Wellington, New Zealand. 
Ham, S. and Weiler, B. (2005). "Interpretation Evaluation Tool Kit - Methods and Tools for Assessing the Effectiveness of Face-to-Face Interpretive Programs." Gold Coast, Australia: Sustainable Tourism Cooperative Research Centre, vi +78 p.

Horn, C. and Simmons, D. (2002). "Community adaptation to tourism: comparisons between Rotorua and Kaikoura, New Zealand." Tourism Management 23(2): 133143.

Hughes, M. and Morrison-Saunders, A.(2005).“Influence of On-site Interpretation Intensity on Visitors to Natural Areas" Journal of Ecotourism 4(3):161-177

INNZ - Interpretation Network New Zealand (2008). Ahoy there! News Letter Winter 2008. Available: http://www.innz.net.nz/Images/NewsletterW08lo.pdf

IUCN - International Union for Conservation of Nature (1994). Guidelines for Protected Area Management Categories. IUCN, Gland, Switzerland and Cambridge, UK. x + 261pp.

IUCN - International Union for Conservation of Nature (2004a). "The Durban Action Plan." V $V^{\text {th }}$ IUCN World Parks Congress, Durban, South Africa, September. Available: http://cmsdata.iucn.org/downloads/durbanactionen.pdf [5/12/2009]

IUCN - International Union for Conservation of Nature (2004b). "Recommendations." $V^{\text {th }}$ IUCN World Parks Congress, Durban, South Africa, September. Available: http://cmsdata.iucn.org/downloads/recommendationen.pdf [5/12/2009]

Jager, E., C. Sheedy, F. Gertsch, T. Phillips, and G. Danchuk (2006). "Managing for visitor experiences in Canada's national heritage places." Parks, 16 (2): 18-24.

Kuo, L. (2002). "The Effectiveness of Environmental Interpretation at ResourceSensitive Tourism Destination." The International Journal of Tourism Research, 4: 87-101.

Lacy, T. D. and M. Whitmore (2006). "Tourism and Recreation.” In Managing Protected Areas: A Global Guide, edited by M. Lockwood, G.L. Worboys, and A. Kothari. IUCN-Earthscan, UK \& USA. 497-527.

Madin, E.M.P., and Fenton, D.M. (2004). "Environmental Interpretation in the Great Barrier Reef Marine Park: An Assessment of Programme Effectiveness" Journal of Sustainable Tourism 12 (2): 121-137.

Maher, H. (2004). "The management of tourism operations on public conservation lands through concessions." A dissertation submitted for the partial fulfillment of the Graduate Diploma in Tourism at the University of Otago, Dunedin, New Zealand.

Mason, P. (2005). "Visitor Management in Protected Areas: From 'Hard' to 'Soft' Approaches?" Current Issues in Tourism, 8 (2\&3): 181-194.

McCool, S.F. (2006). "Managing for visitor experiences in protected areas: promising opportunities and fundamental challenges." Parks 16 (2): 3-9. 
McCool, S.F. (2009). Constructing partnerships for protected area tourism planning in an era of change and messiness. Journal of Sustainable Tourism. 17 (2): 133-148.

McGrath, G. (2007). "Towards Developing Tour Guides as Interpreters of Cultural Heritage: Case of Cuzco, Peru." In Quality Assurance and Certification in Ecotourism, edited by R. Black and A. Cabtree. Oxfordshire: CAB International, pp. 364-394.

Moscardo, G. (1998). "Interpretation and sustainable tourism: Functions, examples and principles.” Journal of Tourism Studies 9 (1): 2-13.

Munro, J. K., Morrison-Saunders, A., and Hugues, M. (2008). Environmental Interpretation Evaluation in Natural Areas.”Journal of Ecotourism 7 (1): 1-14.

NAI - National Association for Interpretation (2009). Mission, Vision, and Core Values. Available: http://www.interpnet.com/about_nai/mission.shtml [18/03/2009]

NZCA - New Zealand Conservation Authority (2005). General Policy for National Parks. DoC and NZCA, Wellington, New Zealand.

NZQA - New Zealand Qualification Authority (2009). Review of Tourism Unit Standards. Available: www.nzqa.govt.nz/nqfdocs/summaries/2009/may09/revsummay09-24.doc

Ormsby, J., Moscardo, G., Pearce, P. and Foxlee, J. (2004). A Review of Research into Tourist and Recreational Uses of Protected Natural Areas. Great Barrier Reef Marine Park Authority, Townsville, Australia. Ii + 57pp.

Parr, D. (2000). Management Practice for Allocation of Recreation Concessions. Department of Conservation, Wellington, New Zealand. Science and Research Internal Report 184. 33p.

Pearce, D.G., Tan, R., and Schott, C. (2007). "Distribution Channels in International Markets: A Comparative Analysis of the Distribution of New Zealand Tourism on Australia, Great Britain and the USA.” Current Issues in Tourism 10 (1): 33-60.

Punch, F. (2005). Introduction to social science research: quantitative and qualitative approaches. London: Sage Publications.

Rodger, K; S. A. Moore; and D. Newsome (2007). "Wildlife Tours in Australia: Characteristics, the Place of Science and Sustainable Futures." Journal of Sustainable Tourism 15(2): 160-179.

SCBD - Secretariat of the Convention on Biological Diversity (2004). Guidelines on Biodiversity and Tourism Development: International guidelines for activities related to sustainable tourism development in vulnerable terrestrial, marine and coastal ecosystems and habitats of major importance for biological diversity and protected areas, including fragile riparian and mountain ecosystems. (CBD Guidelines) Montreal: Secretariat of the Convention on Biological Diversity 29 p. 
Sowman, P. and D. Pearce (2000). "Tourism, national parks and visitor management." In Tourism and National Parks: Issues and Implications, edited by R.W. Buttler and S.W. Boyd. Chichester: John Wiley \& Son, pp. 223-243 .

Staiff, R., Bushell, R. and Kennedy, P. (2002) Interpretation in national parks: Some critical questions. Journal of Sustainable Tourism 10(2), 97-113.

Taylor, N. and J. Gough (2006). "An approach to more integrated planning and management of tourism in natural areas: a case study of the Caltins in New Zealand's wild south east." Paper presented to the 12th International Symposium on Society and Resource Management, Vancouver 3-8 June.

TIANZ - Tourism Industry Association New Zealand (2006). Concession Allocation by the Department of Conservation - where supply is limited - Submission. Wellington, New Zealand, 38p. Available: www.tianz.org.nz/content/library/DOCconcession16407.pdf [07/07/2009]

Tilden F. (1977). Interpreting Our Heritage, $3^{\text {rd }}$ edition. University of North Caroline Press: Chapel Hill-NC, USA. 138p.

Thompson, A. (2005). Tourism concessionaires: an exploratory study of concessionaires who actively contribute to conservation in New Zealand. A dissertation submitted in partial fulfillment of the requirements for the Masters of Parks, Recreation and Tourism at Lincoln University, Canterbury, New Zealand.

TMT - The Ministry of Tourism (2007). New Zealand Tourism Strategy 2015. Wellington, NZ: TMT, TNZ, and TIANZ, 80p.

TMT - The Ministry of Tourism (2009). Tourism Sector Profile - Tourist Activity / Nature Based Tourism. Wellington, New Zealand: TMT, Series B3, 4pp.

TNZ - Tourism New Zealand (2001). 100 Years Pure Progress. Wellington, New Zealand, 50p. Available:

http://www.tourismnewzealand.com/tourism_info/fms/Tourism_Info/Tourism\%20 Centenary.pdf [03/10/2009]

Tonge, J., S. Moore, M. Hockings, G. Worboys and K. Bridle (2005). Developing indicators - sustainable management of visitor use of protected areas in Australia. Gold Coast, Australia: Sustainable Tourism Cooperative Research Centre, 46p.

TTF - Tourism and Transport Forum Australia (2007). Natural Tourism Partnerships Action Plan - Creating effective public-private partnerships for natural tourism and conservation in Australian Parks. TTF, Sydney, Australia. 88pp.

Tubb, K. (2003). “An Evaluation of the Effectiveness of Interpretation within Dartmoor National Park in Reaching the Goals of Sustainable Tourism Development" Journal of Sustainable Tourism 11 (6): 476-498

UNEP - United Nations Environment Programme (2005). Forging Links Between Protected Areas and the Tourism Sector - How Tourism Can Benefit Conservation. Paris: UNEP, 48p. 
UNESCO - United Nations Educational, Scientific, and Cultural Organization (2009). World Heritage - Tongariro National Park. Available: http://whc.unesco.org/en/list/421 [08/09/2009].

Vargas, E. (2007). "Effective nature and culture interpretation for quality ecotourism experiences." Paper presented at the Global Ecotourism Conference 2007, Oslo, Norway, May.

Walker, G. (2007). DOC and Nature-Based Tourism. Available: http://www.ecotourismnz.com/content/library/Gavin_Walker_Presentation_PDF.p df [11/04/2009].

Warren, J., N. Taylor, P. Blaschke, J. Gough, and W. Pihema (2007). "Integrated planning and managing of natural areas for tourism." Paper presented at the 3rd International Conference on Environmental, Cultural, Economic and Social Sustainability, Chenai, India, January. Available: http://www.cresa.co.nz/it/files/Madras\%20Paper\%2003-07.pdf [03/04/2009]

Weaver, D.B., ed. (2001). The Encyclopedia of Ecotourism. CABI: Wallingford.

Wegner, A. (2007). "Relationships with many facets: unpacking the interactions between protected area managers and commercial tour operators." A thesis submitted for the partial fulfillment of the requirements for the degree of Doctor of Philosophy in the Scool of Environmental Science of Murdoch University, Perth, Australia.

Weiler, B. and Ham, S. (2001). "Tour Guides and Interpretation" In Encyclopedia of Ecotourism, edited by D.B. Weaver. Wallingford: CABI Publishing, pp. 549-563.

Weiler, B. and Ham, S. (2002). "Tour guide training: A model for sustainable capacity building in developing countries." Journal of Sustainable Tourism 10 (1), 52-69.

Weiler, B. (2005). "Interpretation Research in Australia." Journal of Interpretation Research 10(2): 38-42.

Zeppel, H. and Muloin, S. (2008). "Conservation Benefits of Interpretation on Marine Wildlife Tours.” Human Dimensions of Wildlife 13: 280-294. 